\title{
3 Wohnungsbewertungsmodell mit Einkommensteuern
}

\subsection{Von investitionstheoretischen Zahlungsströmen abweichende Berechnungsgrundlagen der Einkommensteuer}

\subsubsection{Einkommensteuer als wichtigste Immobiliensteuer für Vermieter}

Die Vermietung einer Wohnimmobilie unterliegt aus Sicht privater Investoren verschiedenen Steuerarten. Bei Anschaffung ist der Kaufpreis Gegenstand einer einmalig fälligen, prozentual von ihm abhängigen Grunderwerbsteuer, die zu den Verkehrssteuern gehört und gewissermaßen Bestandteil der Anschaffungskosten ist. ${ }^{410}$ Während der Besitzdauer wird quartalsweise die Grundsteuer fällig, die im Rahmen der Betriebskosten ergebnisneutral an den Mieter weitergegeben werden kann. ${ }^{411}$ Neben diesen beiden echten Immobiliensteuern kann eine Eigentumswohnung unter bestimmten Umständen Gegenstand von Erbschaft- oder Schenkungsteuer sein. ${ }^{412}$ Von wesentlicher Bedeutung ist besonders die Einkommensteuer, welcher die Vermietungsüberschüsse unterliegen. ${ }^{413}$ Der Gesetzgeber spricht in $\S 21 \mathrm{EStG}$ von Einkünften aus Vermietung und Verpachtung. ${ }^{414}$ Die Einkommensteuer orientiert sich am erzielten wirtschaftlichen Ergebnis und gehört damit zu den Ertragsteuern. ${ }^{415}$ Mit einem Spitzensteuersatz von 45 Prozent übt sie ganz erheblichen Einfluß auf denjenigen Teil des Zukunftserfolgs aus, der einem

${ }^{410}$ Betriebswirtschaftlich handelt es sich um kaufpreisabhängige Transaktionskosten, vgl. zu dieser LINDAUER (2016), S. 96 ff., SCHNEELOCH/MEYERING/PATEK (2017b), S. 57 ff. Zur Grunderwerbsteuer im geschichtlichen Kontext vgl. VAN SUNTUM/SCHULTEWOLTER (2014), S. 193.

${ }^{411}$ Deren Erfassung im Modell ist jedoch unkompliziert: Nach Feststellung des Einheitswerts durch das Finanzamt kann man die Grundsteuer faktisch als Festbetrag betrachten, der allenfalls im Zeitverlauf prozentual erhöht wird. Zur Grundsteuer vgl. BUSCH (2017b), S. 551, FISCHL (2017d).

${ }^{412}$ Dazu vgl. LINDAUER (2016), S. 222 ff., KUßMAUL (2018), S. 162 ff.

${ }^{413}$ Zur Einkommensteuer vgl. SCHNEELOCH/MEYERING/PATEK (2016), S. 43 ff., SCHREIBER (2017), S. 11 ff., GRASHOFF (2018), Rn. 30 ff.

${ }^{414}$ Dies gilt zumindest für Privatpersonen. Fallen die Einkünfte im Rahmen einer anderen Einkunftsart an, z.B. eines Gewerbebetriebs, werden sie dieser Einkunftsart zugerechnet. Man spricht von Subsidiarität, vgl. dazu NACKE (2018), Rn. 280 ff., KUßMAUL (2018), S. 54, SCHALLMOSER (2019), Rn. 581 ff. Dort wird Subsidiarität als „,die Konkurrenz der Konkurrenzen“ bezeichnet. Zur Einkunftsart Vermietung und Verpachtung vgl. GEILS (2016), SCHREIBER (2017), S. 40 f., SCHALLMOSER (2019), KULOSA (2019). Es sei nochmals daran erinnert, daß vorliegend von einer langfristigen Vermietungsabsicht ausgegangen wird. Einkommensteuerliche Aspekte von privaten Veräußerungsgeschäften werden daher bewußt nicht betrachtet, zu diesen vgl. LINDAUER (2016), S. $167 \mathrm{ff}$., DINKELBACH (2017), S. 252 ff., WEBER-GRELLET (2019), RATSCHOW (2019b).

${ }^{415}$ Vgl. HAMBERGER/ABERGER/GRUBER (2005), S. 601, NICKENIG (2018), S. 16. Bei juristischen Personen stellt die Körperschaftsteuer das Pendant zur Einkommensteuer bei natürlichen Personen dar, vgl. SCHNEELOCH/MEYERING/PATEK (2016), S. 160 f., KRAFT/KRAFT (2018), S. 145, RENGERS (2019b), Rn. 30. Eine weitere Ertragsteuer ist die Gewerbesteuer, die sowohl bei natürlichen als auch bei juristischen Personen auf den Gewerbeertrag anzuwenden ist, vgl. SCHNEELOCH/MEYERING/ PATEK (2016), S. 187, LINDAUER (2016), S. 201. Unterkapitel 4.9 widmet sich ausführlich der Körperschaft- und Gewerbesteuer bei juristischen Personen.

(C) Der/die Autor(en) 2021

S. Walochnik, Bewertung von Eigentumswohnungen,

Finanzwirtschaft, Unternehmensbewertung \& Revisionswesen,

https://doi.org/10.1007/978-3-658-30840-7_3 
privaten Investor zu Konsumzwecken verbleibt. ${ }^{416}$ Daher kann ein verläßliches Bewertungsergebnis nur unter Berücksichtigung der Einkommensteuer ermittelt werden. Dies macht sie zur relevantesten aller Immobiliensteuern.

\subsubsection{Solidaritätszuschlag und Kirchensteuer als einkommensteuerabhängige Zuschlagsteuern}

Hand in Hand mit der Einkommensteuer geht der Solidaritätszuschlag. ${ }^{417}$ Ebenso wie die Kirchensteuer ${ }^{418}$ ist der Solidaritätszuschlag eine sogenannte Zuschlagsteuer, d.h. seine Bemessungsgrundlage ist die Einkommensteuerschuld; die Einkommensteuer wird als Maßstabsteuer bezeichnet. ${ }^{419}$ Der Steuersatz des Solidaritätszuschlags beträgt 5,5 Prozent. ${ }^{420}$

Es besteht eine Freigrenze. Der Solidaritätszuschlag wird nur erhoben, wenn die Einkommensteuerlast größer als 974 EUR ist. ${ }^{421}$ Viele weitere Nebenbedingungen wären erforderlich, um sicherzustellen, daß der Solidaritätszuschlag im Modell erst oberhalb dieses Grenzwertes angewendet wird. Einerseits gehört der Solidaritätszuschlag zu den wichtigsten Nebendeterminanten der Einkommensteuer, seine Modellierung darf aber nicht zur weiteren Verkomplizierung des Modells führen. Als sinnvoller Kompromiß, soll im Sinne der Komplexitätsreduktion ein durchgehender Solidaritätszuschlag in Höhe von 5,5 Prozent ohne Freigrenze verwendet werden.

${ }^{416}$ Vgl. auch zum Folgenden ENGELS (1962), S. 123, SCHNEIDER (1992), S. 176, BALLWIESER (1995), S. 19 f., WAMELING (2004), S. 119, JAPES (2011), S. 69 und 111, PATEK/WAMELING (2017), S. 996 f.

${ }^{417}$ Zum Solidaritätszuschlag vgl. SCHNEELOCH/MEYERING/PATEK (2016), S. 204 f., LINDMAYER/DIETZ (2018), S. 377 f., KRAFT/KRAFT (2018), S. 195. Er wird auch auf Grundlage der Körperschaft- und Kapitalertragsteuer erhoben, vgl. dazu LINDBERG (2019b), Rn. 2 ff. Es fällt auf, daß die volle Bezeichnung des Gesetzes die Jahreszahl 1995 enthält. Weil das ursprüngliche Solidaritätszuschlagsgesetz bis zum 30.06.1992 befristet war, hat der Gesetzgeber ab 01.01.1995 erneut einen - nun unbefristeten - Solidaritätszuschlag eingeführt, vgl. LINDBERG (2019a), Rn. 1a.

${ }^{418}$ An dieser Stelle soll exemplarisch nur auf den Solidaritätszuschlag eingegangen werden, da er im Gegensatz zur Kirchensteuer auch ohne Zugehörigkeit zu einer anerkannten Religionsgemeinschaft derzeit von jedem Steuerpflichtigen entrichtet werden $m u ß$ - und der Rechenweg ähnlich ist, vgl. SCHNEELOCH/MEYERING/PATEK (2016), S. 203 ff., GRIESEL (2016), S. 63. Zur Kirchensteuer vgl. ebd., KUßMAUL (2018), S. 105 ff. Zur Behandlung der Kirchensteuer im Rahmen der Abgeltungsteuer vgl. MEYERING/SEROCKA (2012), insbesondere bei unterjährigem Kirchenein- oder -austritt vgl. MEYERING/SEROCKA (2013).

${ }^{419}$ Vgl. WAMELING (2004), S. 132 f., SIEVERT (2016), S. 28 f., DINKELBACH (2017), S. 309 f.

${ }^{420}$ Vgl. § 4 SolZG.

${ }^{421}$ Vgl. § 3 SolZG, vgl. dazu auch LINDBERG (2019b), Rn. 21. 


\subsubsection{Zu versteuerndes Einkommen als steuerliche Bemessungsgrundlage}

Die Einkommensteuer hängt nicht allein von Mieteinkünften ab, sondern vom gesamten persönlichen Einkommen, soweit es aus einer der in $\S 2$ Abs. 1 EStG aufgezählten sieben Einkunftsarten stammt. Nur Einkünfte aus den sieben Einkunftsarten sind steuerpflichtig: ${ }^{422}$

- Einkünfte aus Land- und Forstwirtschaft (§ 13-14a EStG),

- Einkünfte aus Gewerbebetrieb (§ 15-17 EStG),

- Einkünfte aus selbständiger Arbeit (§ $18 \mathrm{EStG})$,

- Einkünfte aus nichtselbständiger Arbeit ( $§ 19 \mathrm{EStG})$,

- Einkünfte aus Kapitalvermögen (§ 20 EStG),

- Einkünfte aus Vermietung und Verpachtung (§ 21 EStG),

- $\quad$ sonstige Einkünfte ( $§ 22-23$ EStG).423

Die Unterscheidung der Einkunftsarten ist z.B. für die Anwendbarkeit unterschiedlicher Freibeträge oder eines Verlustausgleichs relevant - oder aufgrund spezieller Steuern, bspw. knüpft die Gewerbesteuer nur Einkünfte aus Gewerbebetrieb an.

Gemäß dem Grundgedanken der Einkommensteuer soll jeder Steuerpflichtige einen Beitrag aufbringen, der seiner wirtschaftlichen Leistungsfähigkeit angemessen ist. ${ }^{424}$ In Form des zu versteuernden Einkommens soll die gleiche, möglichst objektive Meßlatte an alle Steuerpflichtigen angelegt werden. Die Schritte zu dessen Berechnung folgen

${ }^{422} \mathrm{Vgl}$. HAMBERGER/ABERGER/GRUBER (2005), S. 602, HAMBERGER (2016), S. 1008, HEY/SEER (2018), Rn. 120 ff. Vgl. zu den sieben Einkunftsarten BEECK (2012), S. 12 ff., SCHNEELOCH/MEYERING/PATEK (2016), S. $50 \mathrm{ff}$.

${ }^{423}$ Der Begriff sonstige Einkünfte irritiert, weil er kein Sammelbecken darstellt, sondern nur bestimmte, ausdrücklich definierte Einkünfte umfaßt, z.B. Leibrenten, vgl. SCHNEELOCH/MEYERING/PATEK (2016), S. 82 ff.

${ }^{424}$ Vgl. VAN SUNTUM/SCHULTEWOLTER (2014), S. 202, SCHNEELOCH/MEYERING/PATEK (2016), S. 7 f., JESGARZEWSKI (2016), S. 4 f. Dabei fällen HEY und SEER ein hartes Urteil: Nur theoretisch richte sich die Einkommensteuer nach der wirtschaftlichen Leistungsfähigkeit. „Das geltende Recht ist von diesem Anspruch weit entfernt. “ $H E Y / \operatorname{SEER}$ (2018), Rn. 180. Durch Freibeträge und Freigrenzen komme es nur zu einer Teilbesteuerung des Einkommens, die Bemessungsgrundlage werde aufgrund des Methodenpluralismus bei der Einkünfteermittlung für die verschiedenen Einkunftsarten verfälscht und der Einheitstarif damit verzerrt. Bestimmte Einkunftsarten würden gezielt privilegiert (z.B. Land- und Forstwirtschaft aufgrund der Anwendung von Durchschnittssätzen) und es gälten Realtarife von null Prozent bis zum vollen Steuersatz, je nachdem, ob das Einkommen partiell oder voll erfaßt werde. Je höher seine tatsächlichen Einkünfte, desto bessere steuerliche Beratung könne sich ein Steuerpflichtiger erkaufen - und von dieser sei die wirkliche Steuerbelastung abhängig, vgl. ebd. In der Realität degeneriere die Einkommensteuer zur „Dummensteuer“ (sic!, ebd., Rn. 4), welche diejenigen am stärksten trifft, die am schlechtesten informiert oder beraten sind oder - wie die Lohnsteuerzahler - ihr am wenigsten ausweichen können, vgl. ebd., Rn. 803. Zur Kritik an der Umsetzbarkeit des Gedankens wirtschaftlicher Leistungsfähigkeit, vgl. auch SAVA (2007), S. 102 f., SCHREIBER (2017), S. 11. 
einem normierten Ermittlungsschema. ${ }^{425}$ Zunächst werden die Einkünfte aller Einkunftsarten getrennt voneinander berechnet und danach summiert. Es folgt der Abzug bestimmter Sonder- und Freibeträge. Das Rechenergebnis ist die Bemessungsgrundlage der Einkommensteuer. ${ }^{426}$ Somit erfordert nicht nur das Dilemma der Lenkpreistheorie, ${ }^{427}$ sondern auch das Einkommensteuerrecht eine Gesamtbetrachtung, um Einkünfte aus allen Quellen zu berücksichtigen. ${ }^{428}$ Das Ermittlungsschema lautet wie folgt:

+ Einkünfte aus Gewerbebetrieb ( $\$ 15 \mathrm{ff}$. EStG)

+ Einkünfte aus nichtselbständiger Arbeit (§ $19 \mathrm{EStG})$

+ Einkünfte aus Vermietung und Verpachtung (§ $21 \mathrm{EStG})$

+ Einkünfte aus...

$+\ldots$

= Summe der Einkünfte

./. Entlastungsbeträge

./. Freibetrag für Land- und Forstwirtschaft

+ Hinzurechnungsbeträge

= Gesamtbetrag der Einkünfte

./. Verlustabzug (Verlustvortrag, Verlustrücktrag)

./. Sonderausgaben (Privatpersonen)

./. außergewöhnliche Belastungen (Privatpersonen)

./. Steuerbegünstigungen (Denkmäler, Kulturgüter)

+ Erstattungsüberhänge (Rückerstattung Versicherungsbeiträge)

+ Hinzurechnungsbeträge (Gewerbesteuer)

= Einkommen

./. Kinderfreibeträge

./. Härteausgleich

$=\mathrm{Zu}$ versteuerndes Einkommen

Ferner unterscheidet der Gesetzgeber zwischen Gewinn- und Überschußeinkünften. ${ }^{429}$ Daraus folgen Abweichungen sowohl für die Definition des Einkünftebegriffs als auch für die Art ihrer Berechnung: Die drei erstgenannten Einkunftsarten werden Gewinneinkünfte genannt. ${ }^{430}$ Aus der Perspektive des Steuerrechts ist bei ihnen das unterneh-

${ }^{425}$ Zum Ermittlungsschema der einkommensteuerlichen Bemessungsgrundlage vgl. PFEIFER (2016), S. 425 f., HAMBERGER (2016), S. 1008, NICKENIG (2018), S. 27 ff., SIEGERT (2019), S. 319.

${ }^{426}$ Die funktionale Bewertungstheorie spricht von der Steuerbemessungsfunktion. Sie entspringt einer besonderen Konfliktsituation und dient der Verteilung öffentlicher Lasten, vgl. SIEBEN (1976), S. 494. Einen Überblick über die Steuerbemessungsfunktion gibt SIELAFF (1977).

${ }^{427} \mathrm{Vgl}$. dazu Unterabschnitt 2.1.2.3.

${ }^{428}$ Vgl. ADAM (2000), S. 163, JAPES (2011), S. 13 f., HENSELMANN/KNIEST (2015), S. 319.

${ }^{429} \mathrm{Zu}$ diesem Dualismus der Einkunftsarten vgl. SAVA (2007), GRIESEL (2016), S. 64, DINKELBACH (2017), S. 37 ff., KUßMAUL (2018), S. 27 ff.

${ }^{430}$ Diese umfassen laut $\S 2$ Abs. 2 Nr. 1 EStG Einkünfte aus land- und forstwirtschaftlicher, gewerblicher und selbständiger Tätigkeit. 
merische Gewinnstreben vorherrschend. Steuergegenstand ist der gesamte Vermögenszuwachs aus unternehmerischer Betätigung. Der Gewinn wird durch Betriebsvermögensvergleich zwischen Jahresbeginn und -ende ermittelt. ${ }^{431}$ Bei Überschußeinkünften, zu denen auch Vermietung und Verpachtung gehören, ${ }^{432}$ werden hingegen nur Erträge aus ständig fließender Quelle besteuert, aber keine Wertveränderungen der Quelle selbst. ${ }^{433}$ Den einkommensteuerrelevanten Gewinn bezeichnet man bei diesen als (Werbungskosten-) Überschuß. ${ }^{434}$

\subsubsection{Steuertarif als nichtlineare Funktion des Einkommens}

Für die Berechnung der betragsmäßigen Höhe der Steuerlast wird die Steuertariffunktion auf das zu versteuernde Einkommen angewendet. ${ }^{435}$ Sie unterscheidet fünf Einkommensabschnitte, für die jeweils unterschiedliche Berechnungsvorschriften gelten. Dies führt dazu, daß der Steuersatz einer natürlichen Person mit zunehmendem Einkommen steigt. ${ }^{436}$ Da er sowohl lineare als auch progressiv verlaufende Teilabschnitte beinhaltet, spricht man von einem linear-progressiven Steuertarif:

- Er beginnt mit einer Nullzone, auch Grundfreibetrag genannt. Einkommen bis 9.168 EUR unterliegen keiner Einkommensteuer (Zone 1). Dieser Betrag soll dem verfassungsmäßig geschützten Existenzminimum entsprechen. ${ }^{437}$

- Der Einkommensbereich zwischen 9.169 und 55.960 EUR wird Progressionsbereich genannt (Zonen 2 und 3). Beide Tariffunktionen in diesem Bereich sind quadratischer Natur. ${ }^{438}$

${ }^{431}$ Bei dieser Art der Gewinnermittlung nach $\S 4$ Abs. 1 EStG spricht man von Bilanzierung. Maßstab ist der Unterschied des bilanziellen Eigenkapitals inkl. Unterkonten, der nicht nur Veränderungen des Geldvermögens, sondern auch aller anderen betrieblichen Vermögenswerte erfaßt, vgl. dazu SCHNEELOCH/MEYERING/PATEK (2017a), S. 15 ff., KRAFT/KRAFT(2018), S. 63 f.

432 Überschußeinkunftsarten sind laut $\S 2$ Abs. 2 Nr. 2 EStG die Einkünfte aus nichtselbständiger Tätigkeit, Kapitalvermögen, Vermietung und Verpachtung sowie sonstige Einkünfte.

${ }^{433}$ Vgl. SAVA (2007), S. 124, HEY/SEER (2018), Rn. 182, SCHALLMOSER (2019), Rn. 11.

${ }^{434}$ Vgl. $§ 2$ Abs. 2 Nr. 2 EStG.

${ }^{435}$ Die Intensität der Steuerbelastung bestimmt sich also aus dem Zusammenspiel von Steuersatz und Bemessungsgrundlage, vgl. LOSCHELDER (2019), Rn. 4.

${ }^{436}$ Der progressiv steigende Steuersatz soll das Prinzip der wirtschaftlichen Leistungsfähigkeit zum Ausdruck bringen, vgl. HAMBERGER (2016), S. 1009. Zum Einkommensteuertarif nach § 32a EStG vgl. SCHNEELOCH/MEYERING/PATEK (2016), S. 116 ff., GRASHOFF (2018), Rn. 208 ff., NICKENIG (2018), S. 25 f., SIEGERT (2019), S. 320 f. Die in Deutschland geltende progressive Einkommensteuer wurde im Jahr 1891 eingeführt und ist in ihren Grundzügen noch heute gültig, vgl. VAN SUNTUM/ SCHULTEWOLTER (2014), S. 193.

${ }^{437}$ Vgl. WAGNER (2019), Rn. 39, LOSCHELDER (2019), Rn. 4.

${ }^{438}$ Die Progressionszonen sind determiniert durch einen linear steigenden Grenzsteuersatz und eine progressiv steigende absolute Steuerbelastung, vgl. GRASHOFF (2018), Rn. 210. 
- Oberhalb eines Einkommens von 55.961 EUR bzw. 265.327 EUR beginnt je eine der Proportionalzonen, deren lineare Steuersätze 42 Prozent bzw. 45 Prozent betragen (Zonen 4 bzw. 5). ${ }^{439}$

Die Einkommensteuertariffunktion ist in $§ 32 \mathrm{a}$ Abs. $1 \mathrm{EStG}$ wie folgt definiert: ${ }^{40}$

„Die tarifliche Einkommensteuer bemisst sich nach dem zu versteuernden Einkommen. Sie beträgt im Veranlagungszeitraum 2019 [...] jeweils in Euro für zu versteuernde Einkommen

1. bis 9168 Euro (Grundfreibetrag):

0 ;

2. von 9169 Euro bis 14254 Euro:

$(980,14 \cdot y+1400) \cdot y ;$

3. von 14255 Euro bis 55960 Euro:

$(216,16 \cdot z+2397) \cdot z+965,58 ;$

4. von 55961 Euro bis 265326 Euro:

$0,42 \cdot \mathrm{x}-8780,90$

5. von 265327 Euro an:

$0,45 \cdot \mathrm{x}-16740,68$.

Die Größe , $\mathrm{y}^{`}$ ist ein Zehntausendstel des den Grundfreibetrag übersteigenden Teils des auf einen vollen Euro-Betrag abgerundeten zu versteuernden Einkommens. Die Größe , $\mathrm{Z}^{6}$ ist ein Zehntausendstel des 14254 Euro übersteigenden Teils des auf einen vollen Euro-Betrag abgerundeten zu versteuernden Einkommens. Die Größe , $\mathrm{x}$ “ ist das auf einen vollen Euro-Betrag abgerundete zu versteuernde Einkommen. Der sich ergebende Steuerbetrag ist auf den nächsten vollen Euro-Betrag abzurunden." ${ }^{441}$

Wie man sieht, kennt die gesetzliche Berechnungsvorschrift für verschiedene Abschnitte unterschiedliche Hilfsvariablen, genannt x, y und z. Weil diese Faktoren ohnehin vom zu versteuernden Einkommen abhängen und zudem die Lesbarkeit beeinträch-

${ }^{439}$ Die beiden Proportionalzonen zeichnen sich aus durch einen konstanten Grenzsteuersatz von 42 Prozent bzw. 45 Prozent. Der Durchschnittssteuersatz nähert sich degressiv an den Grenzsteuersatz von 45 Prozent an, erreicht ihn aber nie, vgl. SCHNEELOCH/MEYERING/PATEK (2016), S. 118, FREICHEL/ KRENZIN/LÖSEL/BRÄHLER (2018), S. 29. Den Aufschlag von drei Prozentpunkten in der oberen Proportionalzone nennt man Reichensteuer, vgl. HEY/SEER (2018), Rn. 805.

${ }^{440}$ Abs. 1 definiert den sogenannten Grundtarif für ledige Personen. Den Tarif, der für steuerlich zusammenveranlagte Eheleute gilt, findet man in Abs. 5. Zum Zusammenveranlagungstarif vgl. Unterkapitel 4.8 .

${ }^{441} \S 32 \mathrm{a}$ Abs. 1 EStG. Zu mathematischen Besonderheiten aufgrund der Abrundung auf volle EUR vgl. PFEIFER (2016), S. 428 ff. 
tigen, können die Funktionsvorschriften umgeschrieben werden, damit ihre Abhängigkeit vom Einkommen klarer erkennbar ist. Die umgeformten Funktionsvorschriften zeigt Tabelle 22:

\section{Symbole:}

$\mathrm{E}=\mathrm{zu}$ versteuerndes Einkommen

$S(E)=$ Steuerlast (abhängig vom zu versteuernden Einkommen)

Zone 1: Bis 9.168 Euro (Grundfreibetrag):

$$
S(E)=0
$$

Zone 2: Von 9.169 Euro bis 14.254 Euro:

$$
\begin{aligned}
& S(E)=\left(980,14 \cdot\left[\frac{E-9.168}{10.000}\right]+1.400\right) \cdot\left(\frac{E-9.168}{10.000}\right) \\
& \Leftrightarrow S(E)=0,0000098014 E^{2}-0,039718 E-459,69
\end{aligned}
$$

Zone 3: Von 14.255 Euro bis 55.960 Euro:

$$
\begin{aligned}
& S(E)=\left(216,16 \cdot\left[\frac{E-14.254}{10.000}\right]+2.397\right) \cdot\left(\frac{E-14.254}{10.000}\right)+965,58 \\
& \Leftrightarrow S(E)=0,0000021616 E^{2}-0,178077 E-2.011,92
\end{aligned}
$$

\section{Zone 4: Von 55.961 Euro bis 265.326 Euro:}

$$
S(E)=0,42 E-8.780,90
$$

\section{Zone 5: Von 265.327 Euro an:}

$$
S(E)=0,45 E-16.740,68
$$

\section{Tabelle 22: Formeln der Einkommensteuertariffunktion}

Abbildung 2 zeigt skizzenhaft die Steuerbetragsfunktion, ${ }^{442}$ welche die absolute Steuerlast in Abhängigkeit vom zu versteuernden Einkommen zeigt. In der Abbildung wird insbesondere der progressiv steigende Verlauf der Steuerlast mit zunehmendem Einkommen deutlich. ${ }^{443}$

\footnotetext{
${ }^{442}$ Vgl. zu dieser BEECK (2012), S. 34.

${ }^{443}$ Geläufiger sind zwar Abbildungen von Grenz-, Durchschnitts- oder Differenzsteuersatz. Für die zahlungsstromorientierte Betrachtung sind prozentuale Steuersätze jedoch weniger hilfreich als eine betragsmäßige Steuerlast in EUR. Der Grenzsteuersatz ist die erste Ableitung der Einkommensteuertariffunktion und beschreibt den Steuersatz bezogen auf einen marginalen Einkommenszuwachs, der
} 


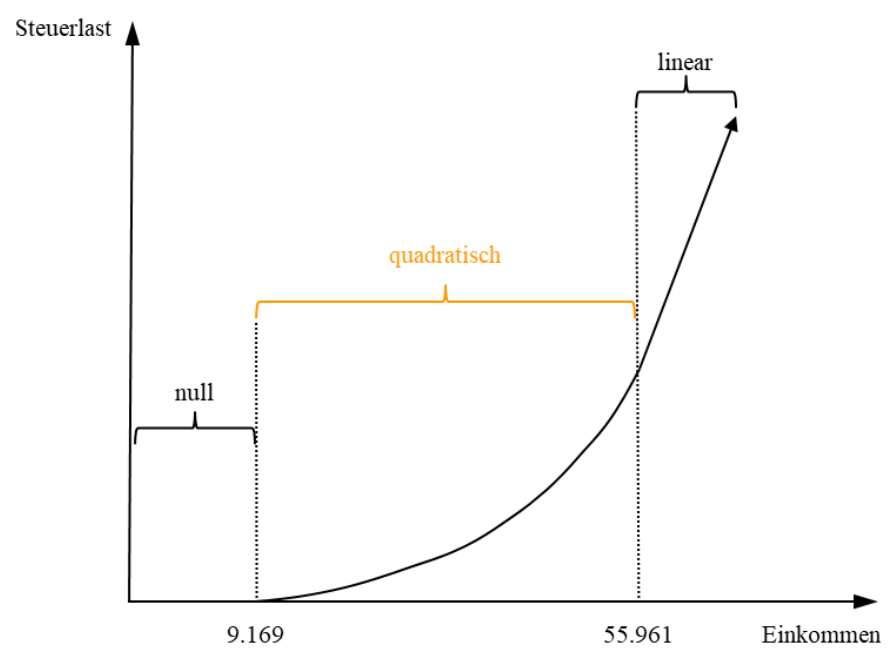

Abbildung 2: Schematische Einkommensteuer-Betragsfunktion

\subsection{Allgemeine Beschreibung der Modellerweiterung}

\subsubsection{Ergänzung investitionstheoretischer Zahlungsströme um ihre steuerrelevanten Schattenobjekte}

Aus investitionstheoretischer Sicht ist auch die abzuführende Einkommensteuerlast ein Zahlungsstrom. Sie ist eine Kostenfunktion, die vom Vorhandensein und von der Höhe anderer Zahlungsströme abhängt. $\mathrm{Zu}$ ihrer Berechnung werden jedoch gesetzliche Normwerte herangezogen. In der Regel weichen die investitionstheoretischen Zahlungsströme (vor Berücksichtigung der Einkommensteuerzahlung) von der einkommensteuerlichen Bemessungsgrundlage ab. Weil jedoch Einkommensteuer nebst Solidaritätszuschlag die entnahmefähigen Überschüsse schlimmstenfalls um 47,5 Prozent mindern, ist eine möglichst treffende Erfassung nötig. Dies gelingt, indem zu jedem investitionstheoretischen Objekt ein Nebenobjekt modelliert wird, das seine steuerrelevante Bemessungsgrundlage abbildet. ${ }^{444}$ Es soll hier als Schattenobjekt bezeichnet werden und

Durchschnittssteuersatz beschreibt den Steuersatz bezogen auf das Gesamteinkommen und der Differenzsteuersatz ist der Steuersatz bezogen auf einen bestimmten Einkommenszuwachs und bezieht sich auf die Differenz zweier Einkommen, vgl. SCHNEELOCH/MEYERING/PATEK (2016), S. 117 f., SIEGERT (2019), S. 321.

${ }^{444} \mathrm{Zu}$ dieser Vorgehensweise vgl. HERING (1998), S. 111 ff. Es ging um „Investoren, die entscheiden müssen, ob sie zur Finanzierung einer Anschaffung ein Darlehen aufnehmen oder ihre bis zu einer bestimmten Höhe steuerfreien Guthaben (ganz oder teilweise) auflösen sollen." ebd. Zum Zahlungsstrom eines Sparbriefes wurde ein zusätzlicher Vektor gebildet, der ausschließlich die steuerrelevanten Zinskomponenten enthielt. Für ein Fallbeispiel vgl. ebd. sowie HERING/KLINGELHÖFER (1998), S. 167. Ähnliche Ansätze findet man bei $\operatorname{HAX}(1985)$, S. 114 f., ROPETER (1998), S. 52 f., ADAM 
verkörpert die einkommensteuerliche Bemessungsgrundlage aus investitionstheoretischer Sicht. Darauf basierend kann die Steuerlast mit zusätzlichen Nebenbedingungen modellendogen berechnet werden.

Welche Umrechnungen erforderlich sind, kann nicht allgemein gesagt werden. Für alle Investitions- und Finanzierungsobjekte ist zu überlegen, ob und inwieweit der Zahlungsstrom vom steuerrelevanten Anteil abweicht. Die hier besprochenen Einkünfte gehören zu den Überschußeinkunftsarten. Für diese ist eine verhältnismäßig einfache Art der Gewinnermittlung anwendbar, die sich hauptsächlich am $\mathrm{Zu}$ - und Abfluß von Geldern orientiert und den Steuerpflichtigen nicht überstrapazieren soll. ${ }^{445}$ Aus Sicht der Investitionstheorie sind Ein- und Auszahlungen relevant, für die Überschußeinkunftsarten sind Einnahmen abzüglich Werbungskosten bedeutsam. Im steuerlichen Sinne sind Einnahmen alle Vorteile in Geld oder Geldeswert, die dem Vermieter im Veranlassungszusammenhang mit der Vermietung zufließen. ${ }^{446}$ Werbungskosten nennt man Aufwendungen, die zu Erwerb, Sicherung oder Erhaltung der Mieteinnahmen dienen. ${ }^{447}$ Forderungen und Verbindlichkeiten bleiben ebenso unberücksichtigt wie der Zuwachs von Reinvermögen oder Vermögensumschichtungen. Daraus kann gefolgert werden, daß der steuerrelevante Anteil dem Zahlungsstrom zumindest ähnlich, in vielen Fällen sogar dekkungsgleich ist.

Im Folgenden sollen Anhaltspunkte hinsichtlich einzelner Komponenten des Zahlungsstroms einer Eigentumswohnung zur Verfügung gestellt werden. Zur Vermeidung von Wiederholungen werden nur diejenigen Punkte beleuchtet, bei denen Abweichungen bestehen, für alles Weitere sei auf Gliederungspunkt 2.2.3.3.2 verwiesen. Es ist vorstellbar, daß ein steuerrelevantes Schattenobjekt genau dem investitionstheoretischen Zahlungsstrom entspricht, wenn Einzahlungen voll zu versteuern und Auszahlungen voll abzugsfähig sind. Es sind auch steuerfreie Zahlungsströme denkbar, zu denen keine Schattenobjekte gehören - ebenso wie negative Werte zur Abbildung von Subventionen. ${ }^{48}$ Denkbar sind auch steuerrelevante Elemente, denen überhaupt kein Zahlungsstrom zugrunde liegt, z.B. Kinderfreibeträge. Diese sind modellierbar als negatives Schattenobjekt ohne Referenzobjekt.

(2000), S. 163, WAMELING (2004), S. 122, JAPES (2011), S. 34 f., BUSSE VON COLBE/WITTE (2018), S. 85 .

${ }^{445}$ Vgl. auch zum Folgenden SCHNEELOCH/MEYERING/PATEK (2016), S. 55 f., HEY/SEER (2018), Rn. 191 ff., KRAFT/KRAFT(2018), S. 65.

${ }^{446}$ Vgl. § 8 Abs. 1 EStG, vgl. dazu auch GEILS (2016), Rn. 102, NACKE (2018), Rn. 450 ff.

${ }^{447}$ Vgl. § 9 Abs. 1 EStG, vgl. dazu FISCHL (2013), Rn. 60 ff., STÜRZER/KOCH/HOPFENSPERGER/STERNS/ STERNS-KOLBECK/ZIEGELMAYER (2016), S. 383, KUßMAUL (2018), S. 60. Einen beispielhaften, alphabetischen Überblick über Werbungskosten im Rahmen der Einkommensteuer gibt THÜRMER (2019), Rn. 700. Die Zulässigkeit ihres Abzugs richtet sich nach dem Veranlassungszusammenhang, vgl. GRIESEL (2016), S. 64. Auch innerhalb der Einkunftsart müssen Werbungskosten dem richtigen Gebäude(teil) zugeordnet werden, was vor allem bei Immobilien eine Rolle spielt, die gleichzeitig selbst- und fremdgenutzt werden, vgl. SCHALLMOSER (2019), Rn. 313.

${ }^{448} \mathrm{Vgl}$. JAPES (2011), S. $106 \mathrm{ff}$. 


\section{Zuflüsse}

\section{Mieteinnahmen}

Ähnlich der Berücksichtigung von Zahlungsströmen müssen Mietzahlungen nach $§ 11$ EStG im Kalenderjahr ihres Zuflusses erfaßt werden. ${ }^{449} \mathrm{Zu}$ den wenigen Ausnahmen zählen regelmäßige Zahlungen, die zehn Tage vor oder nach Jahreswechsel eingehen: Sie müssen dem Kalenderjahr zugerechnet werden, zu dem sie gehören. ${ }^{450}$ Ansatzwahlrechte, Abgrenzungspositionen und andere Gestaltungsmöglichkeiten gibt es praktisch nicht. ${ }^{451}$ Auch bei Mietminderungen, ist - unabhängig von ihrer Berechtigung - nur der eingegangene Teil der Miete zu erfassen. Fällt die Mieteinzahlung aus, wird die unbefriedigte Forderung auch steuerlich nicht erfaßt. Gelingt es zu einem späteren Zeitpunkt, die Forderung beizutreiben, muß sie im Zeitpunkt des Geldeingangs versteuert werden. $^{452}$

\section{Betriebskosten}

Das strikte Prinzip von Zu- und Abflüssen erfaßt auch Zuflüsse aufgrund von Nebenleistungen: Sowohl laufende Betriebskostenvorauszahlungen als auch die Betriebskostenabrechnung $^{453}$ gelten als Einnahmen ${ }^{454}$ - obwohl sie auch steuerlich ein durchlaufender Posten sind. Korrespondierende Ausgaben sind als Werbungskosten abzugsfähig. ${ }^{455}$

\section{Sonstige Einnahmen und Vorteile}

Sämtliche Vorteile, die dem Vermieter im Rahmen der Überlassung der Wohnung zufließen zählen zu den steuerrelevanten Einnahmen aus Vermietung und Verpachtung. Vorstellbar ist z.B. eine Abstandszahlung des Mieters, damit der Vermieter ihn vorzeitig aus einem bindenden Mietvertrag mit fester Laufzeit entläßt. Denkbar ist auch eine Schadenersatzzahlung der WEG zur Kompensation einer Mietminderung aufgrund eines von der WEG zu vertretenden Schadens. ${ }^{456}$

${ }^{449}$ Vgl. auch zum Folgenden GRIESEL (2016), S. 64 f., LINDAUER (2016), S. 136.

${ }^{450}$ Vgl. § 11 Abs. 1 Satz 2 EStG. Man denke bspw. an die Miete für Januar, die aufgrund des Dauerauftrags bereits am 30. Dezember eingeht.

${ }^{451}$ Jedoch besteht ein Wahlrecht, Mieteinnahmen für eine Nutzungsdauer von mehr als fünf Jahren, die auf einmal im Voraus bezahlt werden, sofort zu versteuern oder gleichmäßig über die Dauer zu verteilen, vgl. dazu STÜRZER/KOCH/HOPFENSPERGER/STERNS/STERNS-KOLBECK/ZIEGELMAYER (2016), S. 378. Derartige Fälle sind für private Vermieter von Wohnraum wohl schon aufgrund des starken Mieterschutzes in Deutschland kaum von Bedeutung und werden hier nicht weiter behandelt.

${ }^{452}$ Vgl. KULOSA (2019), Rn. 117, SCHALLMOSER (2019), Rn. 233.

${ }^{453}$ Diese Aussage gilt nur im Fall einer Nachzahlung des Mieters an den Vermieter. Im entgegengesetzten Fall handelt es sich wiederum um Werbungskosten.

${ }^{454}$ Vgl. LINDAUER (2016), S. 137, FISCHL (2017a), Rn. 5 f.

${ }^{455}$ Vgl. KULOSA (2019), Rn. 148.

${ }^{456}$ Viele Beispiele und Fallkonstellationen findet man bei SCHALLMOSER (2019), Rn. 240 ff., dort u.a. Entschädigungszahlungen, Übernahme von Einbauten durch den Mieter, Zahlungen einer Mietausfallversicherung, etc. 


\section{Mietkaution}

Die Mietkaution gehört nicht zu den Einkünften aus Vermietung und Verpachtung, ${ }^{457}$ schließlich erfolgt kein Eigentumsübergang, sondern lediglich eine Verpfändung. Dies gilt zumindest für den Normalfall, daß die Mietkaution bei Beginn des Mietverhältnisses entgegengenommen und bei Beendigung zurückgezahlt wird. Muß der Vermieter die Kaution jedoch als Ersatz für berechtigte, ausstehende Forderungen auflösen, tritt sie an die Stelle des eigentlich geschuldeten Zahlungsstroms, zu dessen Besicherung sie dient.

\section{Abflüsse $^{458}$}

\section{Hausgeld, Jahresabrechnung und Sonderumlagen}

In der Regel besteht bei diesen Positionen Deckungsgleichheit zu investitionstheoretischen Zahlungen. Ein Unterschied besteht jedoch in der Beitragspflicht zur Instandhaltungsrücklage der WEG. Sie wird im Zeitpunkt ihres Abflusses vom Eigentümer aus steuerlicher Sicht als Umbuchung behandelt. Erst bei ihrer Verwendung wird sie steuermindernd wirksam. Für diesen Spezialfall sei auf Unterkapitel 4.3 verwiesen. Bis dahin sei vereinfachend unterstellt, daß die Beitragspflicht zur Rücklage im gleichen Jahr vollständig für Maßnahmen der Instandhaltung verwendet wird.

\section{Größere Erhaltungsaufwendungen}

Bei größeren Erhaltungsaufwendungen besteht ein Wahlrecht, diese sofort in voller Höhe anzusetzen oder über die folgenden zwei bis fünf Jahre abzuschreiben. Hierauf wird in Unterkapitel 4.6 genauer eingegangen. Vorerst wird vereinfachend davon ausgegangen, daß der Vermieter die Aufwendungen im Steuerjahr des Abflusses in voller Höhe als Werbungskosten geltend macht.

\section{Schuldzinsen und sonstige Finanzierungskosten}

Der Tilgungsanteil einer Darlehensrate wird steuerlich als Umbuchung betrachtet und ist nicht abzugsfähig. ${ }^{459}$ Gleiches gilt für die Auszahlung des Darlehens, welche nicht als Einnahme zu versteuern ist. Abzugsfähig sind Schuldzinsen, Nebenkosten der Darlehensaufnahme und alle weiteren Arten von Finanzierungskosten. ${ }^{460}$

\section{Pauschale Werbungskosten}

Es gibt Werbungskostenpauschalen, denen keine Geldbewegung in identischer Höhe zugrunde liegt, z.B. die Kilometerpauschale von 0,30 EUR für Autofahrten zum Mietobjekt. ${ }^{461}$ Oft sollen Pauschalen den Ansatz von Werbungskosten ermöglichen, deren

\footnotetext{
457 Auch zum Folgenden vgl. HAMBERGER (2016), S. 1016 f., STÜRZER/KOCH/HOPFENSPERGER/STERNS/ STERNS-KOLBECK/ZIEGELMAYER (2016), S. 381, SCHALLMOSER (2019), Rn. 240.

${ }^{458}$ Ein Überblick über verschiedene Werbungskosten findet sich bei GEILS (2016), Rn. 104 ff., SCHALLMOSER (2019), Rn. 400, KULOSA (2019), Rn. 148.

${ }^{459}$ Auch zum Folgenden vgl. WREDE (2017), S. 80 f.

${ }^{460}$ Vgl. THÜRMER (2019), Rn. 208, SIEGERT (2019), S. 326 f.

${ }^{461} \mathrm{Vgl}$. STÜRZER/KOCH/HOPFENSPERGER/STERNS/STERNS-KOLBECK/ZIEGELMAYER (2016), S. 389 f.
} 
Erfassungsaufwand unverhältnismäßig ist. Ihr Stellenwert ist bei der Einkunftsart Vermietung und Verpachtung von untergeordneter Bedeutung. ${ }^{462}$

\section{Abschreibung für Abnutzung (AfA)}

Ein Sonderfall der Werbungskosten ist die steuerliche Abschreibung des Kaufpreises. Oftmals stellt sie den wesentlichsten Unterschied zwischen steuerrechtlicher Sichtweise und investitionstheoretischen (Vor-Steuer-) Zahlungsströmen dar. ${ }^{463}$ Investitionstheoretisch ruft der Kaufpreis eine einmalige, sehr große Auszahlung hervor, darf steuerlich jedoch nicht sofort als Werbungskosten geltend gemacht werden. Statt dessen ist eine lineare Abschreibung vorzunehmen. Darunter versteht man die gleichmäßige Verteilung auf die wirtschaftliche Nutzungsdauer. Diese wird von der Finanzverwaltung pauschal mit 50 Jahren unterstellt, entsprechend einer Abschreibung von zwei Prozent p.a. ${ }^{464}$

Bemessungsgrundlage der Abschreibung sind Anschaffungskosten, die neben dem Kaufpreis auch Erwerbsnebenkosten umfassen. Jedoch unterliegt nach der Vorstellung der Finanzverwaltung nur das Gebäude einer Abnutzung, nicht aber das Grundstück. Dies soll dem Gedanken Rechnung tragen, daß die Bauwerkssubstanz im Laufe der Zeit vollständig verschleißt und am Ende der Nutzungsdauer wirtschaftlich nicht mehr nutzbar ist - während das Grundstück z.B. auch nach Abriß des Gebäudes zur erneuten Bebauung wiederverwendet werden kann.

Daher sind die Gesamtkosten zunächst auf Grundstück und Gebäude aufzuteilen. ${ }^{465}$ Die Aufteilung folgt zwar keinem gesetzlich vorgegebenen Schema, soll aber zumindest sachgerecht sein ${ }^{466}$ So ist es - in vertretbarem Rahmen - zulässig, die Aufteilung bereits im notariellen Kaufvertrag vorzunehmen. In vielen Fällen passiert das aber nicht, daher stellt das Bundesfinanzministerium für alle übrigen Fälle ein Excel-Werkzeug zur Verfügung, das wie folgt vorgeht: ${ }^{467} \mathrm{Im}$ ersten Schritt erfolgt eine Bewertung auf Basis von schablonenhaften Normwerten, getrennt für Grundstück und Gebäude. Für das Grundstück werden Bodenrichtwerte herangezogen. Dies sind standortbezogene Vergangenheitspreise für einen Quadratmeter Grundstück. Sie werden von Gutachterausschüssen

${ }^{462}$ Vgl. NICKENIG (2018), S. 42.

${ }^{463}$ Zur Kaufpreisabschreibung im Rahmen von Vermietung und Verpachtung vgl. RENNERT (2012), S. 83 f., FISCHL (2017a), Rn. 34 ff., SIEGERT (2019), S. 324 ff.

${ }^{464}$ Vgl. § 7 Abs. 4, Nr. 2 Buchstabe a EStG, siehe auch VAN SUNTUM/SCHULTEWOLTER (2014), S. 203.

${ }^{465}$ Vgl. auch zum Folgenden KIESEWETTER/SCHÖNEMANN (2011), S. 109, SCHNEELOCH/MEYERING/ PATEK (2016), S. 69, BÄR (2017), S. 6.

466 Auch zum Folgenden vgl. WICHMANN (2017), WREDE (2017), S. 73 f., BRANDIS (2019), Rn. 457 ff.

${ }^{467}$ Das Excel-Werkzeug kann von der Netzseite des Bundesfinanzministeriums heruntergeladen werden (www.bundesfinanzministerium.de), man findet es mit den Begriffen „Berechnung Aufteilung Grundstückskaufpreis“ über die Suchfunktion. 
zusammengetragen und sind meist nach Straßenzügen oder anderen Faktoren der Mikrolage geordnet. ${ }^{468}$ Für Nordrhein-Westfalen findet man Bodenrichtwerte z.B. frei zugänglich auf den Netzseiten von BoRiS NRW ${ }^{469}$ und muß sie lediglich mit der Grundstücksgröße multiplizieren. Zu diesem Zweck sind auf BoRiS NRW neben den Richtwerten auch Vermessungsdaten hinterlegt. Es ist zu beachten, daß jeder Wohneinheit nur ein prozentualer Anteil des Grundstücks zugeordnet ist, ${ }^{470}$ dies erfordert die Umrechnung des gesamten Bodenrichtwertes entsprechend dem Verhältnis der Miteigentumsanteile. Anschließend erfolgt eine nicht weniger schablonenhafte Bewertung des Gebäudes. Dazu übernimmt das Excel-Werkzeug einen Tabellenwert, genannt THK 2010 (,Typisierte Herstellungskosten“). Dieser Gebäudewert pro Quadratmeter richtet sich erstens nach dem Baujahr und zweitens, sofern geschehen, nach Modernisierungsmaßnahmen, die in der Vergangenheit durchgeführt wurden. Letztere erzeugen ein fiktives, jüngeres Baujahr. So erhöhen vergangene Modernisierungsmaßnahmen den quadratmeterbezogenen THK - und damit auch den abschreibungsfähigen Gebäudeanteil des Kaufpreises. Dieser wird mit der Wohnfläche der Eigentumswohnung multipliziert.

Nun liegen Normwerte für Gebäude und Grundstück vor, deren Summe sich höchstens rein zufällig mit dem verhandelten Kaufpreis deckt. Entscheidend für die Umrechnung ist das prozentuale Verhältnis beider Bestandteile zueinander. Dieses wird auf den tatsächlichen Kaufpreis einschließlich Erwerbsnebenkosten übertragen und so der abschreibungsfähige Gebäudeanteil errechnet. Diese Nebenrechnung kann außerhalb des Modells vorgenommen werden, weil die Aufteilung schematisch ist. Das Ergebnis kann als einfacher, zwischen null und eins normierter Multiplikator in das Modell übernommen werden. Der Gebäudeanteil soll hier als $\gamma$ bezeichnet werden. Das Bewertungssubjekt benötigt nur eine überschaubare Anzahl an Eingangsdaten:

- die Adresse des Gebäudes für die Suche nach dem Bodenrichtwert,

- die Grundstücksgröße zur Hochrechnung des quadratmeterbezogenen Bodenrichtwerts,

- die Miteigentumsanteile zur Umrechnung des Grundstückswerts auf das Sondereigentum,

- das Baujahr des Gebäudes sowie eine grobe Vorstellung bereits durchgeführter Modernisierungsmaßnahmen, um den passenden THK herauszusuchen und

- die Wohnfläche zur Hochrechnung des quadratmeterbezogenen THK.

Alle diese Daten werden üblicherweise entweder vom Verkäufer zur Verfügung gestellt bzw. sind kostenlos und öffentlich für jedermann zugänglich. Die Modernisierungsmaßnahmen, welche für die Feinjustierung des THK erforderlich sind, dürften selbst dann bei der ersten Besichtigung nach reinem Augenmaß zu erlangen sein, wenn sie dem

\footnotetext{
${ }^{468}$ Zum Bodenrichtwert vgl. KLEIBER (2011), S. 262, HURLEBAUS (2013), S. 276, VOIGTLÄNDER (2019), S. 82 .

${ }^{469} \mathrm{http}: / / w w w . b o r i s . n r w . d e$.

${ }^{470} \mathrm{Vgl}$. Gliederungspunkt 2.2.3.3.2.2.
} 
Verkäufer unbekannt sind. Schließlich fordert das Excel-Werkzeug nur sehr grobe Angaben, z.B. „Modernisierung Fenster: ja/nein/teilweise“. Außerdem führen diese meist nur zu geringfügigen Veränderungen des Ergebnisses.

Die Zielgröße des linearen Optimierungsansatzes ist unverändert der Grenzpreis p*, der Gebäude, Grundstück und Transaktionskosten beinhaltet. Nur sein Gebäudeanteil stellt die Bemessungsgrundlage der Abschreibung dar, verkörpert durch den Ausdruck $\mathrm{p}^{*} \cdot \gamma$. Für die Modellierung der Schattenobjekte bedeutet dies, daß investitionstheoretisch in $\mathrm{t}=0$ eine Auszahlung in Höhe des Gesamtgrenzpreises $\mathrm{p}^{*}$ anzusetzen ist, während im Zeitpunkt der Investition ein Schattenobjekt von null angesetzt wird. In den folgenden 50 Zeitpunkten ist der Kaufpreis investitionstheoretisch nicht mehr als Auszahlung zu erfassen, jedoch steuermindernd mit dem Ausdruck 0,02 $\cdot \mathrm{p}^{*} \cdot \gamma$.

\subsubsection{Modellmäßige Adaption der steuerlichen Tariffunktion}

\subsubsection{Fehlende Kompatibilität zwischen linearem Totalmodell und nichtlinearer Tariffunktion}

In der Literatur erfolgt eine Immobilienbewertung unter Berücksichtigung von Ertragsteuern bisher, wenn überhaupt, mit Hilfe von Partialmodellen unter Anwendung eines konstanten Steuersatzes, ${ }^{471}$ meist bleiben sie im Modell völlig unberücksichtigt. ${ }^{472}$ Die Verwendung linearer Steuern entspricht lediglich einer prozentualen Kürzung von Einnahmen und Ausgaben. Sie mag für Kapitalgesellschaften vertretbar sein, weil Körperschaft- und Gewerbesteuer konstante Steuersätze aufweisen. ${ }^{473}$

Für Eigentümer einer Wohnimmobilie ist die Annahme pauschaler Steuersätze ebenso einfach wie uninteressant: Private Vermieter sind überwiegend natürliche Personen. Mit rund 81 Prozent sind sie die wichtigste Anbietergruppe von Wohnraum in Deutschland. ${ }^{474} \mathrm{Ihr}$ durchschnittliches Haushalts-Nettoeinkommen beträgt 39.780 EUR pro

${ }^{471}$ Beispielsweise ROPETER (1998), S. 300, HELLERFORTH (2008), S. 56, PFNÜR (2011), S. 94 ff., SCHULTE/SOTELO/ALLENDORF/ROPETER-AHLERS/LANG (2016), S. $600 \mathrm{ff}$.

${ }^{472}$ Zum Beispiel RABE (2011), S. 80, HELLERFORTH (2012), S. 111 ff., ROTTKE/KRAUTZ (2017), S. 794 ff., GREINER (2017), S. 759 ff.

${ }^{473}$ Zur Bewertung unter Berücksichtigung dieser beiden Steuerarten vgl. ausführlich Unterkapitel 4.9.

${ }^{474}$ Das deutsche Wohnungsangebot ist äußerst kleinteilig: Etwa 815.000 Unternehmen stehen in Deutschland 3,9 Mio. private Vermieter gegenüber, vgl. JUST/VOIGTLÄNDER (2017), S. 8 f. Diesen privaten Kleinvermietern gehören nicht weniger als 14 Mio. Wohnungen, vgl. JUST/VOIGTLÄNDER (2017), S. 14 f. In den endgültigen Ergebnissen des Zensus 2011 werden „Privatperson/-en“ und „Gemeinschaft von Wohnungseigentümern/-innen“ als Eigentümer von Wohnungen unterschieden. In „Tabelle 5: Wohngebäude und darin befindliche Wohnungen [...] nach Eigentumsform“ findet man unter der Überschrift „Wohnungen“ unter anderem die Eigentumsformen „Privatperson/-en“ (58,8 Prozent) und „Gemeinschaft von Wohnungseigentümern/-innen“ (22,0 Prozent). Es liegt nahe, auch die Wohnungseigentümergemeinschaften zu den Privatpersonen zu zählen. Somit befinden sich 80,8 Prozent der Wohnungen im Eigentum von Privatpersonen, vgl. STATISTISCHE ÄMTER DES BUNDES UND DER LÄNDER (2015), S. 14 und S. 92 f. Die Unterscheidung der Eigentumsverhältnisse zwischen Privatpersonen und Wohnungseigentümergemeinschaften ist wenig aussagefähig, schließlich gehören auch letztgenannte Wohneinheiten nicht der WEG, sondern befinden sich nur innerhalb eines Gebäudes, dessen Rechtsform eine WEG ist. Eine andere Deutung leuchtet nicht ein. Obwohl 
Jahr. ${ }^{475}$ Man mag argumentieren, daß der Steuersatz im Veranlagungsjahr 2019 bereits $\mathrm{ab}$ einem vergleichsweise niedrigen Einkommen von ca. 55.961 EUR wieder linear und es zudem schwierig ist, Rückschlüsse vom Netto- auf das zu versteuernde Einkommen zu ziehen. Außerdem kommen private Vermieter in Deutschland aus allen Schichten. Das INSTITUT DER DEUTSCHEN WIRTSCHAFT veröffentlichte im Jahr 2017 ein Gutachten, aus dem hervorging, daß immerhin sechs Prozent ,der einkommensschwächsten Haushalte Wohneigentum [vermieten], unter den 20 Prozent einkommensstärksten Haushalten sind es 21 Prozent." ${ }^{476}$ Es liegt nahe, daß das Einkommen durchaus in den Tarifzonen zwei oder drei liegen kann, zumal die vorgenannte Summe sich auf den gesamten Haushalt bezieht. Man denke an Eheleute, von denen nur ein Partner berufstätig ist. Aufgrund des Zusammenveranlagungstarifs reicht der nichtlineare Bereich bei Ehegatten bis zu einem Einkommen von ca. 114.000 EUR und damit doppelt so weit wie bei Ledigen. ${ }^{477}$ Auch die Wirtschaftsrechnung des STATISTISCHEN BUNDESAMTS zeigt, daß auch Haushalte mit Haushalts-Nettoeinkommen (zwischen 20.400 und 31.200 EUR pro Jahr) über Einnahmen aus Vermietung und Verpachtung verfügen. ${ }^{478}$

Zuletzt war es ja gerade die Absicht des Gesetzgebers, durch Schaffung der Rechtsform von Eigentumswohnungen bezahlbaren Wohnraum für möglichst viele Menschen zu schaffen. ${ }^{479}$ Wem der Zugang zu ganzen Mehrfamilienhäusern - z.B. aufgrund von Kreditbeschränkungen - verschlossen bleibt, für den könnten Eigentumswohnungen in Zeiten rasch steigender Immobilienpreise eine bezahlbare Alternative sein. Diese sind erst recht für Investoren interessant.

Die für Privatpersonen anwendbare Tariffunktion aus $\S 32 \mathrm{a}$ EStG ist in Zone zwei und drei nicht linear, sondern quadratisch. ${ }^{480}$ Der Steuersatz steigt mit zunehmendem Ge-

der Erwerb von Immobilien durch eine WEG möglich ist, kennt der Verfasser nach achtjähriger Berufserfahrung nicht einen Fall, in dem eine Wohneinheit im Eigentum der WEG gestanden hätte.

${ }^{475} \mathrm{Vgl}$. INSTITUT DER DEUTSCHEN WIRTSCHAFT KÖLN (2017), S. 14, dort als Monatswert von 3.315 EUR.

${ }^{476}$ INSTITUT DER DEUTSCHEN WIRTSCHAFT KÖLN (2017), S. 4. „Selbstnutzer stellen die größte Eigentümergruppe im deutschen Wohnungsmarkt dar. [...] Die zweitwichtigste Anbietergruppe sind private Kleinvermieter. [Sie] sind typischerweise Eigentümer, die die Vermietung nicht hauptberuflich ausüben, sondern Mietwohnungen als Anlageform oder als Altersvorsorge nutzen." VOIGTLÄNDER (2014), S. 61.

${ }^{477} \mathrm{Zu}$ einer ausführlichen Betrachtung des Zusammenveranlagungstarifs siehe Unterkapitel 4.8.

${ }^{478}$ Vgl. STATISTISCHES BUNDESAMT (2018b), S. 29, auch dort in Form von Monatswerten von 1.700 bis 2.600 EUR. Deren Einnahmen aus Vermietung und Verpachtung sind zwar vorhanden, aber negativ. Erst die nächsthöhere Klasse der Haushalts-Nettoeinkommen zwischen 2.600 und 3.600 EUR erzielte im Durchschnitt positive Einkünfte, vgl. ebd. In den Wirtschaftsrechnungen des STATISTISCHEN BUNDESAMTS findet man rund 5,6 Mio. private Haushalte mit Haus- und Grundbesitz in Form von Eigentumswohnungen. Die Statistik dieser Haushalte ist nach monatlichem Haushaltsnettoeinkommen in neun Klassen gegliedert, doch in jeder Klasse findet man Haushalte mit Besitz an Eigentumswohnungen. Selbst in der untersten Klasse (Einkommen unter 900 EUR) findet man 144.000 Haushalte mit Wohnungseigentum, vgl. STATISTISCHES BUNDESAMT (2019), S. 78.

${ }^{479}$ Vgl. VON HAUFF (2017a), S. 23, DRASDO (2017a), Rn. 18.

${ }^{480} \mathrm{Vgl}$. SCHNEELOCH/MEYERING/PATEK (2016), S. 118, PFEIFER (2016), S. 428. 
samteinkommen. Das ZGPM hingegen basiert auf einem linearen Optimierungsansatz. ${ }^{481}$ Auch die Abrundung der Steuerlast auf volle Euro-Beträge und die daraus folgende fehlende Differenzierbarkeit an den Bereichsübergängen führt zu mathematischen Problemen bei ihrer Erfassung. ${ }^{482}$

Trotz mathematischer Unwägbarkeiten muß die Steuertariffunktion berücksichtigt werden. Die Modellierung eines konstanten Steuersatzes wird der Situation der Vermieter von Wohnimmobilien nicht gerecht und greift ebenso zu kurz wie die Ausblendung steuerlicher Effekte. Mit einem konstanten Steuersatz ist eine realistische Modellierung nicht zu erreichen. Es liegt auf der Hand, daß die nichtlineare Tariffunktion dem linearen Modell zugänglich gemacht werden muß. Das ZGPM, das bereits in Kapitel 2 erfolgreich als Bewertungsmodell für Immobilien vorgestellt und exemplarisch veranschaulicht wurde, ist um weitere Nebenbedingungen zu ergänzen, um den zweigliedrigen Einbezug von Ertragsteuern zu gewährleisten. Dieser besteht erstens aus der Erfassung einer Bemessungsgrundlage mit Hilfe von Schattenobjekten und zweitens der darauf ruhenden Anwendung des Steuertarifs.

\subsubsection{Lösungsmöglichkeit durch lineare Approximation}

Um die quadratische Steuertariffunktion für das lineare Totalmodell nutzbar zu machen, bietet sich eine abschnittsweise lineare Approximation ihres quadratischen Teilbereichs an. ${ }^{483}$ Dies gelingt durch intervallweise Berechnung der Steigung der echten Tariffunktion, wie es in Abbildung 3 schematisch dargestellt ist.

Nichtlineare Abschnitte der Tariffunktion werden durch lineare ersetzt, welche ihnen ähnlich sind. Durch Zuweisung von Intervallgrenzen zerlegt man die Funktion der unabhängigen Variablen (des Einkommens) in Intervalle - und damit auch die von ihr abhängige Steuerlast. Nach Zerlegung liegen mehrere x-y-Koordinatenpunkte vor, die aufsteigend nach ihren $\mathrm{x}$-Werten geordnet werden. Die Verbindungslinie je zweier Punkte verkörpert die durchschnittliche Steigung der echten Steuerbetragsfunktion innerhalb dieses Teilstücks. Sie wird mit dem Steigungsdreieck als $\frac{\mathrm{y}_{2}-\mathrm{y}_{1}}{\mathrm{x}_{2}-\mathrm{x}_{1}}$ berechnet. Man stelle sich vor, jeweils zwei nebeneinander liegende Koordinatenpunkte in aufsteigender Reihenfolge jeweils mit einer Linie zu verbinden. Diese Linie stellt die Menge aller Linearkombinationen zwischen je zwei echten Funktionswerten dar. Die Intervallabschnitte liegen wie Kettenglieder hintereinander und bilden eine vollständig lineare

\footnotetext{
${ }^{481}$ Vgl. HERING (2000a), S. 364.

${ }^{482}$ Vgl. SCHANZ (2006), S. 2 ff., PFEIFER (2016), S. 428.

${ }^{483}$ Auch diesen Vorschlag findet man bei HERING (1998), S. 111 ff. Zur Linearisierung durch abschnittsweise Approximation vgl. SUHL/MELLOULI (2013), S. 107 f., DOMSCHKE/DREXL/KLEIN/SCHOLL (2015), S. 216 f. Zur Interpolation der deutschen Einkommensteuertariffunktion vgl. SCHANZ (2006), S. 5 ff.
} 
Steuerfunktion, die dem ZGPM als Nebenbedingung zugänglich ist. Sie kann wie gewohnt mit dem linearen Simplex-Algorithmus gelöst werden, ohne daß der Rechenaufwand ausufert. ${ }^{484}$

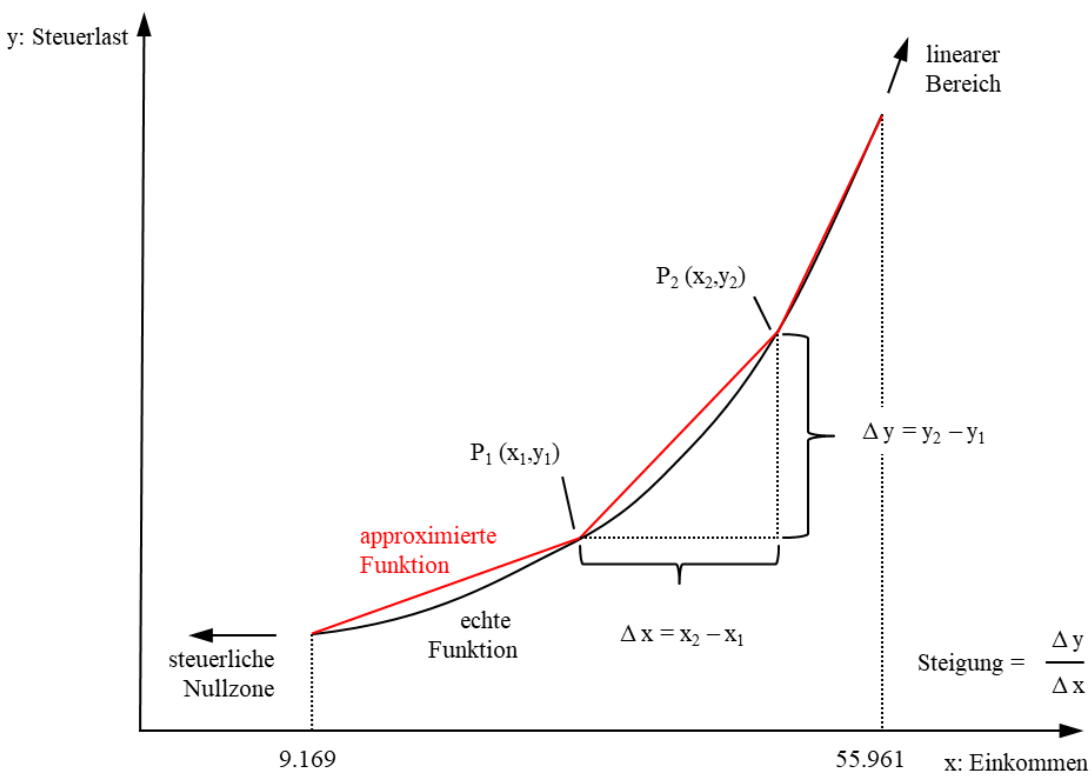

\section{Abbildung 3: Interpolation einer nichtlinearen Funktion}

\subsubsection{Ermittlung geeigneter Interpolationspunkte}

Welche Intervallgrenzen richtig oder angemessen sind, hängt von den situativen Rahmenbedingungen der Bewertungssituation ab und liegt im Ermessen des Betrachters. ${ }^{485}$ Am Anfang steht die Frage nach einer sinnvollen Zahl der Teilabschnitte. Je geringer

${ }^{484}$ Zwar ist auch eine nichtlineare Modellierung denkbar, ruft aber ggf. rechentechnische Probleme hervor, vgl. HERING (2014), S. 326. „Für lineare [...] Modelle existiert leistungsfähige Standardsoftware, wodurch eine optimale Lösung meistens [...] in vertretbarer Zeit gefunden werden kann. Weil dies für nichtlineare Probleme jedoch nicht der Regelfall ist, lohnt sich ein höherer Aufwand für die Modellierung in linearer Form." SUHL/MELLOULI (2013), S. 96. Zu Ungenauigkeiten bei der Lösung nichtlinearer Optimierungsansätze vgl. ELLINGER/BEUERMANN/LEISTEN (2003), S. 216 (Schnittebenenverfahren) und ELLINGER/BEUERMANN/LEISTEN(2003), S. 224 (Gradientenverfahren). Zur nichtlinearen Verallgemeinerung des ZGPM vgl. PFAFF/PFEIFFER/GATHGE (2002), S. 198 ff., sowie in der Variante als Zustands-Grenzpreisvektormodell (ZGPVM) TOLL/KINTZEL (2019). Hier soll dem Weg der linearen Approximation auch deshalb gefolgt werden, weil diese Vorgehensweise zusätzlich auf die Tariffunktionen anderer Länder anwendbar ist, welche per se abschnittsweise linear definiert sind. In den USA nennt man diese Teilabschnitte z.B. Brackets, vgl. Gliederungspunkt 3.2.2.4.

${ }^{485}$ Modellmäßige Vereinfachungen stehen meist ohnehin im subjektiven Ermessen desjenigen, der modelliert, vgl. BALLWIESER (1990), S. 30, ADAM (1996), S. 493 f., LAUX/SCHABEL (2009), S. 25. 
die Zahl der Abschnitte, in die man die Steuerbetragsfunktion zerlegt, desto weiter ist die Approximation von der echten Steuerlast entfernt (vgl. Abbildung 4). Andererseits verursacht ein stärkerer Detaillierungsgrad eine Erhöhung des Rechenaufwands, muß aber nicht zu treffenderen Ergebnissen führen. ${ }^{486}$ Das Bewertungssubjekt muß nach einer hinreichend guten Annäherung an die echte Steuerlast zwischen diesen beiden Extremen suchen.
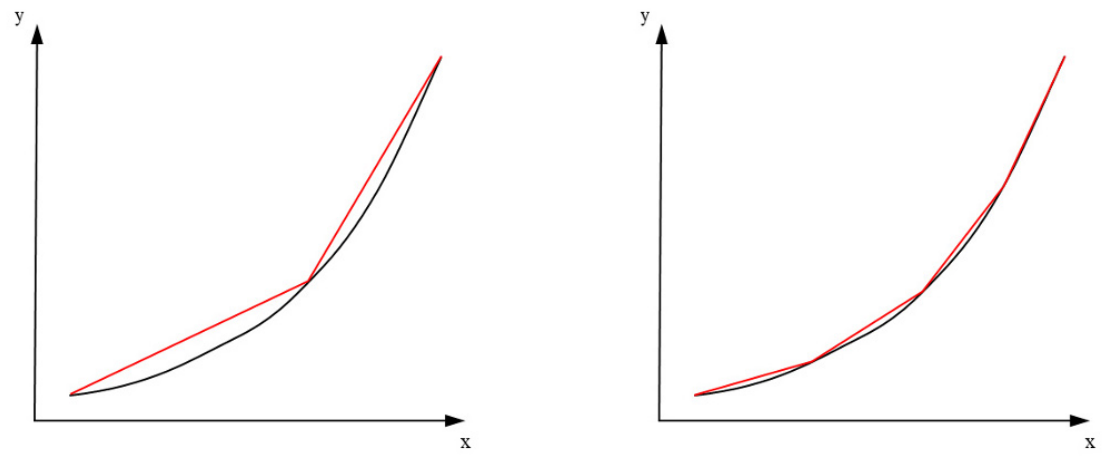

Abbildung 4: Zunehmende Approximationsgüte bei abnehmender Schrittweite

Um sinnvoll erscheinende Interpolationsgrenzen zu suchen, wurde mit Microsoft Excel eine Simulation durchgeführt. Ihr Gegenstand war die Minimierung der maximalen Abweichungen der approximierten von der tatsächlichen Steuerlast bei unterschiedlicher Anzahl und unterschiedlicher Plazierung von Interpolationsgrenzen. Dabei wurde beachtet, daß eine Approximation nur für den nichtlinearen Bereich nötig ist, denn unterhalb besteht keine Steuerpflicht und oberhalb ist die Tariffunktion per se linear.

Zunächst wurde die echte, für den Veranlagungszeitraum 2019 geltende tarifliche Steuerlast für Einkommen zwischen 9.169 und 265.326 EUR in 50 EUR-Schritten berechnet. Ihr wurde jeweils eine angenäherte Funktion gegenübergestellt, um Abweichungen zu messen und die echte mit der approximierten Steuerlast zu vergleichen. Es wurden unterschiedliche angenäherte Funktionen herangezogen, die sich jeweils hinsichtlich der Anzahl der Segmente und der Plazierung der Interpolationsgrenzen unterschieden.

Die erste Annäherung wurde mit acht Teilabschnitten berechnet: Es erschien sinnvoll, die Grenzen der gesetzlichen Tarifzonen als Interpolationspunkte zu verwenden, um Ungenauigkeiten zu minimieren. Intervallgrenzen schienen demzufolge bei null EUR, 9.168 EUR, 14.254 EUR und 55.960 EUR determiniert ebenso wie 265.326 EUR als

${ }^{486}$ Vgl. BALLWIESER (1990), S. 161, JAPES (2011), S. 26 f. „Eine die Steuergesetzgebung in allen Verästelungen nachzeichnende, hochdetaillierte Modellbildung täuscht einen Genauigkeitsgrad der Analyse vor, welcher auf der strategischen Planungsebene überhaupt nicht erreichbar ist. [...] Detailverliebte Steuerwirkungsanalysen kämen also einem hochgenauen Rechnen mit ungenauen Zahlen gleich, so daß die Qualitätssteigerung der Ergebnisse in keinem vernünftigen Verhältnis zum zusätzlichen Rechenaufwand stünde." HERING (2002), S. 37. 
Grenzpunkt zwischen Zone vier und fünf. Der verhältnismäßig große Bereich der dritten Zone legte nahe, hier weitere Unterteilungen mit Schrittweiten von 10.000 EUR vorzunehmen. Daraus resultierten Intervallgrenzen bei 25.000 EUR, 35.000 EUR und 45.000 EUR. Da jedes Steigungsdreieck einen Anfangs- und einen Endpunkt benötigt, war auch ein Punkt oberhalb von 265.326 EUR erforderlich, der willkürlich bei 10 Mio. EUR gesetzt wurde.

Die maximale Abweichung der approximierten von der echten Steuerlast lag bei nur 65 EUR, das 0,8-Quantil lag sogar bei null. ${ }^{487}$ Bereits bei dieser Approximation fiel die Abweichung von der tatsächlichen Steuerlast vernachlässigbar gering aus.

Wenn man Nebenbedingungen für eine zehn Jahre dauernde Detailplanungsphase formulieren möchte, führen acht Teilabschnitte immer noch zu 80 zusätzlichen Nebenbedingungen. Daher wurde die Steuerlast mit immer weniger Teilabschnitten angenähert, beginnend mit sieben, absteigend bis auf drei Intervalle. So sollte untersucht werden, durch welche Teilabschnitte der Rechenaufwand reduziert und trotzdem eine akzeptable Annäherung an die tatsächliche Steuerlast erreicht werden kann.

Neben der Reduktion der Anzahl der Teilabschnitte wurden auch die Intervallgrenzen in 50 EUR-Schritten so lange variiert, bis bei jeweils gegebener Anzahl an Interpolationspunkten die maximale Abweichung der approximierten von der tatsächlichen Steuerlast nicht weiter reduziert werden konnte. Wenn die Verschiebung eines Interpolationspunkts in eine Richtung eine Reduzierung der Abweichung mit sich brachte, wurde sie beibehalten, andernfalls rückgängig gemacht. Brachte auch eine Verschiebung in die andere Richtung keine Verbesserung der Approximationsgüte, wurde der Punkt fixiert und die gleichen Schritte wurden mit dem nächsten Interpolationspunkt fortgesetzt. Die Grenzpunkte bei null und 10.000.000 EUR Einkommen wurden nicht bewegt, ebensowenig die Knickstelle bei 265.326 EUR zwischen den linearen Steuersätzen von 42 und 45 Prozent.

Erstaunlicherweise führte es oft zu Verbesserungen der Approximationsgüte, von den gesetzlichen Tarifgrenzen abzuweichen. Dies ist dadurch erklärbar, daß es mit abnehmender Zahl von Interpolationspunkten sinnvoller erscheint, die relativ eng beieinander liegenden unteren Grenzen (9.168 und 14.254 EUR) zu verwerfen, damit zusätzliche Punkte im mittleren Bereich der Tarifzone drei zur Verfügung stehen. Dort stiften sie aufgrund der relativ starken Krümmung dieses Bereichs eine bessere Annäherung als im noch relativ flachen unteren Funktionsbereich.

Es fällt auf, daß bei acht Intervallen die maximale Abweichung lediglich 65 EUR beträgt, was als vernachlässigbar gering erscheint. Das 0,8-Quantil zeigt außerdem, daß die Annäherung durch sechs, sieben und acht Intervalle in 80 Prozent der Fälle zu überhaupt keiner Abweichung von der echten Steuerlast führt. Dies dürfte u.a. darauf zu-

${ }^{487}$ Das 0,8-Quantil gibt den Wert an, unter dem 80 Prozent aller Werte liegen. In diesem Fall besagt es, daß (mindestens) 80 Prozent aller Abweichungen bei null liegen und somit definitionsgemäß gar keine Abweichungen sind. Zum Quantil vgl. CLEFF (2015), S. 50, WINKER (2017), S. 47. 
rückzuführen sein, daß die gesetzliche Tariffunktion ihre Ergebnisse nicht kaufmännisch, sondern auf volle Euro abrundet ${ }^{488}$ und daher in Excel auch eine Abrundung für die angenäherten Funktionsergebnisse vorgenommen wurde. ${ }^{489}$ Daher spielten Nachkommastellen keine Rolle mehr. Die bei Verwendung dreier Teilabschnitte auftretende maximale Abweichung von 1.532 EUR dürfte im Modell zu starke Verzerrungen hervorrufen, zumal das 0,8-Quantil von 1.279 EUR darauf hindeutet, daß in 20 Prozent der Fälle eine noch größere Abweichung auftritt. Gut geeignet erscheint die Verwendung von fünf Intervallen, deren maximale Abweichung mit 205 EUR noch hinreichend niedrig ist.

Für die vorliegende Situation erscheint dennoch eine Annäherung mit nur vier Intervallabschnitten sinnvoll. Weil der Planungshorizont von zehn Perioden noch immer recht lang ist, kommt der Komplexitätsreduktion ein erheblicher Stellenwert zu. Auf diese Weise können viele Nebenbedingungen eingespart werden.

Hier sei mit Hinweis auf das kaufmännische Vorsichtsprinzip daran erinnert, daß die approximierte Steuerlast systematisch zu hoch geschätzt wird: Die Einkommensteuertariffunktion ist in diesem Bereich eine konvexe Funktion, deren Steigung ständig zunimmt. ${ }^{490}$ Jede Verbindungslinie zwischen zwei Funktionswerten liegt stets auf oder oberhalb der echten Steuerfunktion. Diese Überbewertung der Steuerlast kann mit Blick auf die besonderen Merkmale von Eigentumswohnungen durchaus sinnvoll sein.

Hilfreich ist auch, daß durch die systematische Überbewertung ein gewisser Puffer für zukünftige Änderungen der Tariffunktion berücksichtigt wird. Aufgrund verfassungsrechtlicher Vorgaben zum steuerfreien Existenzminimum verschieben sich die Parameter der Steuertariffunktion jedes Jahr geringfügig, um den steuerlichen Grundfreibetrag an das verfassungsmäßig geschützte, jährlich leicht steigende Existenzminimum anzupassen. ${ }^{491}$ Zwar könnte man vergangene Anpassungen der Tariffunktion nutzen, um Prognosen für zukünftige Veränderungen zu treffen und die Tariffunktion im Zeitablauf zu modellieren. ${ }^{492}$ Es wäre fraglich, wie sinnvoll diese Hochrechnung von Vergangenheitsdaten ist, zumal sie nichts als Pseudo-Objektivität bietet ${ }^{493}$ und das Modell auch andere Langfristfaktoren wie den Inflationseinfluß nicht berücksichtigt. ${ }^{494}$ Auch im Lichte des Erfordernisses von Komplexitätsreduktionen erscheint eine Modellierung der Tariffunktion im Zeitablauf nicht sinnvoll. Die gesamte Bewertung beruht auf Prognosen, deswegen verspricht eine immer detailliertere Modellierung keinen Nutzenzuwachs.

\footnotetext{
${ }^{488}$ Vgl. § 32a Abs. 1 EStG.

${ }^{489} \mathrm{Zu}$ mathematischen Problemen aufgrund der Abrundung vgl. PFEIFER (2016), S. $428 \mathrm{ff}$.

${ }^{490}$ Vgl. DANTZIG (1966), S. 172, WERNERS (2013), S. 46, DÖRSAM (2014), S. 232 f.

${ }^{491}$ Vgl. GRASHOFF (2018), Rn. 209, LOSCHELDER (2019), Rn. 8.

${ }^{492}$ Einen tabellenartigen Überblick über Grenzen der Steuertarifzonen vergangener Jahre seit 2007 gibt WAGNER (2019), Rn. 16.

493 „Bewertungsprobleme drohen [...] zu Scheinproblemen zu werden, da jede noch so anspruchsvolle Bewertungsregel verfehlt ist, wenn die Datenbasis ungesichert erscheint.“ BALLWIESER (1990), S. 10.

${ }^{494}$ Vgl. zum Einfluß von Inflation vgl. MATSCHKE (1986), ADERS (1998), HERING (2017), S. 99 ff.
} 
Vor dem Hintergrund des sehr langfristigen Planungshorizonts muß auf eine Modellierung der Tariffunktion im Zeitablauf verzichtet werden. Die Intervallgrenzen, Steigungen der dazwischen liegenden Abschnitte und die Abweichungen von der echten Einkommensteuerlast sind in Tabelle 23 abgebildet.

\begin{tabular}{|c|c|c|c|c|}
\hline \multirow{9}{*}{ 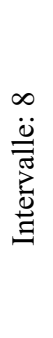 } & Einkommen von ... & ... bis & Steigung & Abweichung in EUR: \\
\hline & 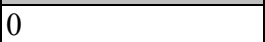 & 9.168 & 0,0000 & \multirow{8}{*}{$\begin{array}{l}\max .: 65 \\
\text { 0,8-Quantil: } 0 \\
\text { 0,6-Quantil: } 0\end{array}$} \\
\hline & 9.168 & 14.254 & 0,1897 & \\
\hline & 14.254 & 25.000 & 0,2630 & \\
\hline & 25.000 & 35.000 & 0,3077 & \\
\hline & 35.000 & 45.000 & 0,3510 & \\
\hline & 45.000 & 55.960 & 0,3964 & \\
\hline & 55.960 & 265.326 & 0,4200 & \\
\hline & 265.326 & 10.000 .000 & 0,4500 & \\
\hline \multirow{8}{*}{ 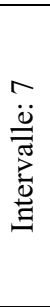 } & Einkommen von ... & ... bis & Steigung & Abweichung in EUR: \\
\hline & 0 & 9.168 & 0,0000 & \multirow{7}{*}{$\begin{array}{l}\max .: 121 \\
\text { 0,8-Quantil: } 0 \\
\text { 0,6-Quantil: } 0\end{array}$} \\
\hline & 9.168 & 14.254 & 0,1897 & \\
\hline & 14.254 & 26.000 & 0,2651 & \\
\hline & 26.000 & 41.000 & 0,3229 & \\
\hline & 41.000 & 55.960 & 0,3877 & \\
\hline & 55.960 & 265.326 & 0,4200 & \\
\hline & 265.326 & 10.000 .000 & 0,4500 & \\
\hline \multirow{7}{*}{ 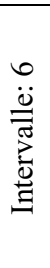 } & Einkommen von ... & ... bis & Steigung & Abweichung in EUR: \\
\hline & 0 & 10.300 & 0,0166 & \multirow{6}{*}{$\begin{array}{l}\max .: 152 \\
\text { 0,8-Quantil: } 0 \\
\text { 0,6-Quantil: } 0\end{array}$} \\
\hline & 10.300 & 22.500 & 0,2392 & \\
\hline & 22.500 & 39.250 & 0,3115 & \\
\hline & 39.250 & 55.960 & 0,3839 & \\
\hline & 55.960 & 265.326 & 0,4200 & \\
\hline & 265.326 & 10.000 .000 & 0,4500 & \\
\hline \multirow{6}{*}{ 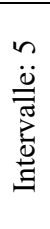 } & Einkommen von ... & ... bis & Steigung & Abweichung in EUR: \\
\hline & 0 & 10.500 & 0,0193 & \multirow{5}{*}{$\begin{array}{l}\text { max.: } 205 \\
\text { 0,8-Quantil: } 171 \\
\text { 0,6-Quantil: } 129\end{array}$} \\
\hline & 10.500 & 27.000 & 0,2526 & \\
\hline & 27.000 & 46.000 & 0,3359 & \\
\hline & 46.000 & 265.326 & 0,4190 & \\
\hline & 265.326 & 10.000 .000 & 0,4500 & \\
\hline \multirow{5}{*}{ 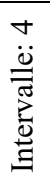 } & Einkommen von ... & ... bis & Steigung & Abweichung in EUR: \\
\hline & 0 & 12.500 & 0,0460 & \multirow{4}{*}{$\begin{array}{l}\max .: 452 \\
\text { 0,8-Quantil: } 378 \\
\text { 0,6-Quantil: } 286\end{array}$} \\
\hline & 12.500 & 41.000 & 0,2929 & \\
\hline & 41.000 & 265.326 & 0,4178 & \\
\hline & 265.326 & 10.000 .000 & 0,4500 & \\
\hline \multirow{4}{*}{ 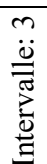 } & Einkommen von ... & ... bis & Steigung & Abweichung in EUR: \\
\hline & 0 & 27.700 & 0,1653 & \multirow{3}{*}{$\begin{array}{l}\text { max.: } 1532 \\
\text { 0,8-Quantil: } 1279 \\
\text { 0,6-Quantil: } 964,6\end{array}$} \\
\hline & 27.700 & 265.326 & 0,4127 & \\
\hline & 265.326 & 10.000 .000 & 0,4500 & \\
\hline
\end{tabular}

Tabelle 23: Einkommensteuer-Interpolation und Abweichung von der echten Steuerlast 
Die mit vier Teilabschnitten angenäherte Funktion muß nun in entsprechende Nebenbedingungen verarbeitet werden. Die Eckpunkte und Steigungen der vier Interpolationsabschnitte zeigt Tabelle 24 .

\begin{tabular}{|r|r|r|r|r|}
\hline $\mathbf{x}$ (Einkommen) & $\mathbf{y}$ (Steuer) & $\boldsymbol{\Delta} \mathbf{x}$ & $\boldsymbol{\Delta} \mathbf{y}$ & Steigung \\
\hline 12.500 & 575 & 12.500 & 575 & $\frac{575}{12.500}=0,0460$ \\
\hline 41.000 & 8.922 & 28.500 & 8.347 & $\frac{8.347}{28.500}=0,2929$ \\
\hline 265.326 & 102.656 & 224.326 & 93.734 & $\frac{93.734}{224.326}=0,4178$ \\
\hline 10.000 .000 & 4.483 .259 & 9.734 .674 & 4.380 .603 & $\frac{4.380 .603}{9.734 .647}=0,4500$ \\
\hline
\end{tabular}

Tabelle 24: Berechnung der Steigung für vier Funktionsabschnitte

\subsubsection{Anwendbarkeit jenseits deutscher Landesgrenzen}

Mit der Interpolation der Einkommensteuertariffunktion wurde eine lineare Steuertariffunktion gebildet, welche die deutsche Tarifvorschrift näherungsweise abbildet. Der Einbau einer abschnittsweise linearen Steuertariffunktion macht das Modell grundsätzlich über deutsche Landesgrenzen hinaus anwendbar, nämlich überall dort, wo Steuersubjekte einem abschnittsweise definierten Steuersatz unterliegen. Mag der nichtlineare Progressionsbereich auch ein deutsches Phänomen der Berechnung der Steuerlast sein. Eine aus hintereinandergeschalteten linearen Abschnitten bestehende Tariffunktion gibt es in vielen Staaten. Es würde den Rahmen der Ausführungen sprengen, auf die Feinheiten unterschiedlicher nationaler Steuergesetzgebungen einzugehen. $\mathrm{Zu}$ diesen Nationen gehören jedoch auch die Vereinigten Staaten von Amerika, die bekanntlich in der betriebswirtschaftlichen Literatur viel Raum einnehmen. ${ }^{495}$

Dort ist die Einkommensteuer eine abschnittsweise definierte, lineare Funktion des steuerpflichtigen Einkommens. Der Internal Revenue Code (IRC) ist das US-amerikanische Pendant zum deutschen Einkommensteuergesetz und definiert in $\S 61 \mathrm{Abs}$. a die Bemessungsgrundlage als gesamtes Einkommen, egal aus welcher Quelle. ${ }^{496}$ Die 15 heranzuziehenden Einkunftsarten umfassen auch Mieteinkünfte. ${ }^{497}$

${ }^{495}$ Vgl. dazu HERING (2004), HERING/BRÖSEL (2004), S. 936 f., HERING/OLBRICH/ROLLBERG (2010), BRÖSEL/TOLL (2011), S. 257 f., BRÖSEL/TOLL (2016), S. 43 ff.

${ }^{496}$ Übers. d. Verf. aus dem Englischen (,Except as otherwise provided in this subtitle, gross income means all income from whatever source derived, including (but not limited to) the following items: [...] (5) Rents; [...]"), § 61 Abs. a IRC.

${ }^{497}$ Um Verwechselungen vorwegzugreifen sei angemerkt, daß die unter $§ 2001$ IRC definierte „estate tax“ (Immobiliensteuer) das Pendant zur deutschen Grunderwerbsteuer ist: „A tax is hereby imposed on the transfer of the taxable estate [...]", vgl. ebd. 
Die US-amerikanische Einkommensteuertariffunktion hat - abgesehen von Anzahl, Grenzen und Steigung der Intervalle - die gleiche Gestalt wie die hier angenäherte Tariffunktion. In den USA ist die Fragmentierung der Tarifzonen, genannt Klammern, ${ }^{498}$ noch stärker ausgeprägt als in Deutschland. Dort gibt es nicht vier, sondern sieben Tarifzonen. Auf das steuerpflichtige Einkommen werden abschnittsweise lineare Steuersätze angewendet, beginnend bei zehn Prozent für Einkommen bis ca. 9.500 USD bis hin zu 37 Prozent für Einkommen ab 500.001 USD. Tabelle 25 zeigt die in $\S 1$ IRC für 2018 bis 2025 definierten Steuertarifzonen, hier am Beispiel eines ledigen Steuerpflichtigen. Wie sich erkennen läßt, wäre auch in den USA der Ansatz eines linearen Steuersatzes eine viel zu starke Pauschalisierung.

\begin{tabular}{|r|r|}
\hline Einkommensgrenzen in USD & Steuersatz \\
\hline von 0 bis 9.525 & $10 \%$ \\
\hline von 9.526 bis 38.700 & $12 \%$ \\
\hline von 38.701 bis 82.500 & $22 \%$ \\
\hline von 82.501 bis 157.500 & $24 \%$ \\
\hline von 157.501 bis 200.000 & $32 \%$ \\
\hline von 200.001 bis 500.000 & $35 \%$ \\
\hline über 500.001 & $37 \%$ \\
\hline
\end{tabular}

Tabelle 25: Steuertarif in den USA

Ebenso wie bei der hier approximierten (und gegensätzlich zur tatsächlichen) deutschen Tariffunktion werden die jeweiligen Steuersätze auch in den USA stufenweise nacheinander auf die Klassen angewendet - und die für jeden Abschnitt isoliert berechnete Steuerlast anschließend addiert. ${ }^{499}$ Das heißt, bei einem Einkommen von bspw. 50.000 USD werden die ersten 9.525 USD mit zehn Prozent besteuert, die nächsten 29.175 USD werden mit zwölf Prozent besteuert und auf die letzten 12.200 USD ist eine Steuer in Höhe von 22 Prozent zu entrichten.

\subsubsection{Erweitertes Zustands-Grenzpreismodell}

\subsubsection{Ermittlung des optimalen Basisprogramms}

Nun sollen die zusätzlichen Nebenbedingungen beschrieben werden, welche in den linearen Optimierungsansatz des ZGPM aufzunehmen sind, um die skizzierte Vorgehensweise zur Modellintegration der Einkommensteuer mathematisch abzubilden. ${ }^{500}$ Weil

498 Übers. d. Verf. aus dem Englischen: „brackets“.

${ }^{499} \mathrm{Vgl}$. § 1 IRC.

${ }^{500}$ Wie eingangs erwähnt, greift ein konstanter Steuersatz bei der Bewertung von Wohnimmobilien ebenso zu kurz wie die Ausblendung steuerlicher Effekte: Rund 80 Prozent der Wohnimmobilien in Deutschland sind Eigentum natürlicher Personen (siehe Fußnote 36), deren Steuerlast mit der nichtlinearen Tariffunktion aus § 32a EStG berechnet wird. Während die Berücksichtigung eines solchen Steuertarifs bei der Bewertung von Eigentumswohnungen unabdingbar erscheint, verwendet man in der restlichen Bewertungsliteratur - wenn überhaupt - lineare Steuersätze (siehe Fußnote 48). Obwohl bereits HERING (1998), S. 111 eine abschnittsweise Linearisierung durch Interpolation vorschlug, ist es dem Verfasser nicht gelungen, entsprechende Ansätze zur Berücksichtigung der Tarif- 
auch im Basisprogramm steuerpflichtige Einkünfte vorliegen, sind Anpassungen sowohl für das Basis- als auch für das Bewertungsprogramm erforderlich. Da für das Bewertungsprogramm aufgrund der Abschreibung umfangreichere Modifikationen erforderlich sind, werden dessen Modifikationen weiter unten separat beschrieben, es folgen zunächst die Modifikationen im Basisprogramm:

$\mathrm{Zu}$ jedem investitionstheoretischen Investitions- oder Finanzierungsobjekt ist ein Schattenobjekt zu bilden, welches dessen steuerrelevanten Anteil abbildet. Deren Summe determiniert das zu versteuernde Einkommen der Periode. Es wird mit folgender Nebenbedingung in eine abschnittsweise Steuerbemessungsgrundlage übergeleitet:

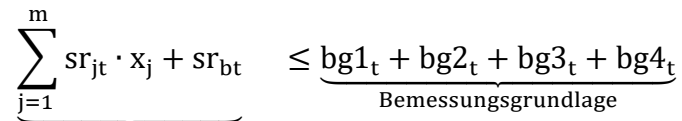

$$
\forall \mathrm{t} \in\{1,2, \ldots, \mathrm{n}\}
$$

Summe der Schattenobjekte

Die linke Seite der Ungleichung umfaßt den steuerrelevanten Schattenanteil $s_{j t}$ für jeden Zahlungsstrom $g_{j t}$. Weil jedes Schattenobjekt mit derselben Durchführungshäufigkeit $\mathrm{x}_{\mathrm{j}}$ multipliziert wird wie das originäre Objekt, erzwingt die Durchführung eines Objekts automatisch auch dessen steuerliche Erfassung. Der feststehende Zahlungsstrom $b_{t}$ beinhaltet einen steuerrelevanten Teil, der als $s_{b t}$ bezeichet sei.

Die Herleitung der Bemessungsgrundlage erfolgt objektbezogen durch die Schattenobjekte auf der linken Seite. ${ }^{501}$ Die Berechnung der Steuerlast erfordert jedoch ein in bestimmte Intervalle gegliedertes Einkommen, abgebildet durch bg $1_{t}+\operatorname{bg} 2_{t}+b g 3_{t}+$ $\operatorname{bg} 4_{t}$ auf der rechten Seite. Dieser Zwischenschritt ist notwendig, weil jedes Teilglied

funktion zu finden. Dies mag sicherlich dem Umstand geschuldet sein, daß Investitionen oder Unternehmen zumeist aus der Perspektive von Kapitalgesellschaften bewertet werden, in deren Entscheidungsfeld konstante Steuersätze von Bedeutung sind. Durchaus verbreitet ist jedoch die Modellierung einer von Zahlungsströmen abweichenden Steuerbemessungsgrundlage - häufig in Form von zusätzlichen Variablen, z.B. zur Abbildung von Abschreibungen oder anderen Nebenrechnungen, vgl. z.B. ADAM (2000), S. 168, JAPES (2011), S. 33 ff., GÖTZE (2014), S. 137 ff., BUSSE VON COLBE/WITTE (2018), S. 85 ff. Ein Totalmodell zur Investitionsplanung, welches auch gewinnabhängige Steuern berücksichtigt, stellt ROSENBERG (1975) vor. Er unternimmt detaillierte Umrechnungen, um von Zahlungsströmen ausgehend mehrere steuerliche Bemessungsgrundlagen zu ermitteln (vgl. ebd., S. 104 ff.), auf die schließlich sechs verschiedene Steuersätze angewendet werden (vgl. ebd., S. 128 f.). Jedoch handelt es sich auch bei diesen um lineare Steuersätze, die als exogenes Datum in die Rechnung eingehen. In der Steuerliteratur hingegen setzt man sich mit mathematischen Eigenheiten der Tariffunktion auseinander. Weil diese jedoch nicht Nebenbedingung eines Bewertungskalküls ist, gilt die Aufmerksamkeit der Tariffunktion selbst. So würdigt SCHANZ (2006) verschiedene Methoden zu ihrer Interpolation, und PFEIFFER (2016), S. $428 \mathrm{ff}$. befaßt sich mit der gesetzlich vorgeschriebenen Abrundung der Steuerlast, aufgrund derer die Funktion nicht überall stetig und differenzierbar ist.

${ }^{501}$ Auch im Einkommensteuerrecht gilt die Objektbezogenheit, bspw. bei der Prüfung der Einkunftserzielungsabsicht, die z.B. für jede vermietete Nichtwohnimmobilie separat geprüft werden muß, vgl. KULOSA (2019), Rn. 26, SCHALLMOSER (2019), Rn. 150. 
mit einer unterschiedlichen Steigung zu multiplizieren ist, um die Steuerlast zu berechnen. Mit zunehmender Summe der Schattenobjekte füllen sich dessen Kettenglieder sukzessive von links $\left(\mathrm{bg} 1_{\mathrm{t}}\right)$ nach rechts $\left(\mathrm{bg} 4_{\mathrm{t}}\right) .^{502}$

Die Überlegungen zu den Intervallgrenzen werden aus Unterabschnitt 3.2.2.3 übernommen: Die Intervalle müssen als nichtnegativ definiert sein, damit der Algorithmus Steuerzahlungen nicht durch Ansatz negativer Bemessungsgrundlagen umgeht. Sie müssen Obergrenzen haben, da sie einen Teilbereich von bestimmter Länge abbilden. Ist dieser Teilabschnitt voll, muß der Algorithmus gezwungen sein, zum nächsthöheren Teilabschnitt zu springen, für welchen ein höherer Steuersatz gilt. Als Obergrenze sind nicht die absoluten Werte der Intervallgrenzen, sondern die Intervalllängen zu verwenden. Dies führt zu folgenden Nebenbedingungen:

$$
\begin{aligned}
& 0 \leq \mathrm{bg} 4_{\mathrm{t}} \leq 12.500 \\
& 0 \leq \mathrm{bg} 2_{\mathrm{t}} \leq 28.500 \\
& 0 \leq \mathrm{bg} 3_{\mathrm{t}} \leq 224.326 \\
& 0 \leq \mathrm{bg} 4_{\mathrm{t}} \leq \text { unbeschränkt }
\end{aligned}
$$$$
\forall \mathrm{t} \in\{1,2, \ldots, \mathrm{n}\}
$$

Auf Basis dieser Bemessungsgrundlage kann der Algorithmus nun die approximierte Steuerlast errechnen, indem er die jeweiligen Auslastungen jedes Intervallabschnitts mit den in Gliederungspunkt 3.2.2.3 definierten Steigungen multipliziert. Auf diese Weise errechnet die folgende Nebenbedingung die periodenspezifische Steuerlast $\mathrm{St}_{\mathrm{t}}$ :

$$
-\mathrm{St}_{\mathrm{t}} \leq-0,046 \cdot \operatorname{bg} 1_{\mathrm{t}}-0,2929 \cdot \mathrm{bg} 2_{\mathrm{t}}-0,4178 \cdot \operatorname{bg} 3_{\mathrm{t}}-0,45 \cdot \mathrm{bg} 4_{\mathrm{t}}
$$

$$
\forall \mathrm{t} \in\{1,2, \ldots, \mathrm{n}\}
$$

Die Steuerlast $\mathrm{St}_{\mathrm{t}}$ ist schließlich in die Liquiditätsnebenbedingung $\mathrm{zu}$ integrieren. Schließlich stehen die zu ihrer Begleichung aufzuwendenden Mittel anderweitig nicht mehr zur Verfügung. ${ }^{503}$ Ebenso muß der Solidaritätszuschlag in der Liquiditätsnebenbedingung berücksichtigt werden. Wie in Abschnitt 2.1.2.4 erläutert, wird unterstellt, daß der Solidaritätszuschlag bereits ab dem ersten Euro erhoben wird und sein Steuersatz 5,5 Prozent der Einkommensteuerlast beträgt. Um diesen zu ermitteln, wird die Steuerlast mit dem Faktor 1,055 multipliziert. ${ }^{504}$

${ }^{502}$ Es ist gewährleistet, daß der Algorithmus mit dem ersten Intervall bg $1_{\mathrm{t}}$ beginnt, weil er Auszahlungen möglichst zu vermeiden sucht. Der Algorithmus beginnt mit dem Intervall, welches die niedrigste Steigung hat und somit die geringsten Kosten mit sich bringt.

${ }^{503}$ Zur modelltechnischen Vereinfachung wird angenommen, daß die Einkommensteuer am Ende des Kalenderjahres sowohl rechtsverbindlich festgesetzt, als auch sofort bezahlt wird. Ebenso könnte man die Einkommensteuer als Zahlungsstrom in der nächsten Periode modellieren, was aber nur die gesamte Rechnung ohne zusätzlichen Nutzen verkompliziert.

${ }^{504}$ Vereinfachend wird die Kirchensteuer in der vorliegenden Arbeit ausgeblendet, weil ihre Anwendung dem Solidaritätszuschlag ähnlich ist. Während letzterer von jedem Steuerpflichtigen zu tragen ist, muß die Kirchensteuer nur von Angehörigen anerkannter Religionsgemeinschaften entrichtet werden, vgl. Abschnitt 3.1.2. 
Weil davon ausgegangen wird, daß der Investor zumindest einen Teil seines Einkommens aus nichtselbständiger Tätigkeit bezieht, muß berücksichtigt werden, daß arbeitgeberseitig bereits Lohnsteuer (zzgl. Solidaritätszuschlag) vom Einkommen $b_{t}$ einbehalten und abgeführt wurde. Es handelt sich um eine Vorauszahlung auf die Einkommensteuer, die auf die Steuerlast angerechnet werden muß. ${ }^{505} \mathrm{In}$ der vorgenannten Nebenbedingung wurde die Steuerlast auf Basis der gesamten Bemessungsgrundlage errechnet, welche auch $b_{t}$ umfaßt. Die Liquiditätsnebenbedingung muß um die Korrekturfaktoren KorrSt $t_{t}$ bzw. KorrSolZ ${ }_{t}$ ergänzt werden, um die bereits einbehaltene Lohnsteuer nebst Solidaritätszuschlag wieder hinzuzurechnen und Doppelerfassungen zu vermeiden. ${ }^{506}$

$-\sum_{\mathrm{j}=1}^{\mathrm{m}} \mathrm{g}_{\mathrm{jt}} \cdot \mathrm{x}_{\mathrm{j}}+\overline{\mathrm{w}}_{\mathrm{t}} \cdot \mathrm{EN}+1,055 \cdot \mathrm{St}_{\mathrm{t}} \leq \mathrm{b}_{\mathrm{t}}+\mathrm{KorrSt}_{\mathrm{t}}+\mathrm{KorrSolZ}_{\mathrm{t}} \quad \forall \mathrm{t} \in\{1,2, \ldots, \mathrm{n}\}$

Der Zusammenhang zwischen Schattenobjekten, Einkommen und Steuerlast soll abschließend noch einmal grafisch dargestellt werden: Das Einkommen ist eine auf der Abszisse verlaufende Funktion ohne Steigung und besteht aus den Kettengliedern bg $_{\mathrm{t}}$. Mit zunehmender Summe der Schattenobjekte füllen sich dessen Intervalle von links nach rechts. Die Steuerfunktion ist an dieselben Intervalle gebunden, besitzt jedoch für jeden Abschnitt unterschiedliche Steigungen. Proportional zum Einkommen füllt sich auch diese Funktion. Die Steuerlast jedes Intervalls ergibt sich als Produkt von dessen Länge, Steigung und Auslastung, die gesamte Steuerlast durch deren Addition.

Abbildung 5 zeigt diese Zusammenhänge beispielhaft für ein Einkommen von 42.501 EUR. Es ergibt sich eine approximierte Steuerlast von 9.550 EUR, verglichen mit 9.460 EUR tatsächlicher Steuerlast:

$12.500 \cdot 0,046 \cdot 100 \%+28.500 \cdot 0,2929 \cdot 100 \%+224.326 \cdot 0,4178 \cdot 0,67 \%$ $\approx 9.550$

${ }^{505}$ Zum Charakter der Lohnsteuer als vorab bereits bezahlte Einkommensteuer vgl. SIEVERT (2016), S. 28, SCHREIBER (2017), S. 75.

${ }^{506}$ Eine solche Pflicht zur Steuervorauszahlung besteht nicht nur bei nichtselbständiger Tätigkeit, wo die Steuerlast automatisch vom Gehalt abgezogen wird. Auch Selbständige sind bspw. zu quartalsweisen Vorauszahlungen verpflichtet; die Höhe orientiert sich an der voraussichtlichen Steuerschuld, vgl. dazu ETTLICH (2019), Rn. 56 ff. 


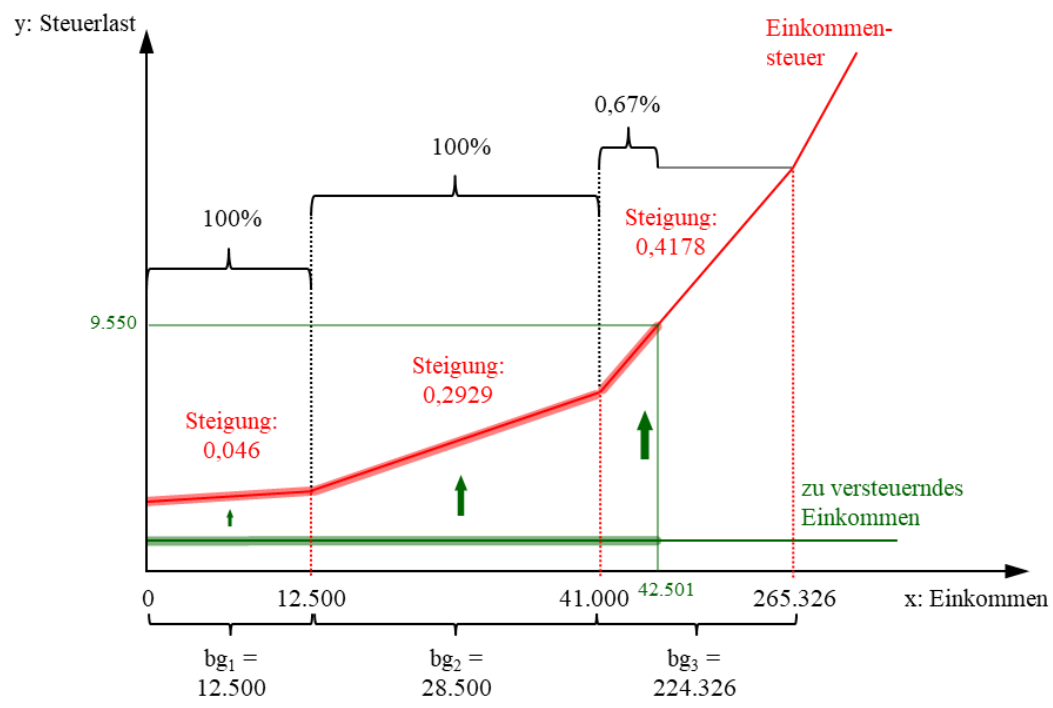

Abbildung 5: Intervallweise Approximation der Einkommensteuerlast

Aus den zuvor beschriebenen Nebenbedingungen kann nun folgender linearer Optimierungsansatz zusammengesetzt werden, um das optimale Basisprogramm ohne Kauf der Eigentumswohnung unter Berücksichtigung der Einkommensteuer zu errechnen:507

max. Entn; Entn := EN

Liquiditätsnebenbedingungen:

$-\sum_{j=1}^{m} g_{j 0} \cdot x_{j} \leq b_{0}$

und

$-\sum_{\mathrm{j}=1}^{\mathrm{m}} \mathrm{g}_{\mathrm{jt}} \cdot \mathrm{x}_{\mathrm{j}}+\overline{\mathrm{w}}_{\mathrm{t}} \cdot \mathrm{EN}+1,055 \cdot \mathrm{St}_{\mathrm{t}} \leq \mathrm{b}_{\mathrm{t}}+\mathrm{KorrSt}_{\mathrm{t}}+\operatorname{KorrSolZ}_{\mathrm{t}} \quad \forall \mathrm{t} \in\{1,2, \ldots, \mathrm{n}\}$

Bemessungsgrundlage:

$\mathrm{sr}_{\mathrm{bt}}+\sum_{\mathrm{j}=1}^{\mathrm{m}} \mathrm{sr}_{\mathrm{jt}} \cdot \mathrm{x}_{\mathrm{j}} \leq \mathrm{bg} 1_{\mathrm{t}}+\mathrm{bg} 2_{\mathrm{t}}+\operatorname{bg} 3_{\mathrm{t}}+\mathrm{bg} 4_{\mathrm{t}} \quad \forall \mathrm{t} \in\{1,2, \ldots, \mathrm{n}\}$

${ }^{507}$ Wie bereits angemerkt, werden die Veränderungen zur Vorstufe in blauer Schrift hervorgehoben. 
Steuerlast:

$-\mathrm{St}_{\mathrm{t}} \leq-0,046 \cdot \operatorname{bg} 1_{\mathrm{t}}-0,2929 \cdot \mathrm{bg} 2_{\mathrm{t}}-0,4178 \cdot \mathrm{bg} 3_{\mathrm{t}}-0,45 \cdot \mathrm{bg} 4_{\mathrm{t}}$

mit

$$
\begin{aligned}
& 0 \leq \mathrm{bg} 1_{\mathrm{t}} \leq 12.500 \\
& 0 \leq \mathrm{bg} 2_{\mathrm{t}} \leq 28.500 \\
& 0 \leq \mathrm{bg} 3_{\mathrm{t}} \leq 224.326 \\
& 0 \leq \mathrm{bg} 4_{\mathrm{t}} \leq \text { unbeschränkt }
\end{aligned}
$$$$
\forall \mathrm{t} \in\{1,2, \ldots, \mathrm{n}\}
$$

Nichtnegativitätsbedingungen und Obergrenzenrestriktionen: ${ }^{508}$

$$
\begin{array}{ll}
E N \geq 0 & \forall \mathrm{t} \in\{1,2, \ldots, \mathrm{n}\} \\
\mathrm{x}_{\mathrm{j}} \geq 0 & \forall \mathrm{j} \in\{1,2, \ldots, \mathrm{m}\} \\
\mathrm{x}_{\mathrm{j}} \leq \mathrm{x}_{\mathrm{j}}^{\max } & \forall \mathrm{j} \in\{1,2, \ldots, \mathrm{m}\}
\end{array}
$$

\subsubsection{Ermittlung des optimalen Bewertungsprogramms}

Die vorgenannten Nebenbedingungen gelten auch für den Bewertungsansatz, müssen dort aber um das Bewertungsobjekt und seine Steuerwirkung ergänzt werden. Von Bedeutung ist vor allem die Abschreibung. Wie schon in Unterabschnitt 2.1.2.1 erwähnt, wurde bereits im Rahmen der Datenbeschaffung berechnet, welcher Anteil des Grenzpreises als Abschreibungsgrundlage zulässig ist. ${ }^{509}$ Er geht als Faktor $\gamma$ in die Berechnung ein, der zwischen null und eins normiert ist. Daß die Aufteilung auf vermeintlich objektiven (Vergangenheits-)Werten ohne jeglichen Bezug zum Bewertungsobjekt erfolgt, kann vernachlässigt werden. Der tatsächliche Grenzpreis umfaßt sowohl den abschreibungsfähigen als auch den nicht abschreibungsfähigen Anteil, unabhängig davon, daß der Gesetzgeber steuerlich nur einen Teil davon als Werbungskosten gelten läßt. Die Zielgröße wird unverändert mit der Bedingung $\mathrm{p} \geq 0$ als nichtnegativ deklariert. Weil der Grenzpreis einschließlich Transaktionskosten unverändert die vom Algorithmus zu maximierende Größe ist, muß die Zielfunktion nicht geändert werden:

$\max . \mathrm{U} ; \mathrm{U}:=\mathrm{p}$

Daher lautet die Liquiditätsnebenbedingung für den Entscheidungszeitpunkt $t=0$ :

$-\sum_{j=1}^{m} g_{j 0} \cdot x_{j}+p \leq b_{0}$

Da bei Lösung des Simplexalgorithmus die Werte aller Variablen im Ergebnistableau ausgegeben werden, kann aus Gründen der Praktikabilität eine Nebenbedingung zur Berechnung des um Transaktionskosten bereinigten Grenzpreises aufgenommen werden.

\footnotetext{
${ }^{508}$ Hier sei angemerkt, daß es nicht zwangsläufig eine Nichtnegativitätsbedingung für die Steuerlast geben muß. Allgemein sind auch Subventionen als negative Steuern vorstellbar.

${ }^{509}$ Dazu stellt das Bundesfinanzministerium auf seiner Netzseite einen Rechner zur Verfügung, der frei heruntergeladen werden kann, vgl. Abschnitt 3.2.1.
} 
Diese Größe ist für die Verhandlungssituation relevant: Maximal der um Transaktionskosten bereinigte Grenzpreis für Gebäude- und Grundstücksteil kann an den Verkäufer bezahlt werden. Durch Aufnahme folgender Nebenbedingung kann man diesen Teil einfach ablesen und sich eine manuelle Umrechnung ersparen:

$\mathrm{p}_{\mathrm{oT}}=\frac{\mathrm{p}}{1,08}$

Die Liquiditätsnebenbedingungen sind dem Basisprogramm sehr ähnlich. Hinsichtlich der Zeitpunkte $\mathrm{t}=1$ bis $\mathrm{t}=\mathrm{n}$ unterscheiden sie sich nur dahingehend vom Basisprogramm, daß sie den Zahlungsstrom des Bewertungsobjekts $\mathrm{g}_{\mathrm{Kt}}$ beinhalten:

$-\sum_{j=1}^{m} g_{j t} \cdot x_{j}+\bar{w}_{t} \cdot E N+1,055 \cdot \mathrm{St}_{t} \leq \mathrm{b}_{t}+\mathrm{g}_{\mathrm{Kt}}+\mathrm{KorrSt}_{\mathrm{t}}+\mathrm{KorrSolZ}_{\mathrm{t}}$

$\forall \mathrm{t} \in\{1,2, \ldots, \mathrm{n}\}$

Der steuerrelevante Anteil des Bewertungsobjekts wird $\mathrm{sr}_{\mathrm{Kt}}$ genannt. In der hier vorgenommenen Schreibweise beinhaltet die Bemessungsgrundlage der Eigentumswohnung einerseits die zweiprozentige Abschreibung auf den Gebäudeanteil, die ohne Zahlungsstrom geltend gemacht wird. ${ }^{510}$ Andererseits beinhaltet sie die steuerrelevanten Anteile des Zahlungsstroms $\mathrm{g}_{\mathrm{Kt}}$, bestehend aus Einzahlungen minus Auszahlungen. Es ist zu beachten, daß die Abschreibung aufgrund steuerlicher Regelungen auf den Zeitraum vom ersten bis zum fünfzigsten Jahr beschränkt ist. Soll ein längerer Planungshorizont modelliert werden, existiert ab dem einundfünfzigsten Jahr keine Abschreibung mehr. ${ }^{511}$

$\mathrm{sr}_{\mathrm{bt}}+\mathrm{sr}_{\mathrm{Kt}}-\underbrace{0,02}_{\text {AfA-Satz }} \cdot \gamma \cdot \mathrm{p}+\sum_{\mathrm{j}=1}^{\mathrm{m}} \mathrm{sr}_{\mathrm{jt}} \cdot \mathrm{x}_{\mathrm{j}} \leq \mathrm{bg} 1_{\mathrm{t}}+\mathrm{bg} 2_{\mathrm{t}}+\mathrm{bg} 3_{\mathrm{t}}+\mathrm{bg} 4_{\mathrm{t}}$

bzw.

$\forall \mathrm{t} \in\{1,2, \ldots, 50\}$

$\mathrm{sr}_{\mathrm{bt}}+\mathrm{sr}_{\mathrm{Kt}}+\sum_{\mathrm{j}=1}^{\mathrm{m}} \mathrm{sr}_{\mathrm{jt}} \cdot \mathrm{x}_{\mathrm{j}} \leq \mathrm{bg} 1_{\mathrm{t}}+\mathrm{bg} 2_{\mathrm{t}}+\mathrm{bg} 3_{\mathrm{t}}+\mathrm{bg} 4_{\mathrm{t}} \quad \forall \mathrm{t} \in\{51, \ldots, \mathrm{n}\}$

${ }^{510}$ Die zweiprozentige Abschreibung gilt für Gebäude, die nach dem 31.12.1924 fertiggestellt worden sind, vgl. § 7 Abs. 4 Nr. 2a EStG. Für vorher fertiggestellte Gebäude gilt ein Abschreibungssatz von zweieinhalb Prozent, vgl. $\S 7$ Abs. 4 Nr. 2b EStG, und für Betriebsgebäude, deren Bauantrag nach dem 31.03.1985 gestellt wurde, ein Abschreibungssatz von drei Prozent, vgl. § 7 Abs. 4 Nr. 1 EStG.

${ }^{511}$ Es wurde bewußt ein Planungshorizont von 50 Jahren gewählt, der an die steuerlich unterstellte Nutzungsdauer von Wohnimmobilien angelehnt ist. Im Sinne einer übersichtlichen Darstellung enthalten die Nebenbedingungen in der vorliegenden Arbeit stets die Abschreibungskomponente. Bei anderslautender Modellierung mit Wahl eines längeren Planungshorizonts darf die Abschreibung nur während der ersten 50 Jahre berücksichtigt werden. Soll hingegen ein kürzerer Planungshorizont erfaßt werden, ist zu fragen, ob dieser Planungshorizont für Wohnimmobilien angemessen ist und es sollte in Abhängigkeit von der jeweiligen Problemstellung nach einer Möglichkeit gesucht werden, ob und wie die verbleibenden Abschreibungsbeträge berücksichtigt werden können. Der vorzeitige Verkauf der Eigentumswohnung ist nicht Gegenstand der vorliegenden Ausführungen. Zur Behandlung der in Anspruch genommenen Abschreibung im Rahmen von privaten Veräußerungsgeschäften vgl. LINDAUER (2016), S. 182 ff., WEBER-GRELLET (2019), Rn. 84, RATSCHOW (2019b), Rn. 190 ff., SCHALLMOSER (2019), Rn. 168. 
Bei der approximierten Steuerlast und deren Erfassung in den Liquiditätsnebenbedingungen gibt es keinen Unterschied zum Basisprogramm. Der lineare Optimierungsansatz für das Bewertungsprogramm unter Berücksichtigung von Einkommensteuern kann nun wie folgt aufgestellt werden:

$\max . \mathrm{U} ; \mathrm{U}:=\mathrm{p}$

Berechnung des Grenzpreises ohne Transaktionskosten:

$\mathrm{p}_{\mathrm{oT}}=\frac{\mathrm{p}}{1,08}$

Liquiditätsnebenbedingungen:

$-\sum_{j=1}^{m} g_{j 0} \cdot x_{j}+p \leq b_{0}$

und

$-\sum_{j=1}^{m} g_{j t} \cdot x_{j}+\bar{w}_{t} \cdot E N+1,055 \cdot \mathrm{St}_{t} \leq \mathrm{b}_{t}+\mathrm{g}_{\mathrm{Kt}}+\mathrm{KorrSt}_{\mathrm{t}}+\mathrm{KorrSolZ}_{\mathrm{t}}$

Bemessungsgrundlage:

$\forall \mathrm{t} \in\{1,2, \ldots, \mathrm{n}\}$

$\mathrm{sr}_{\mathrm{bt}}+\mathrm{sr}_{\mathrm{Kt}}-\underbrace{0,02}_{\text {AfA-Satz }} \cdot \gamma \cdot \mathrm{p}+\sum_{\mathrm{j}=1}^{\mathrm{m}} \mathrm{sr}_{\mathrm{jt}} \cdot \mathrm{x}_{\mathrm{j}} \leq \mathrm{bg} 1_{\mathrm{t}}+\mathrm{bg} 2_{\mathrm{t}}+\mathrm{bg} 3_{\mathrm{t}}+\mathrm{bg} 4_{\mathrm{t}}$

$\forall \mathrm{t} \in\{1,2, \ldots, \mathrm{n}\}$

Steuerlast:

$-\mathrm{St}_{\mathrm{t}} \leq-0,046 \cdot \mathrm{bg} 1_{\mathrm{t}}-0,2929 \cdot \mathrm{bg} 2_{\mathrm{t}}-0,4178 \cdot \mathrm{bg} 3_{\mathrm{t}}-0,45 \cdot \mathrm{bg} 4_{\mathrm{t}}$

mit $0 \leq b g 1_{t} \leq 12.500$

$0 \leq \mathrm{bg} 2_{\mathrm{t}} \leq 28.500$

$0 \leq \mathrm{bg} 3_{\mathrm{t}} \leq 224.326$

$0 \leq \mathrm{bg} 4_{\mathrm{t}} \leq$ unbeschränkt

$\forall \mathrm{t} \in\{1,2, \ldots, \mathrm{n}\}$

Nichtnegativitätsbedingungen und Obergrenzenrestriktionen:

$-\mathrm{EN} \leq-\mathrm{EN}^{*}$

$\mathrm{EN} \geq 0$

$\mathrm{p} \geq 0$

$x_{j} \geq 0$

$\forall \mathrm{j} \in\{1,2, \ldots, \mathrm{m}\}$

$\mathrm{x}_{\mathrm{j}} \leq \mathrm{x}_{\mathrm{j}}^{\max }$

$\forall \mathrm{j} \in\{1,2, \ldots, \mathrm{m}\}$ 


\subsection{Exemplarische Veranschaulichung der Modellerweiterung}

\subsubsection{Ergänzung der Zahlungsströme um ihre steuerrelevanten Schattenobjekte}

\subsubsection{Geldanlage- und Kreditobjekte}

Der Investor hat in Unterkapitel 2.3 seinen Grenzpreis für den Kauf der Wohnung berechnet und bereits erste Verhandlungen mit dem derzeitigen Eigentümer geführt. Er weiß, daß er Vermietungsüberschüsse mit der Finanzverwaltung teilen muß. Daraus folgert er, daß eine differenziertere Betrachtung erforderlich ist und Ertragsteuern zu berücksichtigen sind. Die Optimierungsansätze aus Unterkapitel 2.3 sind nun entsprechend zu ergänzen, um auch die Steuerlast zu berücksichtigen. Zur Ermittlung der Bemessungsgrundlage ist die Ergänzung aller investitionstheoretischen Objekte um deren steuerrelevanten Anteil erforderlich.

Am einfachsten kann die Vorgehensweise an Geldanlage- und Kreditobjekten verdeutlicht werden, daher seien diese zuerst vorgeführt: Der Kreditbetrag der einperiodigen Kreditlinien $A_{t}$ ist jeweils auf 40.000 EUR beschränkt. Jeder aufgenommene Euro muß in der Folgeperiode zuzüglich acht Prozent Zinsen zurückgezahlt werden. Daraus ergibt sich die investitionstheoretische Zahlungsreihe

$(+1 ;-1,08) \cdot A_{t}$

mit $0 \leq A_{t} \leq 40.000$,

denn bei einer Durchführungshäufigkeit von eins käme es in $\mathrm{t}=0 \mathrm{zu}$ einer Einzahlung von +1 EUR und in der Folgeperiode zu einer Auszahlung von $-1,08$ EUR. Auszahlung und Tilgung des Kredits werden steuerlich als reine Vermögensumschichtungen behandelt. Nur der Zinsanteil ist steuerlich abzugsfähig. ${ }^{512}$ Das steuerrelevante Schattenobjekt beinhaltet nur Schuldzinsen und blendet alle weiteren Geldbewegungen aus:

$(0 ;-0,08) \cdot A_{t}$

mit $0 \leq A_{t} \leq 40.000$

Es sei daran erinnert, daß jeder Zahlungsstrom mit seinem steuerrelevanten Schattenobjekt verknüpft ist, weil beide mit der Durchführungshäufigkeit $\mathrm{A}_{\mathrm{t}}$ multipliziert werden.

Das Gesagte gilt analog für Kreditlinie B, die sich nur hinsichtlich Zinssatz und Kreditobergrenze unterscheidet. Die maximale Höhe der Kreditaufnahme ist erstens auf 450.000 EUR und zweitens auf die Höhe des Kaufpreises (einschließlich Transaktionskosten) beschränkt. Dies führt zum investitionstheoretischen Zahlungsstrom

$(+1 ;-1,01) \cdot \mathrm{B}_{\mathrm{t}}$

mit $0 \leq \mathrm{B}_{\mathrm{t}} \leq \mathrm{p}$

${ }^{512} \mathrm{Vgl}$. Abschnitt 3.2.1. Dies gilt natürlich nur, sofern ein Veranlassungszusammenhang der Schuldzinsen zur Einkunftsart Vermietung und Verpachtung besteht, vgl. WREDE (2017), S. 72, THÜRMER (2019), Rn. 113 und Rn. 208. Zur Abzugsfähigkeit von Schuldzinsen bei Weiternutzung eines Kredits für eine andere Immobilie vgl. SCHALLMOSER (2019), Rn. 295. Man könnte durch Formulierung weiterer Nebenbedingungen eine Abhängigkeit der steuerlichen Abzugsfähigkeit von der Investitionshöhe bestimmter Objekte erreichen. Dies bringt aber eine große Zahl weiterer Nebenbedingungen mit sich und steigert erneut die Komplexität. 


$$
\text { und } 0 \leq \mathrm{B}_{\mathrm{t}} \leq 450.000 \text {, }
$$

gefolgt vom steuerlichen Schattenobjekt

$(0 ;-0,01) \cdot B_{t}$

$$
\text { mit } 0 \leq \mathrm{B}_{\mathrm{t}} \leq \mathrm{p}
$$

und $0 \leq \mathrm{B}_{\mathrm{t}} \leq 450.000$.

Die einperiodige Kassenhaltung auf dem Girokonto hat keinerlei steuerliche Auswirkung, weil erstens unterstellt wird, daß auf dem Girokonto keine Zinsen gezahlt werden. Zweitens unterliegen Zinseinkünfte der Abgeltungsteuer und fließen nicht in das zu versteuernde Einkommen ein. ${ }^{513}$ Die Steuerschuld wird unmittelbar an der Quelle abgeführt und muß in der Steuererklärung nicht mehr deklariert werden. Eine steuerliche Erfassung im Modell ist nicht notwendig. Tabelle 26 zeigt die investitionstheoretischen Zahlungsströme (Mitte) der Kreditobjekte sowie die darauf basierenden steuerrelevanten Schattenobjekte (rechts, in Gelb hervorgehoben).

\begin{tabular}{|l|c|c|c|c|}
\hline Kreditobjekte & \multicolumn{2}{|c|}{ Zahlungsstrom } & \multicolumn{2}{c|}{ Schattenobjekt } \\
\hline Einnahmen & $\mathbf{t}=\mathbf{t}$ & $\mathbf{t}=\mathbf{t}+\mathbf{1}$ & $\mathbf{t}=\mathbf{t}$ & $\mathbf{t}=\mathbf{t}+\mathbf{1}$ \\
\hline Kreditlinie A: & 1,00 & & 0,00 & \\
\hline Kreditlinie B: & 1,00 & & 0,00 & \\
\hline Ausgaben & $\mathbf{t}=\mathbf{t}$ & $\mathbf{t}=\mathbf{t}+\mathbf{1}$ & $\mathbf{t}=\mathbf{t}$ & $\mathbf{t}=\mathbf{t}+\mathbf{1}$ \\
\hline Kreditlinie A: & & $-1,08$ & & $-0,08$ \\
\hline Kreditlinie B: & & $-1,01$ & & $-0,01$ \\
\hline
\end{tabular}

Tabelle 26: Zahlungsströme und Schattenobjekte der Kreditobjekte

\subsubsection{Bewertungsobjekt}

Die Abschreibung auf den Kaufpreis stellt hinsichtlich des Bewertungsobjekts die bedeutsamste Abweichung zwischen investitionstheoretischen (Vor-Steuer-) Zahlungsströmen und der Sichtweise des Steuerrechts dar. Um die prozentuale Aufteilung des Kaufpreises auf Grundstück und Gebäude vorzunehmen, sind schematische Berechnungen basierend auf Normwerten erforderlich. Auf der Netzseite des Bundesfinanzministeriums findet der Investor ein zu diesem Zweck dienendes Excel-Werkzeug nebst Anleitung.

Für die Berechnung des Grundstücksanteils benötigt er die Größe des Grundstücks, den Bodenrichtwert und die MEA der Wohneinheit. Letztere erfährt er vom Verkäufer, es sind 104,97/1.000stel. Auf der Netzseite von BoRiS NRW recherchiert er, daß der Bodenrichtwert 230 EUR/qm beträgt. Auf Basis von Katasterdaten kann er dort ebenfalls die Grundstücksgröße relativ genau nachmessen; sie beträgt 1282,099 qm, was sich mit den Angaben des Grundbuchamts deckt. Daraus ergibt sich der auf die Wohneinheit entfallende Bodenwert in Höhe von

${ }^{513}$ Zur Abgeltungsteuer vgl. JAPES (2011), S. 178, SIEVERT (2016), S. 28, DINKELBACH (2017), S. 72 ff., KRAFT/KRAFT (2018), S. 94, FREICHEL/KRENZIN/LÖSEL/BRÄHLER (2018), S. 240. Zu Ausnahmen von dieser Regel vgl. SCHNEELOCH/MEYERING/PATEK (2016), S. 151, LINDMAYER/DIETZ (2018), S. 372. 


$$
230 \frac{\mathrm{EUR}}{\mathrm{qm}} \cdot 1.282,1 \mathrm{qm} \cdot \frac{104,97}{1.000}=30.953,84 \mathrm{EUR} .
$$

Weil das Excel-Werkzeug an mehreren Stellen zwangsläufig rundet, errechnet es einen hiervon abweichenden Wert von 30.960 EUR. Für den Gebäudewert zieht das Programm die THK (,Typisierte Herstellungskosten“) heran. Es handelt sich um schematisierte Tabellenwerte für einen Quadratmeter Wohnfläche, die sich nach Gebäudealter und vorgenommenen Modernisierungen richten. Bei der nächsten Besichtigung schaut sich der Investor daher verschiedene Gewerke genauer an und stellt fest, daß vor mehreren Jahren die Heizungsanlage erneuert wurde und manche Fenster und Leitungen ersetzt wurden. So errechnet das Programm aus dem ursprünglichen Baujahr 1968 ein fiktives Baujahr 1971 und kommt zu einem THK von 686 EUR pro qm Wohnfläche. Es ergibt sich ein Gebäude-Normwert von

$$
686 \frac{\mathrm{EUR}}{\mathrm{qm}} \cdot 73 \mathrm{qm}=50.078 \mathrm{EUR},
$$

wobei auch hier die Quadratmeter vom Programm gerundet wurden. In Summe ergibt sich ein Normwert von 81.038 EUR für Grundstück und Gebäude. Dies entspricht einer Aufteilung von 38,2 Prozent für das Grundstück und 61,8 Prozent für das Gebäude. Für die Abschreibung sind allein die Verhältniszahlen von Bedeutung. Um die Bemessungsgrundlage zu ermitteln, muß der tatsächliche Kaufpreis mit diesen Werten aufgeteilt werden. Somit kann er den Faktor $\gamma=0,618$ in das Modell übernehmen. Dies ist der Anteil des Grenzpreises, welcher der steuerlichen Abschreibung unterliegt.

Im Zeitpunkt $t=0$ ist investitionstheoretisch die tatsächliche Kaufpreisauszahlung $\mathrm{zu}$ berücksichtigen, verkörpert durch den Grenzpreis einschließlich Erwerbsnebenkosten. Das steuerrechtliche Schattenobjekt bleibt jedoch leer. ${ }^{514}$ Während des restlichen Zeitraums ist der Kaufpreis investitionstheoretisch nicht mehr als Auszahlung zu erfassen, wohl aber in seiner steuermindernden Wirkung, verkörpert durch die zweiprozentige Abschreibung, die sich auf den Gebäudeanteil nebst Transaktionskosten bezieht. Während der ersten 50 Perioden sind diese als $0,02 \cdot 0,618 \cdot \mathrm{p}=0,01236 \cdot \mathrm{p} \mathrm{zu}$ erfassen und als Werbungskosten anzusetzen.

Einen weiteren Sonderfall stellen Fahrten zum Mietobjekt dar. Zwar existiert auch für Fahrtkosten ein tatsächlicher Zahlungsstrom, kann aber nicht mit vertretbarem Aufwand

\footnotetext{
${ }^{514}$ Auch sämtliche Anschaffungsnebenkosten müssen zum Kaufpreis addiert und mit ihm abgeschrieben werden. Allerdings gibt es eine Reihe an Kosten, die nicht als Anschaffungskosten klassifiziert werden und daher unmittelbar im Zeitpunkt des Kaufs angesetzt werden können, bspw. Finanzierungskosten oder Renovierungskosten, um die Wohnung in vermietbaren Zustand zu versetzen, vgl. FISCHL (2013), Rn. 74 ff., HAMBERGER (2016), S. 1017 f., LINDMAYER/DIETZ(2018), S. 324. Weitere Beispiele finden sich bei STÜRZER/KOCH/HOPFENSPERGER/STERNS/STERNS-KOLBECK/ZIEGELMAYER (2016), S. $383 \mathrm{ff}$.
} 
erfaßt werden. Daher ist der Ansatz einer Kilometerpauschale von 0,30 EUR/km zulässig. ${ }^{515}$ Der Investor geht davon aus, daß er in jedem Jahr zehn Fahrten ansetzen kann. Dies entspricht Fahrtkosten von $10 \cdot 25 \mathrm{~km} \cdot 0,30 \frac{\mathrm{EUR}}{\mathrm{km}}=75 \mathrm{EUR}$.

Darüber hinaus vermutet der Investor keine weiteren Abweichungen zwischen Zahlungsströmen und steuerlicher Betrachtung. Zur besseren Verständlichkeit zeigt Tabelle 27 die Bestandteile der Vermietungseinkünfte in nicht saldierter Form. Abweichungen zwischen Zahlungsströmen und Schattenobjekten sind in Gelb hervorgehoben.

\begin{tabular}{|l|r|r|}
\hline Bewertungsobjekt Wohnung: & Zahlungsstrom & Schattenobjekt \\
\hline Einnahmen & & \\
\hline Mieteinnahmen & $4.810,95$ & $4.810,95$ \\
\hline Einnahmen aus Betriebskosten & $1.686,92$ & $1.686,92$ \\
\hline Werbungskosten & & \\
\hline Ausgaben für Betriebskosten & $-1.830,07$ & $-1.830,07$ \\
\hline Nicht umlagefähige Betriebskosten & $-363,52$ & $-363,52$ \\
\hline Instandhaltungskosten & $-768,18$ & $-768,18$ \\
\hline Pauschale Werbungskosten & 0,00 & $-\mathbf{7 5 , 0 0}$ \\
\hline Summe (ohne Kaufpreis und AfA) & $\mathbf{3 . 5 3 6 , 1 0}$ & $\mathbf{3 . 4 6 1 , 1 0}$ \\
\hline Kaufpreis (in t=0) & $-\mathbf{p}$ & $-0,00$ \\
\hline Abschreibungen (in t=1 bis t=50) & 0,00 & $\mathbf{- 0 , 0 1 2 3 6} \mathbf{~ p}$ \\
\hline
\end{tabular}

Tabelle 27: Zahlungsströme und Schattenobjekte des Bewertungsobjekts

\subsubsection{Nichtselbständige und selbständige Arbeit}

Gemeinsamer Ausgangspunkt von investitionstheoretischer und steuerrechtlicher Sicht ist das Bruttoeinkommen. Steuerrelevante Bemessungsgröße sind die hieraus errechneten Einkünfte aus nichtselbständiger Arbeit. ${ }^{516}$ Bestimmte Sozialversicherungsbeiträge sind steuerlich nur teilweise abzugsfähig. ${ }^{517}$

Investitionstheoretisch relevant ist das bereits versteuerte Einkommen aus nichtselbständiger Tätigkeit, verkörpert durch den feststehenden Zahlungsstrom $b_{t}$, von dem bereits Sozialabgaben und Lebenshaltungskosten abgezogen wurden. Es kann nach Belieben investiert oder konsumiert werden. Die folgende Tabelle zeigt, welche verschiedenen Posten aus den beiden Perspektiven abgezogen werden müssen, um zu konsistenten Ergebnissen zu gelangen.

${ }^{515} \mathrm{Vgl}$. STÜRZER/KOCH/HOPFENSPERGER/STERNS/STERNS-KOLBECK/ZIEGELMAYER (2016), S. 386.

${ }^{516}$ Vgl. zu Einkünften aus nichtselbständiger Arbeit SCHNEELOCH/MEYERING/PATEK (2016), S. 78 f., SCHREIBER (2017), S. 35 ff., DINKELBACH (2017), S. 102 ff., KRÜGER (2019).

${ }^{517}$ Zur (teilweisen) Abzugsfähigkeit von Sozialabgaben vgl. KRAFT/KRAFT (2018), S. 121 f., KUßMAUL (2018), S. 73 ff., GESERICH (2019), Rn. 330 ff. Insbesondere zur gesetzlichen Rentenversicherung vgl. HUTTER (2019), Rn. 190 ff. Sozialabgaben werden im Ermittlungsschema als sogenannte Sonderausgaben berücksichtigt. Deren Abzug erfolgt, verglichen mit den Werbungskosten, erst an späterer Stelle. Für die vorliegende Bewertung ist dies jedoch bedeutungslos, daher werden Werbungskosten und Sonderausgaben gleich behandelt. 


\begin{tabular}{|l|r|r|}
\hline Nichtselbständige Tätigkeit: & Zahlungsstrom & Schattenobjekt \\
\hline Einnahmen & & \\
\hline Einkommen & $52.044,00$ & $52.044,00$ \\
\hline Werbungskosten bzw. Ausgaben & & $-0,00$ \\
\hline Nicht abziehbare Kosten der Einkunftsart & $-930,84$ & $-9.543,00$ \\
\hline Abziehbare Kosten der Einkunftsart & $-9.543,00$ & $\mathbf{4 2 . 5 0 1 , 0 0}$ \\
\hline Bemessungsgrundlage & $\mathbf{4 1 . 5 7 0 , 1 6}$ & \\
\hline Einkommensteuer & $-9.461,00$ & \\
\hline Solidaritätszuschlag & $-520,35$ & \\
\hline Lebenshaltungskosten & $-29.760,00$ & \\
\hline Verfügbares Einkommen & $\mathbf{1 . 8 2 8 , 8 1}$ & \\
\hline
\end{tabular}

Tabelle 28: Zahlungsströme und Schattenobjekte des Bruttoeinkommens

Das frei verfügbare Einkommen wurde bereits in Kapitel 2 auf Basis eines Bruttogehalts von 52.044 EUR berechnet. Rechnergestützt wurden Sozialabgaben in Höhe von 10.473,84 EUR ermittelt, von diesen waren 9.543,00 EUR steuerlich abzugsfähig. Das zu versteuernde Einkommen betrug demnach 42.501 EUR. Darauf basierend wurden 9.461 EUR Lohnsteuer sowie 520,35 EUR Solidaritätszuschlag ermittelt, die arbeitgeberseitig bereits einbehalten und abgeführt wurden. Vom Nettoeinkommen, das dem Investor schließlich ausgezahlt wurde, mußten noch Lebenshaltungskosten von 29.760 EUR bestritten werden. Nach deren Abzug beträgt das frei verfügbare Einkommen 1.828,81 EUR, ausgedrückt durch den Zahlungsstrom $b_{t}$.

Bei Ansatz eines Bruttogehalts von 52.044 EUR und einer Bemessungsgrundlage von 42.501 EUR ist die Konsistenz zwischen investitionstheoretischer und steuerrechtlicher Sicht gewahrt. Der zweite Wert ist zwar etwas willkürlich gewählt, weil er aus der rechnergestützten Ermittlung der Lohnsteuer hervorgeht und nicht umgekehrt. In gewisser Weise wird die Bemessungsgrundlage somit für die Berechnung zurechtgebogen. Dies dient aber dazu, in einem fiktiven Beispiel die Konsistenz der Rechenergebnisse zu wahren, denn jede Bewertung muß dem Blickwinkel, aus dem sie erfolgt, gerecht werden. ${ }^{518}$ Somit ist auch die Belastung durch Steuern, Sozialversicherungsabgaben und weiteren relevanten Komponenten verpflichtend, allerdings unter Wahrung einer angemessenen Komplexitätsbegrenzung. Schließlich steht die exemplarische Grenzpreisermittlung einer fiktiven Eigentumswohnung im Mittelpunkt - und nicht die Berechnung von Lohnnebenkosten einer fiktiven Person. Es gibt eine Vielzahl an Faktoren, deren Berücksichtigung nicht zwangsläufig zu besseren Ergebnissen führt, aber von der eigentlichen Betrachtung ablenkt und ggf. auch die Rechenbarkeit beeinträchtigt. ${ }^{519}$

Die freiberufliche Tätigkeit ist ein periodenübergreifendes Objekt: Die Einzahlungen eines Zeitpunkts hängen davon ab, ob der Investor im vorhergehenden Zeitpunkt inve-

\footnotetext{
${ }^{518}$ Zur Entscheidungsfeldbezogenheit vgl. MATSCHKE (1972), S. 147, SIEBEN (1977), S. 64.

${ }^{519}$ Vgl. BALLWIESER (1990), S. 25 f., ADAM (1996), S. 229, JAPES (2011), S. 26 f. und S. 43, HERING (2017), S. 89.
} 
stiert hat. Es sei angenommen, daß die Ausgaben steuerlich erst im jeweils zweiten Zeitpunkt, gemeinsam mit den Einnahmen, angesetzt werden dürfen, weil die Finanzverwaltung hier im Beispiel nur durch finanzielle Rückflüsse von der Einkunftserzielungsabsicht überzeugt werden kann. So können weitere, von den Geldbewegungen abweichende Schattenobjekte modelliert werden.

\begin{tabular}{|l|r|r|r|r|}
\hline Freiberufliche Tätigkeit & \multicolumn{2}{|c|}{ Zahlungsstrom } & \multicolumn{2}{|c|}{ Schattenobjekt } \\
\hline Einnahmen & $\mathbf{t}$ & $\mathbf{t}+\mathbf{1}$ & $\mathbf{t}$ & $\mathbf{t}+\mathbf{1}$ \\
\hline Seminargebühr & 0,00 & $49.000,00$ & 0,00 & $49.000,00$ \\
\hline Werbungskosten & $\mathbf{t}$ & $\mathbf{t}+\mathbf{1}$ & $\mathbf{t}$ & $\mathbf{t}+\mathbf{1}$ \\
\hline Herstellung Seminarunterlagen & $-20.000,00$ & $-0,00$ & $-0,00$ & $-20.000,00$ \\
\hline Herstellung Vorbereitungsmaterial & $-9.000,00$ & $-0,00$ & $-0,00$ & $-9.000,00$ \\
\hline Versandkosten & $-900,00$ & $-0,00$ & $-0,00$ & $-900,00$ \\
\hline Servicepauschale (30 Prozent) & $-0,00$ & $-14.700,00$ & $-0,00$ & $-14.700,00$ \\
\hline Summe & $-\mathbf{2 9 . 9 0 0 , 0 0}$ & $\mathbf{3 4 . 3 0 0 , 0 0}$ & $-\mathbf{0 , 0 0}$ & $\mathbf{4 . 4 0 0 , 0 0}$ \\
\hline
\end{tabular}

Tabelle 29: Zahlungsströme und Schattenobjekte der freiberuflichen Tätigkeit

\subsubsection{Tabellarische Übersicht der bewertungsrelevanten Investitions- und Finanzierungsobjekte}

Die investitionstheoretisch und einkommensteuerlich relevanten Objekte sind in den folgenden Tabellen zusammengefaßt: Während Tabelle 30 Objekte mit einperiodiger Lebensdauer abbildet, zeigt Tabelle 31 die mehrperiodigen Objekte.

\begin{tabular}{|l|r|r|r|r|r|r|}
\hline Zahlungsstrom & Obergrenze & Symbol & $\mathbf{t}-\mathbf{1}$ & $\mathbf{t}$ & $\mathbf{t}+\mathbf{1}$ & $\mathbf{t}+\mathbf{2}$ \\
\hline $\begin{array}{l}\text { Freiberufliche } \\
\text { Tätigkeit }\end{array}$ & 1 & $\mathrm{I}_{\mathrm{t}}$ & - & $-29.900,00$ & $34.300,00$ & - \\
\hline Kassenhaltung & $\infty$ & $\mathrm{G}_{\mathrm{t}}$ & - & $-1,00$ & 1,00 & - \\
\hline Kreditlinie A & 40.000 & $\mathrm{~A}_{\mathrm{t}}$ & - & 1 & $-1,08$ & - \\
\hline Kreditlinie B & min $\{\mathrm{p} ; 450.000\}$ & $\mathrm{B}_{\mathrm{t}}$ & - & 1 & $-1,01$ & - \\
\hline Schattenobjekt & Obergrenze & Symbol & $\mathbf{t}-\mathbf{1}$ & $\mathbf{t}$ & $\mathbf{t}+\mathbf{1}$ & $\mathbf{t}+\mathbf{2}$ \\
\hline $\begin{array}{l}\text { Freiberufliche } \\
\text { Tätigkeit }\end{array}$ & 1 & $\mathrm{sr}_{\mathrm{It}}$ & - & $-0,00$ & 4.400 & - \\
\hline Kassenhaltung & $\infty$ & $\mathrm{sr}_{\mathrm{Gt}}$ & - & $-0,00$ & 0,00 & - \\
\hline Kreditlinie A & 40.000 & $\mathrm{sr}_{\mathrm{At}}$ & - & 0,00 & $-0,08$ & - \\
\hline Kreditlinie B & $\operatorname{min~}\{\mathrm{p} ; 450.000\}$ & $\mathrm{sr}_{\mathrm{Bt}}$ & - & 0,00 & $-0,01$ & - \\
\hline
\end{tabular}

Tabelle 30: Zahlungsströme und Schattenobjekte einperiodiger Objekte

\begin{tabular}{|l|r|r|r|r|r|}
\hline Zahlungsstrom & Symbol & $\mathbf{t}=\mathbf{0}$ & $\mathbf{t}=\mathbf{1}$ & $\mathbf{t}=\mathbf{2}$ & $\mathbf{t}=\mathbf{3}$ \\
\hline Feste Zahlungen & $\mathrm{b}_{\mathrm{t}}$ & 0 & $1.828,81$ & $1.828,81$ & $\ldots$ \\
\hline Wohnung & $\mathrm{g}_{\mathrm{Kt}}$ & $-\mathrm{p}$ & 3.536 & 3.536 & $\ldots$ \\
\hline Schattenobjekt & Symbol & $\mathbf{t = 0}$ & $\mathbf{t = 1}$ & $\mathbf{t}=\mathbf{2}$ & $\mathbf{t}=\mathbf{3}$ \\
\hline Feste Zahlungen & $\mathrm{sr}_{\mathrm{bt}}$ & 0 & $42.501,00$ & $42.501,00$ & $\ldots$ \\
\hline Wohnung & $\mathrm{sr}_{\mathrm{Kt}}$ & 0 & $3.461,1-0,01236 \mathrm{p}$ & $3.461,1-0,01236 \mathrm{p}$ & $\ldots$ \\
\hline
\end{tabular}

Tabelle 31: Zahlungsströme und Schattenobjekte mehrperiodiger Objekte 


\subsubsection{Ermittlung des optimalen Basisprogramms}

Mit Hilfe dieser Daten kann der Investor nun den Ansatz zur Ermittlung des steuerlichen Basisprogramms aufstellen. Weil der allgemeine Ansatz für das Basisprogramm bereits in Unterabschnitt 2.3.4.1 ausführlich vorgestellt wurde, soll hier nur auf die Unterschiede zum Modell ohne Steuern eingegangen werden. ${ }^{520}$

max. Entn; Entn $:=$ EN

Einkommensteuer und Solidaritätszuschlag wirken sich unmittelbar auf die verfügbaren Mittel aus. Daher ist die Einkommensteuerlast $\mathrm{St}_{t}$ in den Liquiditätsnebenbedingungen zu berücksichtigen. Während die Einkommensteuer weiter unten durch separate Nebenbedingungen ermittelt wird, dient der schlichte Faktor 1,055 zur Erfassung des Solidaritätszuschlags. Im Rahmen der nichtselbständigen Arbeit wurden bereits 9.461 EUR Lohnsteuer und 520,35 EUR Solidaritätszuschlag einbehalten. Beides sind Steuervorauszahlungen auf die durch $\mathrm{St}_{\mathrm{t}}$ verkörperte Gesamt-Steuerlast. Sie dürfen nicht doppelt erfaßt werden und werden daher als Korrekturfaktor wieder hinzugerechnet. Damit die Nebenbedingungen aufgrund von Nachkommastellen nicht unnötig lang werden, wird das Einkommen $b_{t}$ auf 1.828 EUR und der Solidaritätszuschlag auf 520 EUR gerundet.

$$
\begin{aligned}
& 29900 \mathrm{I}_{0} \quad+1 \mathrm{G}_{0}-1 \mathrm{~A}_{0} \leq 0 \\
& 29900 I_{1}-34300 I_{0}+1 G_{1}-1 G_{0}-1 A_{1}+1,08 A_{0}+E N+1,055 \cdot \mathrm{St}_{1} \leq 1828+9461+520 \\
& 29900 I_{2}-34300 I_{1}+1 G_{2}-1 G_{1}-1 A_{2}+1,08 A_{1}+E N+1,055 \cdot \mathrm{St}_{2} \leq 1828+9461+520 \\
& 29900 \mathrm{I}_{3}-34300 \mathrm{I}_{2}+1 \mathrm{G}_{3}-1 \mathrm{G}_{2}-1 \mathrm{~A}_{3}+1,08 \mathrm{~A}_{2}+\mathrm{EN}+1,055 \cdot \mathrm{St}_{3} \leq 1828+9461+520 \\
& 29900 I_{4}-34300 I_{3}+1 G_{4}-1 G_{3}-1 A_{4}+1,08 A_{3}+E N+1,055 \cdot \mathrm{St}_{4} \leq 1828+9461+520 \\
& 29900 I_{5}-34300 I_{4}+1 G_{5}-1 G_{4}-1 A_{5}+1,08 A_{4}+E N+1,055 \cdot \mathrm{St}_{5} \leq 1828+9461+520 \\
& 29900 \mathrm{I}_{6}-34300 \mathrm{I}_{5}+1 \mathrm{G}_{6}-1 \mathrm{G}_{5}-1 \mathrm{~A}_{6}+1,08 \mathrm{~A}_{5}+\mathrm{EN}+1,055 \cdot \mathrm{St}_{6} \leq 1828+9461+520 \\
& 29900 \mathrm{I}_{7}-34300 \mathrm{I}_{6}+1 \mathrm{G}_{7}-1 \mathrm{G}_{6}-1 \mathrm{~A}_{7}+1,08 \mathrm{~A}_{6}+\mathrm{EN}+1,055 \cdot \mathrm{St}_{7} \leq 1828+9461+520 \\
& 29900 I_{8}-34300 I_{7}+1 G_{8}-1 G_{7}-1 A_{8}+1,08 A_{7}+E N+1,055 \cdot \mathrm{St}_{8} \leq 1828+9461+520 \\
& 29900 I_{9}-34300 I_{8}+1 G_{9}-1 G_{8}-1 A_{9}+1,08 A_{8}+E N+1,055 \cdot \mathrm{St}_{9} \leq 1828+9461+520 \\
& -34300 \mathrm{I}_{9} \quad-1 \mathrm{G}_{9} \quad+1,08 \mathrm{~A}_{9}+28,36 \cdot \mathrm{EN}+1,055 \cdot \mathrm{St}_{10} \\
& \leq 1828+9461+520+(28,36-1) \cdot 1828
\end{aligned}
$$

Die Liquiditätsnebenbedingung für den Zeitpunkt des Planungshorizonts $t=10$ erfaßt neben dem periodenspezifischen Einkommen auch den Barwert der Überschüsse jenseits des Planungshorizonts. Im Basisprogramm bestehen diese annahmegemäß lediglich aus dem nichtselbständigen Einkommen $b_{t}$, alle übrigen Objekte enden in $t=10$. Auch eine Berechnung der Steuerlast ist über $\mathrm{t}=10$ hinaus weder erforderlich noch zielführend: Vom Gehalt wurde bereits die Einkommensteuer abgezogen und weitere steuerrelevante Objekte existieren jenseits von $t=10$ nicht. Die Steuerlast von $b_{t}$ ent-

${ }^{520}$ Wie bereits angemerkt, werden die Veränderungen im Vergleich zur jeweiligen Vorstufe in blauer Schrift hervorgehoben. 
spricht dem Korrekturfaktor der Steuervorauszahlungen. Nichtselbständiges Einkommen, Steuerlast und bereits abgeführte Steuern werden nur für $\mathrm{t}=10 \mathrm{erfaßt}$ und für den Zeitraum jenseits des Detailplanungshorizonts herausgekürzt. ${ }^{521}$

$$
\cdots+\underbrace{1,055 \cdot \mathrm{St}_{10}}_{\begin{array}{c}
\text { Veranlagte ESt } \\
\text { (Steuerbescheid) }
\end{array}} \leq \underbrace{1.828}_{\begin{array}{c}
\text { verfügbares } \\
\text { Einkommen }
\end{array}}+\underbrace{9.461+520}_{\begin{array}{c}
\text { bereits abgeführte } \\
\text { Lohnsteuer und SolZ }
\end{array}}+\cdots
$$

Jenseits des Detailplanungshorizonts wird der Fortbestand des Einkommens nach allen Abzügen mit folgendem Ausdruck berücksichtigt. Der um eins reduzierte Barwertfaktor bewirkt, daß das Einkommen von $\mathrm{t}=10$ nicht doppelt erfaßt wird.

$$
\ldots+(28,36-1) \cdot 1.828
$$

Die Ermittlung der Steuerlast beginnt mit einer Nebenbedingung, welche die Summe der Schattenobjekte jeder Periode in die vier Teilabschnitte der Bemessungsgrundlage überleitet, genannt $b g 1_{t}, b g 2_{t}, b g 3_{t}$ und bg $4_{t}$. Der exogene Zahlungsstrom $b_{t}$ aus nichtselbständiger Arbeit beinhaltet ein Schattenobjekt von 42.501 EUR. Die freiberufliche Tätigkeit führt bei vollständiger Durchführung zu steuerpflichtigen Einkünften von 4.400 EUR. Hinsichtlich der Kreditlinie A kann für jeden in Anspruch genommenen Euro der Zinsanteil von 0,08 EUR als Werbungskosten angesetzt werden.

$$
\begin{aligned}
& 42501+4400 \mathrm{I}_{0}-0,08 \mathrm{~A}_{0} \leq \mathrm{bg} 1_{1}+\mathrm{bg} 2_{1}+\mathrm{bg} 3_{1}+\mathrm{bg} 4_{1} \\
& 42501+4400 \mathrm{I}_{1}-0,08 \mathrm{~A}_{1} \leq \mathrm{bg} 1_{2}+\mathrm{bg} 2_{2}+\mathrm{bg} 3_{2}+\mathrm{bg} 4_{2} \\
& 42501+4400 \mathrm{I}_{2}-0,08 \mathrm{~A}_{2} \leq \mathrm{bg} 1_{3}+\mathrm{bg} 2_{3}+\mathrm{bg} 3_{3}+\mathrm{bg} 4_{3} \\
& 42501+4400 \mathrm{I}_{3}-0,08 \mathrm{~A}_{3} \leq \mathrm{bg} 1_{4}+\mathrm{bg} 2_{4}+\mathrm{bg} 3_{4}+\mathrm{bg} 4_{4} \\
& 42501+4400 \mathrm{I}_{4}-0,08 \mathrm{~A}_{4} \leq \mathrm{bg} 1_{5}+\mathrm{bg} 2_{5}+\mathrm{bg} 3_{5}+\mathrm{bg} 4_{5} \\
& 42501+4400 \mathrm{I}_{5}-0,08 \mathrm{~A}_{5} \leq \mathrm{bg} 1_{6}+\mathrm{bg} 2_{6}+\mathrm{bg} 3_{6}+\mathrm{bg} 4_{6} \\
& 42501+4400 \mathrm{I}_{6}-0,08 \mathrm{~A}_{6} \leq \mathrm{bg} 1_{7}+\mathrm{bg} 2_{7}+\mathrm{bg} 3_{7}+\mathrm{bg} 4_{7} \\
& 42501+4400 \mathrm{I}_{7}-0,08 \mathrm{~A}_{7} \leq \mathrm{bg} 1_{8}+\mathrm{bg} 2_{8}+\mathrm{bg} 3_{8}+\mathrm{bg} 4_{8} \\
& 42501+4400 \mathrm{I}_{8}-0,08 \mathrm{~A}_{8} \leq \mathrm{bg} 1_{9}+\mathrm{bg} 2_{9}+\mathrm{bg} 3_{9}+\mathrm{bg} 4_{9} \\
& 42501+4400 \mathrm{I}_{9}-0,08 \mathrm{~A}_{9} \leq \mathrm{bg} 1_{10}+\mathrm{bg} 2_{10}+\operatorname{bg} 3_{10}+\operatorname{bg} 4_{10}
\end{aligned}
$$

Auf die Ermittlung der periodenspezifischen Bemessungsgrundlage folgt die Berechnung der Steuerlast. Durch die vorgenannten Nebenbedingungen wurden die vier Teilabschnitte der Bemessungsgrundlage durch die Summe der genutzten Schattenobjekte befüllt. Die relative Steuerbelastung der Abschnitte, mathematisch ausgedrückt durch deren Steigungen, wurde bereits in Unterabschnitt 3.2.2.3 festgelegt. Durch deren Multiplikation mit der jeweiligen Auslastung errechnen folgende Nebenbedingungen die Steuerlast $\mathrm{St}_{\mathrm{t}}$ zur Weiterverwendung in den Liquiditätsnebenbedingungen:

$$
\begin{aligned}
& -\mathrm{St}_{1} \leq-0,046 \cdot \operatorname{bg} 1_{1}-0,2929 \cdot \operatorname{bg} 2_{1}-0,4178 \cdot \operatorname{bg} 3_{1}-0,45 \cdot \operatorname{bg} 4_{1} \\
& -\mathrm{St}_{2} \leq-0,046 \cdot \operatorname{bg} 1_{2}-0,2929 \cdot \operatorname{bg} 2_{2}-0,4178 \cdot \operatorname{bg} 3_{2}-0,45 \cdot \operatorname{bg} 4_{2} \\
& -\mathrm{St}_{3} \leq-0,046 \cdot \operatorname{bg} 1_{3}-0,2929 \cdot \operatorname{bg} 2_{3}-0,4178 \cdot \operatorname{bg} 3_{3}-0,45 \cdot \operatorname{bg} 4_{3} \\
& -\mathrm{St}_{4} \leq-0,046 \cdot \operatorname{bg} 1_{4}-0,2929 \cdot \operatorname{bg} 2_{4}-0,4178 \cdot \operatorname{bg} 3_{4}-0,45 \cdot \operatorname{bg} 4_{4} \\
& -\mathrm{St}_{5} \leq-0,046 \cdot \operatorname{bg} 1_{5}-0,2929 \cdot \operatorname{bg} 2_{5}-0,4178 \cdot \operatorname{bg} 3_{5}-0,45 \cdot \operatorname{bg} 4_{5}
\end{aligned}
$$

${ }^{521}$ Dieser Sachverhalt ist im Bewertungsprogramm von Bedeutung und wird dort wieder aufgegriffen. 
$-\mathrm{St}_{6} \leq-0,046 \cdot \mathrm{bg} 1_{6}-0,2929 \cdot \mathrm{bg} 2_{6}-0,4178 \cdot \operatorname{bg} 3_{6}-0,45 \cdot \operatorname{bg} 4_{6}$

$-\mathrm{St}_{7} \leq-0,046 \cdot \operatorname{bg} 1_{7}-0,2929 \cdot \operatorname{bg} 2_{7}-0,4178 \cdot \operatorname{bg} 3_{7}-0,45 \cdot \operatorname{bg} 4_{7}$

$-\mathrm{St}_{8} \leq-0,046 \cdot \mathrm{bg} 1_{8}-0,2929 \cdot \mathrm{bg} 2_{8}-0,4178 \cdot \operatorname{bg} 3_{8}-0,45 \cdot \operatorname{bg} 4_{8}$

$-\mathrm{St}_{9} \leq-0,046 \cdot \mathrm{bg} 1_{9}-0,2929 \cdot \mathrm{bg} 2_{9}-0,4178 \cdot \mathrm{bg} 3_{9}-0,45 \cdot \mathrm{bg} 4_{9}$

$-\mathrm{St}_{10} \leq-0,046 \cdot \mathrm{bg} 1_{10}-0,2929 \cdot \mathrm{bg} 2_{10}-0,4178 \cdot \mathrm{bg} 3_{10}-0,45 \cdot \mathrm{bg} 4_{10}$

Für die Teilabschnitte sind Ober- und Untergrenzen erforderlich. Die Untergrenze von null verhindert, daß der Algorithmus negative Abschnitte ansetzt oder miteinander verrechnet, um Steuerzahlungen zu umgehen. ${ }^{522}$ Obergrenzen sind erforderlich, damit der Algorithmus am Ende jedes Abschnitts zur jeweils nächsthöheren, teureren Tarifzone springt. Wie erwähnt entspricht die Obergrenze eines Abschnitts seiner Länge und nicht seiner oberen Einkommensgrenze. Für den letzten Abschnitt besteht keine Obergrenze, weil der Spitzensteuersatz von 45 Prozent für beliebig hohe Einkommen gilt.

$0 \leq \mathrm{bg} 1_{1}, \operatorname{bg} 1_{2}, \operatorname{bg} 1_{3}, \operatorname{bg} 1_{4}, \operatorname{bg} 1_{5}, \operatorname{bg} 1_{6}, \operatorname{bg} 1_{7}, \operatorname{bg} 1_{8}, \operatorname{bg} 1_{9}, \operatorname{bg} 1_{10} \leq 12.500$

$0 \leq \mathrm{bg} 2_{1}, \operatorname{bg} 2_{2}, \operatorname{bg} 2_{3}, \operatorname{bg} 2_{4}, \operatorname{bg} 2_{5}, \operatorname{bg} 2_{6}, \operatorname{bg} 2_{7}, \operatorname{bg} 2_{8}, \operatorname{bg} 2_{9}, \operatorname{bg} 2_{10} \leq 28.500$

$0 \leq \mathrm{bg} 3_{1}, \operatorname{bg} 3_{2}, \operatorname{bg} 3_{3}, \operatorname{bg} 3_{4}, \operatorname{bg} 3_{5}, \operatorname{bg} 3_{6}, \operatorname{bg} 3_{7}, \operatorname{bg} 3_{8}, \operatorname{bg} 3_{9}, \operatorname{bg} 3_{10} \leq 224.326$

$0 \leq \mathrm{bg}_{1}, \mathrm{bg}_{2}, \mathrm{bg}_{4}, \mathrm{bg} 4_{4}, \mathrm{bg} 4_{5}, \mathrm{bg} 4_{6}, \mathrm{bg} 4_{7}, \mathrm{bg} 4_{8}, \mathrm{bg} 4_{9}, \mathrm{bg} 4_{10}$

Nebenbedingungen für Obergrenzen und Nichtnegativität werden nicht verändert:

$0 \leq \mathrm{G}_{0}, \mathrm{G}_{1}, \mathrm{G}_{2}, \mathrm{G}_{3}, \mathrm{G}_{4}, \mathrm{G}_{5}, \mathrm{G}_{6}, \mathrm{G}_{7}, \mathrm{G}_{8}, \mathrm{G}_{9}$

$0 \leq \mathrm{I}_{0}, \mathrm{I}_{1}, \mathrm{I}_{2}, \mathrm{I}_{3}, \mathrm{I}_{4}, \mathrm{I}_{5}, \mathrm{I}_{6}, \mathrm{I}_{7}, \mathrm{I}_{8}, \mathrm{I}_{9} \leq 1$

$0 \leq A_{0}, A_{1}, A_{2}, A_{3}, A_{4}, A_{5}, A_{6}, A_{7}, A_{8}, A_{9} \leq 40.000$

$0 \leq \mathrm{EN}$

Zur Lösung des linearen Optimierungsansatzes wurde das Programm Lingo verwendet. Es ergibt sich ein optimaler Zielfunktionswert von 2.146,62 EUR. Nachfolgender VOFI zeigt diesen nebst allen Investitions- und Finanzierungsobjekten, die im optimalen Programm vorkommen. ${ }^{523}$ Weiterhin findet man im VOFI nicht nur die Durchführungshäufigkeit aller Objekte, sondern auch die detaillierte, periodenspezifische Steuerlast sowie den Saldo von Kreditlinien und Guthaben als fiktiven Kontostand.

Daß die Ergebnisse beachtlich vom Basisprogramm ohne Steuern abweichen, ist nicht verwunderlich. Die bisherige Modellierung war unvollständig und suggerierte Entnahmemöglichkeiten, die es gar nicht gibt, weil zwingende Kosten in Form der Einkommensteuer unberücksichtigt blieben. Die Breite des Entnahmestroms ohne Steuern lag bei 2.523 EUR jährlich, mit Berücksichtigung von Steuern jedoch nur noch bei 2.147 EUR. Dies zeigt die erheblichen Auswirkungen der Berücksichtigung von Steuern bereits bei einem verhältnismäßig geringen Steuersatz von ca. 23 Prozent.

\footnotetext{
${ }^{522}$ Eine gute Modellierung ist nicht nur notwendig, um Rechenzeit zu sparen, sondern auch, um falsche Ergebnisse zu vermeiden, vgl. SUHL/MELLOULI (2013), S. 96, ähnlich DANTZIG (1966), S. 40 ff.

${ }^{523}$ Es sei daran erinnert, daß die Nachkommastellen aller Ergebnisse gerundet wurden.
} 


\begin{tabular}{|c|c|c|c|c|c|c|c|c|c|c|c|}
\hline & $\mathbf{t}=\mathbf{0}$ & $\mathbf{t = 1}$ & $\mathbf{t}=\mathbf{2}$ & $\mathbf{t = 3}$ & $\mathbf{t = 4}$ & $\mathbf{t = 5}$ & $\mathbf{t}=\mathbf{6}$ & $\mathbf{t}=\mathbf{7}$ & $\mathbf{t = 8}$ & $\mathbf{t = 9}$ & $\begin{array}{l}\mathbf{t}=\mathbf{1 0} \& \\
\text { Barwert }\end{array}$ \\
\hline $\mathrm{EN}$ & - & -2147 & -2147 & -2147 & -2147 & -2147 & -2147 & -2147 & -2147 & -2147 & -60878 \\
\hline $\mathrm{I}_{\mathrm{t}}$ & -29900 & -29900 & -29900 & -29900 & -29900 & -29900 & -29900 & -29900 & -29900 & -29900 & - \\
\hline $\mathrm{I}_{\mathrm{t}-1}$ & - & 34300 & 34300 & 34300 & 34300 & 34300 & 34300 & 34300 & 34300 & 34300 & 34300 \\
\hline $\mathrm{G}_{\mathrm{t}}$ & 0 & 0 & 0 & 0 & 0 & 0 & 0 & 0 & 0 & 0 & - \\
\hline $\mathrm{G}_{\mathrm{t}-1}$ & - & 0 & 0 & 0 & 0 & 0 & 0 & 0 & 0 & 0 & 0 \\
\hline $\mathrm{A}_{\mathrm{t}}$ & 29900 & 29190 & 28448 & 27672 & 26862 & 26016 & 25132 & 24209 & 23244 & 22236 & - \\
\hline $\mathrm{A}_{\mathrm{t}-1}$ & - & -29900 & -29190 & -28448 & -27672 & -26862 & -26016 & -25132 & -24209 & -23244 & -22236 \\
\hline $\mathrm{A}(\mathrm{Zins})$ & - & -2392 & -2335 & -2276 & -2214 & -2149 & -2081 & -2011 & -1937 & -1859 & -1779 \\
\hline $\mathrm{b}_{\mathrm{t}}$ & - & 1828 & 1828 & 1828 & 1828 & 1828 & 1828 & 1828 & 1828 & 1828 & 51842 \\
\hline $\mathrm{St}_{\mathrm{t}}$ & - & -10389 & -10412 & -10437 & -10463 & -10490 & -10519 & -10548 & -10579 & -10611 & -10645 \\
\hline KorrSt & - & 9461 & 9461 & 9461 & 9461 & 9461 & 9461 & 9461 & 9461 & 9461 & 9461 \\
\hline SolZ & - & -571 & -573 & -574 & -575 & -577 & -579 & -580 & -582 & -584 & -585 \\
\hline KorrSolZ & - & 520 & 520 & 520 & 520 & 520 & 520 & 520 & 520 & 520 & 520 \\
\hline$\sum$ & 0 & 0 & 0 & 0 & 0 & 0 & 0 & 0 & 0 & 0 & 0 \\
\hline Konto & -29900 & -29190 & -28448 & -27672 & -26862 & -26016 & -25132 & -24209 & -23244 & -22236 & 0 \\
\hline
\end{tabular}

Tabelle 32: VOFI des optimalen Basisprogramms mit Steuern

Die freiberufliche Investition wird vollständig durchgeführt. Grenzobjekt ist in allen Perioden die Kreditlinie A. Sie dient auch hier zur Beschaffung der erforderlichen Investitionssumme, da in $\mathrm{t}=0$ keinerlei Anfangsvermögen zur Verfügung steht. Weil das Modell neben der einbehaltenen Lohnsteuer nun auch die von der freiberuflichen Tätigkeit hervorgerufene Steuerbelastung berücksichtigt, ergibt sich eine Mehrbelastung von etwa 400 EUR. Die Tilgung des Darlehens A erfolgt daher auch deutlich langsamer als im Fall ohne Steuern: In $t=9$ ist noch eine Restschuld von ca. 22.300 EUR vorhanden, verglichen mit ca. 13.500 EUR im Fall ohne Steuern.

Der Algorithmus gibt als Kuppelprodukt der optimalen Lösung zusätzlich auch die periodenspezifische Bemessungsgrundlage aus, welche auf zweierlei Weise ausgelesen werden kann: Tabelle 33 zeigt sie als summierte Auslastung der Teilabschnitte, während Tabelle 34 die Höhe der steuerrelevanten Schattenobjekte addiert. Der Vergleich beider Summen ermöglicht eine Überprüfung auf Fehler. Hier stimmt die Rechnung: Die Bemessungsgrundlage beider Rechenwege stimmt überein, ebenso wie der daraus errechnete Steuersatz. Man beachte die negative Bemessungsgrundlage des Kreditobjekts A: Abzugsfähige Schuldzinsen mindern die Bemessungsgrundlage.

\begin{tabular}{|c|c|c|c|c|c|c|c|c|c|c|c|}
\hline & $\mathbf{t}=\mathbf{0}$ & $\mathbf{t}=\mathbf{1}$ & $\mathbf{t = 2}$ & $\mathbf{t = 3}$ & $\mathbf{t = 4}$ & $\mathbf{t}=\mathbf{5}$ & $\mathbf{t}=\mathbf{6}$ & $\mathbf{t}=\mathbf{7}$ & $\mathbf{t}=\mathbf{8}$ & $\mathbf{t}=\mathbf{9}$ & $\mathbf{t}=\mathbf{1 0}$ \\
\hline bg $1_{\mathrm{t}}$ & - & 12500 & 12500 & 12500 & 12500 & 12500 & 12500 & 12500 & 12500 & 12500 & 12500 \\
\hline bg $2_{\mathrm{t}}$ & - & 28500 & 28500 & 28500 & 28500 & 28500 & 28500 & 28500 & 28500 & 28500 & 28500 \\
\hline bg $3_{\mathrm{t}}$ & - & 3509 & 3566 & 3625 & 3687 & 3752 & 3820 & 3890 & 3964 & 4042 & 4122 \\
\hline bg $4_{\mathrm{t}}$ & - & 0 & 0 & 0 & 0 & 0 & 0 & 0 & 0 & 0 & 0 \\
\hline$\sum \mathrm{bg}_{\mathrm{t}}$ & - & 44509 & 44566 & 44625 & 44687 & 44752 & 44820 & 44890 & 44964 & 45042 & 45122 \\
\hline $\mathrm{St}_{\mathrm{t}}$ & - & 10389 & 10412 & 10437 & 10463 & 10490 & 10519 & 10548 & 10579 & 10611 & 10645 \\
\hline $\mathrm{St}_{\mathrm{t}} \%$ & - & $23,34 \%$ & $23,36 \%$ & $23,39 \%$ & $23,41 \%$ & $23,44 \%$ & $23,47 \%$ & $23,50 \%$ & $23,53 \%$ & $23,56 \%$ & $23,59 \%$ \\
\hline
\end{tabular}

Tabelle 33: Bemessungsgrundlage, berechnet mit Interpolationsabschnitten 


\begin{tabular}{|c|c|c|c|c|c|c|c|c|c|c|c|}
\hline & $\mathbf{t}=\mathbf{0}$ & $\mathbf{t}=\mathbf{1}$ & $\mathbf{t}=\mathbf{2}$ & $\mathbf{t}=\mathbf{3}$ & $\mathbf{t}=\mathbf{4}$ & $\mathbf{t}=\mathbf{5}$ & $\mathbf{t}=\mathbf{6}$ & $\mathbf{t}=\mathbf{7}$ & $\mathbf{t}=\mathbf{8}$ & $\mathbf{t}=\mathbf{9}$ & $\mathbf{t}=\mathbf{1 0}$ \\
\hline $\mathrm{I}_{\mathrm{t}-1}$ & - & 4400 & 4400 & 4400 & 4400 & 4400 & 4400 & 4400 & 4400 & 4400 & 4400 \\
\hline $\mathrm{sr}_{\mathrm{At}-1}$ & - & -2392 & -2335 & -2276 & -2214 & -2149 & -2081 & -2011 & -1937 & -1859 & -1779 \\
\hline $\mathrm{sr}_{\mathrm{Bt}-1}$ & - & - & - & - & - & - & - & - & - & - & - \\
\hline $\mathrm{sr}_{\mathrm{bt}}$ & - & 42501 & 42501 & 42501 & 42501 & 42501 & 42501 & 42501 & 42501 & 42501 & 42501 \\
\hline$\sum \mathrm{sr}_{\mathrm{t}}$ & - & 44509 & 44566 & 44625 & 44687 & 44752 & 44820 & 44890 & 44964 & 45042 & 45122 \\
\hline $\mathrm{St}_{\mathrm{t}}$ & - & 10389 & 10412 & 10437 & 10463 & 10490 & 10519 & 10548 & 10579 & 10611 & 10645 \\
\hline $\mathrm{St}_{\mathrm{t}} \%$ & - & $23,34 \%$ & $23,36 \%$ & $23,39 \%$ & $23,41 \%$ & $23,44 \%$ & $23,47 \%$ & $23,50 \%$ & $23,53 \%$ & $23,56 \%$ & $23,59 \%$ \\
\hline
\end{tabular}

Tabelle 34: Bemessungsgrundlage, berechnet mit Schattenobjekten

\subsubsection{Ermittlung des optimalen Bewertungsprogramms}

Die Zielfunktion zur Ermittlung des optimalen Bewertungsprogramms unterscheidet sich nicht von der Modellvariante ohne Steuern, weil der zu maximierende Wert nach wie vor der Grenzpreis einschließlich Transaktionskosten ist:

$\max . \mathrm{U} ; \mathrm{U}:=\mathrm{p}$

Abschreibungen sind nur auf den Gebäudeanteil des Kaufpreises erlaubt, daher ist eine künstliche Aufspaltung des Grenzpreises erforderlich. Der benötigte Faktor wurde bereits ermittelt und beträgt 61,8 Prozent des Grenzpreises einschließlich Transaktionskosten. ${ }^{524}$ Multipliziert mit der jährlichen Abschreibung von zwei Prozent ergibt sich eine jährliche Abschreibung in Höhe von 0,618 0,02 = 0,01236, also 1,236 Prozent des Grenzpreises inkl. Transaktionskosten.

Damit der Grenzpreis zur Vorbereitung der Verhandlung nicht manuell um Transaktionskosten bereinigt werden muß, ist folgende Nebenbedingung hilfreich, weil der Simplexalgorithmus im Rahmen der Lösung ohnehin die Werte aller Variablen im Ergebnistableau ausgibt:

$$
\mathrm{p}_{\mathrm{oT}}=\frac{\mathrm{p}}{1,08}
$$

Um der Verschlechterung der Lesbarkeit aufgrund der zunehmenden Anzahl an Variablen entgegenzuwirken, wurde das frei verfügbare Einkommen in den Liquiditätsnebenbedingungen mit den Steuer-Korrekturfaktoren zu $1.828+9.461+520=11.809$ zusammengefaßt.

Wie bereits in der Modellvariante ohne Steuern werden die Liquiditätsnebenbedingungen um den Zahlungsstrom des Bewertungsobjekts und um die immobilienbezogene Kreditlinie B ergänzt. In der ersten Periode wird die Auszahlung in Höhe des Grenzpreises erfaßt. Auf der rechten Seite aller Liquiditätsnebenbedingungen werden Mietüberschüsse in Höhe von 3.536,10 EUR hinzugefügt.

${ }^{524} \mathrm{Vgl}$. Unterabschnitt 3.3.1.2. 


$$
\begin{aligned}
& 29900 \mathrm{I}_{0} \quad+1 \mathrm{G}_{0}-1 \mathrm{~A}_{0} \quad-1 \mathrm{~B}_{0} \quad+\mathrm{p} \leq 0 \\
& 29900 \mathrm{I}_{1}-34300 \mathrm{I}_{0}+1 \mathrm{G}_{1}-1 \mathrm{G}_{0}-1 \mathrm{~A}_{1}+1,08 \mathrm{~A}_{0}-1 \mathrm{~B}_{1}+1,01 \mathrm{~B}_{0}+\mathrm{EN}+1,055 \cdot \mathrm{St}_{1} \leq 11809+3536,1 \\
& 29900 \mathrm{I}_{2}-34300 \mathrm{I}_{1}+1 \mathrm{G}_{2}-1 \mathrm{G}_{1}-1 \mathrm{~A}_{2}+1,08 \mathrm{~A}_{1}-1 \mathrm{~B}_{2}+1,01 \mathrm{~B}_{1}+\mathrm{EN}+1,055 \cdot \mathrm{St}_{2} \leq 11809+3536,1 \\
& 29900 \mathrm{I}_{3}-34300 \mathrm{I}_{2}+1 \mathrm{G}_{3}-1 \mathrm{G}_{2}-1 \mathrm{~A}_{3}+1,08 \mathrm{~A}_{2}-1 \mathrm{~B}_{3}+1,01 \mathrm{~B}_{2}+\mathrm{EN}+1,055 \cdot \mathrm{St}_{3} \leq 11809+3536,1 \\
& 29900 \mathrm{I}_{4}-34300 \mathrm{I}_{3}+1 \mathrm{G}_{4}-1 \mathrm{G}_{3}-1 \mathrm{~A}_{4}+1,08 \mathrm{~A}_{3}-1 \mathrm{~B}_{4}+1,01 \mathrm{~B}_{3}+\mathrm{EN}+1,055 \cdot \mathrm{St}_{4} \leq 11809+3536,1 \\
& 29900 \mathrm{I}_{5}-34300 \mathrm{I}_{4}+1 \mathrm{G}_{5}-1 \mathrm{G}_{4}-1 \mathrm{~A}_{5}+1,08 \mathrm{~A}_{4}-1 \mathrm{~B}_{5}+1,01 \mathrm{~B}_{4}+\mathrm{EN}+1,055 \cdot \mathrm{St}_{5} \leq 11809+3536,1 \\
& 29900 \mathrm{I}_{6}-34300 \mathrm{I}_{5}+1 \mathrm{G}_{6}-1 \mathrm{G}_{5}-1 \mathrm{~A}_{6}+1,08 \mathrm{~A}_{5}-1 \mathrm{~B}_{6}+1,01 \mathrm{~B}_{5}+\mathrm{EN}+1,055 \cdot \mathrm{St}_{6} \leq 11809+3536,1 \\
& 29900 \mathrm{I}_{7}-34300 \mathrm{I}_{6}+1 \mathrm{G}_{7}-1 \mathrm{G}_{6}-1 \mathrm{~A}_{7}+1,08 \mathrm{~A}_{6}-1 \mathrm{~B}_{7}+1,01 \mathrm{~B}_{6}+\mathrm{EN}+1,055 \cdot \mathrm{St}_{7} \leq 11809+3536,1 \\
& 29900 \mathrm{I}_{8}-34300 \mathrm{I}_{7}+1 \mathrm{G}_{8}-1 \mathrm{G}_{7}-1 \mathrm{~A}_{8}+1,08 \mathrm{~A}_{7}-1 \mathrm{~B}_{8}+1,01 \mathrm{~B}_{7}+\mathrm{EN}+1,055 \cdot \mathrm{St}_{8} \leq 11809+3536,1 \\
& 29900 \mathrm{I}_{9}-34300 \mathrm{I}_{8}+1 \mathrm{G}_{9}-1 \mathrm{G}_{8}-1 \mathrm{~A}_{9}+1,08 \mathrm{~A}_{8}-1 \mathrm{~B}_{9}+1,01 \mathrm{~B}_{8}+\mathrm{EN}+1,055 \cdot \mathrm{St}_{9} \leq 11809+3536,1 \\
& -34300 \mathrm{I}_{9} \quad-1 \mathrm{G}_{9} \quad+1,08 \mathrm{~A}_{9} \quad+1,01 \mathrm{~B}_{9}+28,36 \cdot \mathrm{EN}+1,055 \cdot \mathrm{St}_{10} \\
& +(28,36-1) \cdot 1,055 \cdot \mathrm{St}_{\mathrm{d}} \leq 28,36 \cdot(11809+3536,1)
\end{aligned}
$$

Bei der Ermittlung des Bewertungsprogramms ist eine Berücksichtigung der Steuerlast auch jenseits der Detailplanungsphase erforderlich. Die vom Zielfunktionswert abhängige, nicht zahlungswirksame Abschreibung zwingt ebenso zur Berechnung der Steuerlast jenseits des Planungshorizonts wie auch die steuerpflichtigen Mietüberschüsse. Lediglich im Basisprogramm war es möglich, auf die Berechnung zu verzichten, weil nur bei der nichtselbständigen Arbeit bereits eine Steuervorauszahlung in Form von Lohnsteuer abgeführt wurde, und weil nur diese im Basisprogramm jenseits des Planungshorizontes zu finden war. Es ist sinnvoll, eine pauschalisierende durchschnittliche Steuerlast $\mathrm{St}_{\mathrm{d}}$ für die 40 Perioden der Grobplanungsphase anzusetzen, weil auch sämtliche Zahlungsströme der Perioden nach $t=10$ pauschalisiert als Barwert erfaßt werden. Die freiberufliche Tätigkeit endet in $t=10$ und die Mietüberschüsse sind in jedem Jahr ebenso identisch wie die Abschreibung. Daher wird für alle Perioden jenseits des zehnten Jahres eine gleichbleibende, durchschnittliche Steuerbemessungsgrundlage herangezogen, bestehend aus Mietüberschüssen, Abschreibung und Einkommen aus nichtselbständiger Tätigkeit. ${ }^{525}$ Ebenso kontinuierlich werden die Korrekturfaktoren für die bereits einbehaltene Lohnsteuer nebst Solidaritätszuschlag als Gegengewicht zu St $t_{d}$ angewandt, damit es nicht zu fälschlichen Doppelerfassungen kommt. Der Zinssatz des Barwertfaktors am Ende des Planungshorizonts repräsentiert den geschätzten Grenzzinsfuß und damit auch Kreditgeschäfte aller 40 Jahre jenseits des Planungshorizonts, weil Kredit- und Geldanlageobjekte explizit nur bis zur zehnten Periode modelliert wurden. Die Erfassung der Einkommensteuer in der letzten Liquiditätsnebenbedingung erfolgt zweigliedrig. Der Ausdruck

$\ldots+1,055 \cdot \mathrm{St}_{10}+\cdots$

erfaßt die Steuerlast der zehnten Periode, während der Faktor (28,36-1) zum Ansatz der pauschalen Steuerlast für die Zeit jenseits des Planungshorizonts dient:

$\ldots+(28,36-1) \cdot 1,055 \cdot \mathrm{St}_{\mathrm{d}} \leq \ldots$

${ }^{525}$ Auch eine explizite Modellierung der Steuerlast aller 50 Perioden ist möglich, vgl. Unterkapitel 4.4. 
Die Zahlungsströme aus Vermietung und Verpachtung bzw. aus nichtselbständiger Arbeit bestehen über $\mathrm{t}=10$ hinaus fort und werden in der letzten Liquiditätsnebenbedingung mit dem Faktor 28,36 übergreifend erfaßt, weil dieser für die letzte Periode sowie für die gesamte Grobplanungsphase gilt:

$\ldots \leq 28,36 \cdot(11.809+3.536,10)$

Die Nebenbedingungen zur Berechnung der Bemessungsgrundlage werden um den steuerrelevanten Teil des Bewertungsobjekts sowie um Schuldzinsen der Kreditlinie B ergänzt. Der steuerrelevante Anteil der Mietüberschüsse beträgt 3.461,10 EUR. Dieser Überschuß beinhaltet keine Abschreibungen. Diese wurden als eigenständiges Objekt abgebildet und von den übrigen steuerrelevanten Mieteinkünften getrennt, weil sie mit dem Zielfunktionswert verknüpft sind.

Wie bereits erwähnt, haben nur die nichtselbständige Tätigkeit und die Mieteinnahmen über $\mathrm{t}=10$ hinaus Bestand und fließen in eine fiktive Bemessungsgrundlage ein, welche die Steuerlast für alle 40 Perioden jenseits des Planungshorizonts determiniert. ${ }^{526}$

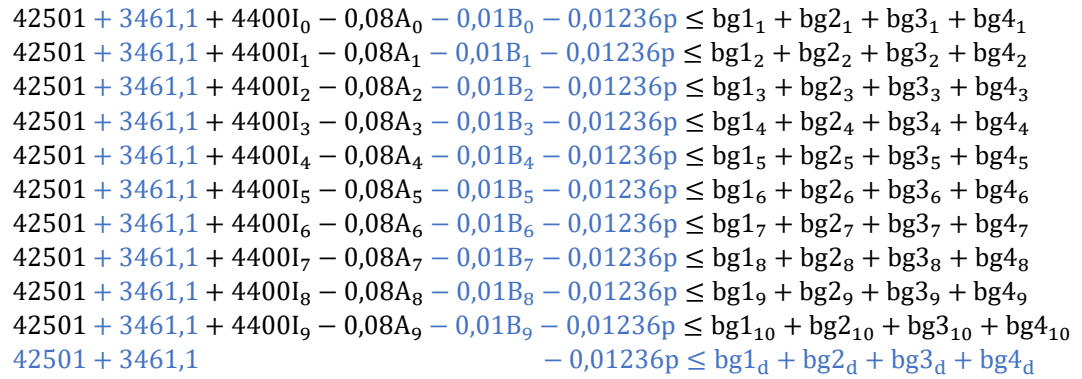

Die Berechnung der periodenspezifischen Steuerlast unterscheidet sich ebensowenig vom Basisprogramm wie die Größe der Intervallabschnitte. Zwar beinhalten die vorgenannten Nebenbedingungen zusätzliche Schattenobjekte, die Steuerberechnung greift aber nur auf die rechten Seiten dieser Nebenbedingungen zurück, welche keinen Verän-

\footnotetext{
${ }^{526}$ Alternativ wurde eine Modellierung versucht, bei welcher die Steuerlast der zweiten Phase aus dem Durchschnitt der Steuerlast der ersten zehn Perioden hervorging. Dieser Ansatz scheiterte aufgrund des hohen Gewichts des Barwertfaktors. Der Algorithmus versuchte, in der ersten Phase möglichst hohe Kosten und somit niedrige Steuerlasten für die Folgeperioden zu erzeugen, um in den letzten 40 Perioden die überproportional vorteilhafte Wirkung von deren Fortschreibung zu nutzen. Beim Versuch, dies zu modellieren, unterblieb die - eigentlich lohnende - freiberufliche Tätigkeit, weil ihre Gewinne auch die Steuerlast der zweiten Phase steigerten. Der Algorithmus reizte sogar die (mangels freiberuflicher Tätigkeit) überhaupt nicht benötigte Kreditlinie A vollständig aus, um die nachteilige steuerliche Wirkung der Zinskosten in den ersten zehn Perioden für steuerliche Vorteile in den späteren 40 Perioden zu nutzen.
} 
derungen unterliegen. Lediglich den nachfolgenden Nebenbedingungen muß eine zusätzliche Ungleichung für die Durchschnittsperiode hinzuzufügt werden, deren Steuerlast auf die gesamte Grobplanungsphase angewendet wird. ${ }^{527}$

$-\mathrm{St}_{1} \leq-0,046 \cdot \mathrm{bg} 1_{1}-0,2929 \cdot \mathrm{bg} 2_{1}-0,4178 \cdot \mathrm{bg} 3_{1}-0,45 \cdot \mathrm{bg} 4_{1}$
$-\mathrm{St}_{2} \leq-0,046 \cdot \mathrm{bg} 1_{2}-0,2929 \cdot \mathrm{bg} 2_{2}-0,4178 \cdot \mathrm{bg} 3_{2}-0,45 \cdot \mathrm{bg} 4_{2}$
$-\mathrm{St}_{3} \leq-0,046 \cdot \mathrm{bg} 1_{3}-0,2929 \cdot \mathrm{bg} 2_{3}-0,4178 \cdot \mathrm{bg} 3_{3}-0,45 \cdot \mathrm{bg} 4_{3}$
$-\mathrm{St}_{4} \leq-0,046 \cdot \mathrm{bg} 1_{4}-0,2929 \cdot \mathrm{bg} 2_{4}-0,4178 \cdot \mathrm{bg} 3_{4}-0,45 \cdot \mathrm{bg} 4_{4}$
$-\mathrm{St}_{5} \leq-0,046 \cdot \mathrm{bg} 1_{5}-0,2929 \cdot \mathrm{bg} 2_{5}-0,4178 \cdot \mathrm{bg} 3_{5}-0,45 \cdot \mathrm{bg} 4_{5}$
$-\mathrm{St}_{6} \leq-0,046 \cdot \mathrm{bg} 1_{6}-0,2929 \cdot \mathrm{bg} 2_{6}-0,4178 \cdot \mathrm{bg} 3_{6}-0,45 \cdot \mathrm{bg} 4_{6}$
$-\mathrm{St}_{7} \leq-0,046 \cdot \mathrm{bg} 1_{7}-0,2929 \cdot \mathrm{bg} 2_{7}-0,4178 \cdot \mathrm{bg} 3_{7}-0,45 \cdot \mathrm{bg} 4_{7}$
$-\mathrm{St}_{8} \leq-0,046 \cdot \mathrm{bg} 1_{8}-0,2929 \cdot \mathrm{bg} 2_{8}-0,4178 \cdot \mathrm{bg} 3_{8}-0,45 \cdot \mathrm{bg} 4_{8}$
$-\mathrm{St}_{9} \leq-0,046 \cdot \mathrm{bg} 1_{9}-0,2929 \cdot \mathrm{bg} 2_{9}-0,4178 \cdot \mathrm{bg} 3_{9}-0,45 \cdot \mathrm{bg} 4_{9}$
$-\mathrm{St}_{10} \leq-0,046 \cdot \operatorname{bg} 1_{10}-0,2929 \cdot \mathrm{bg} 2_{10}-0,4178 \cdot \mathrm{bg} 3_{10}-0,45 \cdot \mathrm{bg} 4_{10}$
$-\mathrm{St}_{\mathrm{d}} \leq-0,046 \cdot \operatorname{bg} 1_{\mathrm{d}}-0,2929 \cdot \mathrm{bg} 2_{\mathrm{d}}-0,4178 \cdot \mathrm{bg} 3_{\mathrm{d}}-0,45 \cdot \mathrm{bg} 4_{\mathrm{d}}$

Die Intervallgrenzen der Bemessungsgrundlage gelten nun zusätzlich für die Periode d, welche pauschal auf die gesamte Grobplanungsphase wirkt.

$0 \leq \operatorname{bg} 1_{1}, \operatorname{bg} 1_{2}, \operatorname{bg} 1_{3}, \operatorname{bg} 1_{4}, \operatorname{bg} 1_{5}, \operatorname{bg} 1_{6}, \operatorname{bg} 1_{7}, \operatorname{bg} 1_{8}, \operatorname{bg} 1_{9}, \operatorname{bg} 1_{10}, \operatorname{bg} 1_{d} \leq 12.500$

$0 \leq \operatorname{bg} 2_{1}, \operatorname{bg} 2_{2}, \operatorname{bg} 2_{3}, \operatorname{bg} 2_{4}, \operatorname{bg} 2_{5}, \operatorname{bg} 2_{6}, \operatorname{bg} 2_{7}, \operatorname{bg} 2_{8}, \operatorname{bg} 2_{9}, \operatorname{bg} 2_{10}, \operatorname{bg} 2_{d} \leq 28.500$

$0 \leq \mathrm{bg} 3_{1}, \mathrm{bg} 3_{2}, \mathrm{bg} 3_{3}, \mathrm{bg} 3_{4}, \operatorname{bg} 3_{5}, \operatorname{bg} 3_{6}, \mathrm{bg} 3_{7}, \operatorname{bg} 3_{8}, \operatorname{bg} 3_{9}, \operatorname{bg} 3_{10}, \operatorname{bg} 3_{\mathrm{d}} \leq 224.326$

$0 \leq \mathrm{bg} 4_{1}, \mathrm{bg} 4_{2}, \mathrm{bg} 4_{3}, \mathrm{bg} 4_{4}, \mathrm{bg} 4_{5}, \mathrm{bg} 4_{6}, \mathrm{bg} 4_{7}, \mathrm{bg} 4_{8}, \mathrm{bg} 4_{9}, \mathrm{bg} 4_{10}, \mathrm{bg} 4_{\mathrm{d}}$

Hinsichtlich der Obergrenzen- und Nichtnegativitätsbedingungen treten, wie bereits im Fall ohne Steuern, weitere Restriktionen hinzu.

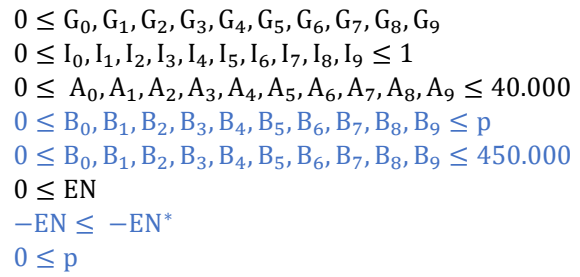

Die Höhe der Kreditlinie B ist auf den Grenzpreis oder auf 450.000 EUR beschränkt, je nachdem, was niedriger ist. Auch die Nebenbedingung, daß der Entnahmestrom den Wert aus dem Basisprogramm nicht unterschreiten darf, ist bereits aus dem Modell ohne Steuern bekannt. Der nachfolgende VOFI zeigt den optimalen Zielfunktionswert und die Durchführungshäufigkeiten der Investitions- und Finanzierungsobjekte im optimalen Programm.

Es ergibt sich ein Grenzpreis einschließlich Erwerbsnebenkosten in Höhe von 90.431 EUR. Die zweiprozentige Abschreibung, die sich auf seinen Gebäudeanteil bezieht, beträgt 1.118 EUR p.a. Zur Nutzung in der Verhandlungssituation muß der Investor diese Summe noch um acht Prozent Transaktionskosten bereinigen. Es verbleiben 83.732

${ }^{527}$ Diese dient der Steuerberechnung eines durchschnittlichen Jahres und wird dann in den Liquiditätsnebenbedingungen mit dem Barwertfaktor multipliziert. Der Barwertfaktor 28,36 geht weder in die Nebenbedingungen zur Berechnung der Bemessungsgrundlage noch der Steuerlast ein. 
EUR, die er dem Verkäufer maximal bieten kann. Da der Kaufpreis in einer Summe an den Verkäufer zu entrichten ist, spielt die Aufteilung auf Gebäude- und Grundstücksanteil keine Rolle.

Im VOFI kann man erkennen, daß die zinsgünstige Kreditlinie B erwartungsgemäß zur Finanzierung des Bewertungsobjekts verwendet wird. Die Breite des Entnahmestroms beträgt unverändert 2.147 EUR und die freiberufliche Tätigkeit wird ebenfalls in allen Perioden in vollem Umfang ausgeführt.

Kreditlinie B ist auf die Höhe des Grenzpreises beschränkt, und kann nur als Immobilienkredit verwendet werden. Für die Erstinvestition in die freiberufliche Tätigkeit muß in $\mathrm{t}=0$ die teurere Kreditlinie A beansprucht werden. Es ist jedoch keine Nebenbedingung für die Darlehenstilgung definiert worden, daher gilt diese Beschränkung nur für die Kreditaufnahme. Um die Überschüsse optimal zu nutzen, tilgt der Algorithmus so viel wie möglich von der verhältnismäßig teuren Kreditlinie A. ${ }^{528}$ Aufgrund der höheren Zinskosten erfolgen zunächst ausschließlich Tilgungen der teureren Kreditlinie A. Bevor diese in $\mathrm{t}=10$ vollständig zurückgeführt ist, sieht der Algorithmus keine Verpflichtung, auch nur einen Cent von Kreditlinie B zu tilgen; die Restschuld von Kreditlinie B bleibt neun Jahre lang unverändert. Die hinzugetretenen Mietüberschüsse ermöglichen einen deutlich schnelleren Schuldenabbau verglichen mit dem Basisprogramm. Ihnen steht jedoch eine jährliche Zinsbelastung von ca. 904 EUR aufgrund Kreditlinie B entgegen, die es im Basisprogramm nicht gab. Da die Zinsbelastung der Kreditlinie A sukzessive abnimmt, entfallen Werbungskosten, und die Steuerlast steigt pro Jahr um ca. 100 EUR. ${ }^{529}$

${ }^{528}$ Die Orientierung am Engpaß, verkörpert in Form des Zinsfußes, gewährleistet eine richtige Kapitalnutzung an der Stelle, wo sie den optimalen Nutzen bringt. Daher spricht man auch von der optimalen Geltungszahl, vgl. SCHMALENBACH (1947), S. 85. Ähnlich GUTENBERG (1983), S. 165, der anmerkt, daß Engpässe die Gesamtplanung - zumindest kurzfristig - regulieren.

${ }^{529}$ Dies ist aber nicht entscheidend, weil nach Abzug von Steuern noch immer ein größerer Vorteil verbleibt. Selbst bei Anwendbarkeit des Spitzensteuersatzes kann man maximal 45 Prozent der Zinskosten über den steuerlichen Weg zurückholen, aber 55 Prozent oder mehr blieben für immer verloren, vgl. RENNERT (2012), S. 87. 


\begin{tabular}{|c|c|c|c|c|c|c|c|c|c|c|c|}
\hline & $\mathbf{t}=\mathbf{0}$ & $t=1$ & $t=2$ & $\mathbf{t}=\mathbf{3}$ & $t=4$ & $t=5$ & $t=6$ & $t=7$ & $t=8$ & $t=9$ & \begin{tabular}{|l|}
$t=10 \&$ \\
Barwert
\end{tabular} \\
\hline $\mathrm{p}$ & -90431 & - & - & - & - & - & - & - & - & - & - \\
\hline EN & - & -2147 & -2147 & -2147 & -2147 & -2147 & -2147 & -2147 & -2147 & $\mid-2147$ & \begin{tabular}{|l|}
-60878 \\
\end{tabular} \\
\hline $\mathrm{I}_{\mathrm{t}}$ & -29900 & -29900 & \begin{tabular}{|l|}
-29900 \\
\end{tabular} & -29900 & -29900 & -29900 & -29900 & -29900 & -29900 & -29900 & - \\
\hline $\mathrm{I}_{\mathrm{t}-1}$ & - & 34300 & 34300 & 34300 & 34300 & 34300 & 34300 & 34300 & 34300 & 34300 & 34300 \\
\hline $\mathrm{G}_{\mathrm{t}}$ & 0 & 0 & 0 & 0 & 0 & 0 & 0 & 0 & 0 & 0 & - \\
\hline $\mathrm{G}_{\mathrm{t}-1}$ & - & 0 & 0 & 0 & 0 & 0 & 0 & 0 & 0 & 0 & 0 \\
\hline $\mathrm{A}_{\mathrm{t}}$ & 29900 & 27192 & 24363 & 21408 & 18320 & 15094 & 11724 & 8203 & 4525 & 682 & - \\
\hline$A_{t-1}$ & - & -29900 & -27192 & -24363 & -21408 & -18320 & -15094 & -11724 & -8203 & -4525 & -682 \\
\hline A (Zins) & - & -2392 & -2175 & -1949 & -1713 & -1466 & -1208 & -938 & -656 & -362 & -55 \\
\hline $\mathrm{B}_{\mathrm{t}}$ & 90431 & 90431 & 90431 & 90431 & 90431 & 90431 & 90431 & 90431 & 90431 & 90431 & - \\
\hline $\mathrm{B}_{\mathrm{t}-1}$ & - & -90431 & -90431 & -90431 & -90431 & -90431 & -90431 & \begin{tabular}{|l|}
-90431 \\
\end{tabular} & -90431 & \begin{tabular}{|l|}
-90431 \\
\end{tabular} & -90431 \\
\hline B (Zins) & - & -904 & -904 & -904 & -904 & -904 & -904 & -904 & -904 & -904 & -904 \\
\hline $\mathrm{b}_{\mathrm{t}}$ & - & 1828 & 1828 & 1828 & 1828 & 1828 & 1828 & 1828 & 1828 & 1828 & 51842 \\
\hline $\mathrm{g}_{\mathrm{Kt}}$ & - & 3536 & 3536 & 3536 & 3536 & 3536 & 3536 & 3536 & \begin{tabular}{|l|}
3536 \\
\end{tabular} & 3536 & 100284 \\
\hline $\mathrm{St}_{\mathrm{t}}$ & - & \begin{tabular}{|l|}
-10990 \\
\end{tabular} & \begin{tabular}{|l|}
-11080 \\
\end{tabular} & -111175 & -11274 & -11377 & -11485 & -11597 & -11715 & -11838 & -300035 \\
\hline KorrSt $_{t}$ & - & 9461 & 9461 & 9461 & 9461 & 9461 & 9461 & 9461 & 9461 & 9461 & 268314 \\
\hline SolZ & - & -604 & -609 & -615 & -620 & -626 & -632 & -638 & -644 & -651 & -16502 \\
\hline KorrSolZ $_{t}$ & - & 520 & 520 & 520 & 520 & 520 & 520 & 520 & 520 & 520 & 14747 \\
\hline$\sum$ & 0 & 0 & 0 & 0 & 0 & 0 & 0 & 0 & 0 & 0 & 0 \\
\hline Konto & 20331 & -117623 & -114794 & -111839 & 0875 & 0552 & 10215 & -98634 & -9495 & \begin{tabular}{|l|l|}
-9113 \\
\end{tabular} & 0 \\
\hline
\end{tabular}

Tabelle 35: VOFI des optimalen Bewertungsprogramms mit Steuern

Auch im Bewertungsprogramm gibt der Algorithmus mit der Lösung die steuerlichen Bemessungsgrundlagen aller Perioden aus. Diese lassen sich entweder aus der Summe der Intervallabschnitte oder aus der Summe aller Schattenobjekte errechnen. Sie sind nebst Steuerlast in den folgenden Tabellen abgebildet.

\begin{tabular}{|c|c|c|c|c|c|c|c|c|c|c|c|}
\hline & $\mathbf{t}=\mathbf{0}$ & $\mathbf{t}=\mathbf{1}$ & $\mathbf{t}=\mathbf{2}$ & $\mathbf{t = 3}$ & $\mathbf{t}=\mathbf{4}$ & $\mathbf{t}=\mathbf{5}$ & $\mathbf{t}=\mathbf{6}$ & $\mathbf{t}=\mathbf{7}$ & $\mathbf{t}=\mathbf{8}$ & $\mathbf{t}=\mathbf{9}$ & $\mathbf{t}=\mathbf{1 0}$ \\
\hline $\mathrm{bg} 1_{\mathrm{t}}$ & - & 12500 & 12500 & 12500 & 12500 & 12500 & 12500 & 12500 & 12500 & 12500 & 12500 \\
\hline $\mathrm{bg} 2_{\mathrm{t}}$ & - & 28500 & 28500 & 28500 & 28500 & 28500 & 28500 & 28500 & 28500 & 28500 & 28500 \\
\hline $\mathrm{bg} 3_{\mathrm{t}}$ & - & 4948 & 5165 & 5391 & 5627 & 5874 & 6133 & 6402 & 6684 & 6978 & 7286 \\
\hline $\mathrm{bg}_{\mathrm{t}}$ & - & 0 & 0 & 0 & 0 & 0 & 0 & 0 & 0 & 0 & 0 \\
\hline$\sum \mathrm{bg}_{\mathrm{t}}$ & - & 45948 & 46165 & 46391 & 46627 & 46874 & 47133 & 47402 & 47684 & 47978 & 48286 \\
\hline $\mathrm{St}_{\mathrm{t}}$ & - & 10990 & 11080 & 11175 & 11274 & 11377 & 11485 & 11597 & 11715 & 11838 & 11967 \\
\hline $\mathrm{St}_{\mathrm{t}} \%$ & - & $23,92 \%$ & $24,00 \%$ & $24,09 \%$ & $24,18 \%$ & $24,27 \%$ & $24,37 \%$ & $24,47 \%$ & $24,57 \%$ & $24,67 \%$ & $24,78 \%$ \\
\hline
\end{tabular}

Tabelle 36: Bemessungsgrundlage, berechnet mit Interpolationsabschnitten

\begin{tabular}{|c|c|c|c|c|c|c|c|c|c|c|c|}
\hline & $\mathbf{t}=\mathbf{0}$ & $\mathbf{t}=\mathbf{1}$ & $\mathbf{t = 2}$ & $\mathbf{t = 3}$ & $\mathbf{t = 4}$ & $\mathbf{t = 5}$ & $\mathbf{t = 6}$ & $\mathbf{t = 7}$ & $\mathbf{t = 8}$ & $\mathbf{t = 9}$ & $\mathbf{t = 1 0}$ \\
\hline $\mathrm{sr}_{\mathrm{It}-1}$ & - & 4400 & 4400 & 4400 & 4400 & 4400 & 4400 & 4400 & 4400 & 4400 & 4400 \\
\hline $\mathrm{sr}_{\mathrm{At}-1}$ & - & -2392 & -2175 & -1949 & -1713 & -1466 & -1208 & -938 & -656 & -362 & -55 \\
\hline $\mathrm{sr}_{\mathrm{Bt}-1}$ & - & -904 & -904 & -904 & -904 & -904 & -904 & -904 & -904 & -904 & -904 \\
\hline $\mathrm{sr}_{\mathrm{bt}}$ & - & 42501 & 42501 & 42501 & 42501 & 42501 & 42501 & 42501 & 42501 & 42501 & 42501 \\
\hline $\mathrm{sr}_{\mathrm{Kt}}$ & - & 3461,1 & 3461,1 & 3461,1 & 3461,1 & 3461,1 & 3461,1 & 3461,1 & 3461,1 & 3461,1 & 3461,1 \\
\hline $\mathrm{AfA}$ & - & -1118 & -1118 & -1118 & -1118 & -1118 & -1118 & -1118 & -1118 & -1118 & -1118 \\
\hline$\sum \mathrm{sr}_{\mathrm{t}}$ & - & 45948 & 46165 & 46391 & 46627 & 46874 & 47133 & 47402 & 47684 & 47978 & 48286 \\
\hline $\mathrm{St}_{\mathrm{t}}$ & - & 10990 & 11080 & 11175 & 11274 & 11377 & 11485 & 11597 & 11715 & 11838 & 11967 \\
\hline $\mathrm{St}_{\mathrm{t}} \%$ & - & $23,92 \%$ & $24,00 \%$ & $24,09 \%$ & $24,18 \%$ & $24,27 \%$ & $24,37 \%$ & $24,47 \%$ & $24,57 \%$ & $24,67 \%$ & $24,78 \%$ \\
\hline
\end{tabular}

Tabelle 37: Bemessungsgrundlage, berechnet mit Schattenobjekten 
Die im Vergleich zum Basisprogramm hinzugetretenen Mietüberschüsse in Höhe von 3.461,10 EUR sind höher als die Summe aus Abschreibung und Zinsen aus dem Immobilienkredit, welche gemeinsam etwa 2.000 EUR p.a. ausmachen. Diese wirken der steuerlichen Belastung 50 Jahre lang zumindest dämpfend entgegen. So kommt es insgesamt $\mathrm{zu}$ einer Steigerung der steuerlichen Bemessungsgrundlage um Werte zwischen ca. 1.500 EUR (in $t=1$ ) und 3.100 EUR (in $t=10$ ), und die Steuerlast steigt um einen Betrag zwischen ca. 600 EUR (in $t=1$ ) und 1.300 EUR (in $t=10$ ). Daß die Bemessungsgrundlage und damit auch die Steuerlast von Jahr zu Jahr kontinuierlich zunehmen, ist auf die sich ständig reduzierende Zinsbelastung aufgrund von Kreditlinie A zurückzuführen, mit der auch die Werbungskosten immer weiter abnehmen.

Entsprechend dem Gedanken des Entscheidungswerts erfolgt trotz der hieraus folgenden Überschüsse dennoch keine höhere periodische Entnahme als im Basisprogramm. Der aus der Eigentumswohnung entspringende Zukunftserfolg befindet sich in gesammelter Form im Grenzpreis, verkörpert durch die fiktive, maximal verschmerzbare Kaufpreiszahlung in $\mathrm{t}=0$.

Open Access Dieses Kapitel wird unter der Creative Commons Namensnennung 4.0 International Lizenz (http://creativecommons.org/licenses/by/4.0/deed.de) veröffentlicht, welche die Nutzung, Vervielfältigung, Bearbeitung, Verbreitung und Wiedergabe in jeglichem Medium und Format erlaubt, sofern Sie den/die ursprünglichen Autor(en) und die Quelle ordnungsgemäß nennen, einen Link zur Creative Commons Lizenz beifügen und angeben, ob Änderungen vorgenommen wurden.

Die in diesem Kapitel enthaltenen Bilder und sonstiges Drittmaterial unterliegen ebenfalls der genannten Creative Commons Lizenz, sofern sich aus der Abbildungslegende nichts anderes ergibt. Sofern das betreffende Material nicht unter der genannten Creative Commons Lizenz steht und die betreffende Handlung nicht nach gesetzlichen Vorschriften erlaubt ist, ist für die oben aufgeführten Weiterverwendungen des Materials die Einwilligung des jeweiligen Rechteinhabers einzuholen.

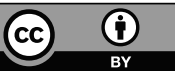

